Naira Tieme Yamamoto

\title{
Padrão de distribuição vertical dos foraminíferos bentônicos vivos no talude continental do setor norte da Bacia de Campos, margem sudeste brasileira: resposta da fauna ao aporte de matéria orgânica
}

\author{
Dissertação apresentada ao Instituto \\ Oceanográfico da Universidade de São \\ Paulo, como parte dos requisitos para \\ obtenção do título de Mestre em Ciências, \\ Programa de Oceanografia, área de \\ Oceanografia Geológica.
}

Orientadora: Profa. Dra. Silvia Helena de Mello e Sousa 
Universidade de São Paulo

Instituto Oceanográfico

\section{Padrão de distribuição vertical dos foraminíferos bentônicos vivos no talude continental do setor norte da Bacia de Campos, margem sudeste brasileira: Resposta da fauna ao aporte de matéria orgânica}

versão corrigida

Naira Tieme Yamamoto

Dissertação apresentada ao Instituto Oceanográfico da Universidade de São Paulo, como parte dos requisitos para obtenção do Título de Mestre em Ciências, Programa de Oceanografia, área de Oceanografia Geológica.

Julgada em

Conceito

Prof (a). Dr.(a).

Conceito

Prof (a). Dr.(a).

Conceito

Prof.(a). Dr.(a). 
"Renda-se, como eu me rendi. Mergulhe no que você não conhece como eu mergulhei. Não se preocupe em entender, viver ultrapassa qualquer entendimento"

Clarice Linspector 


\section{Sumário}

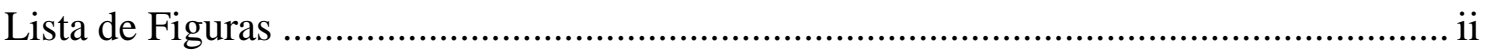

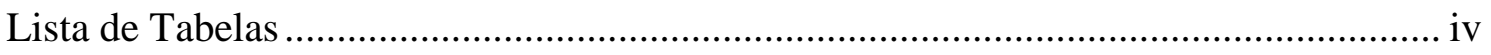

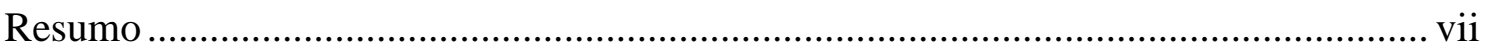

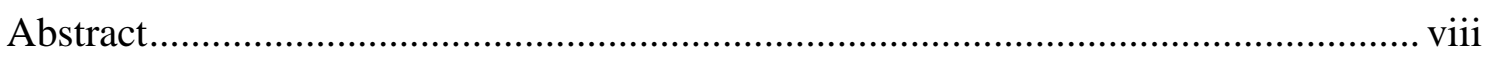

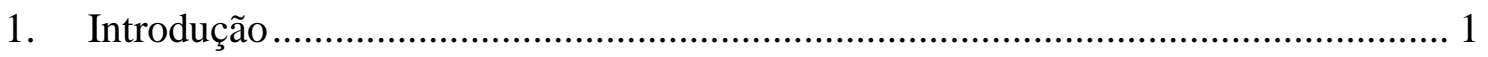

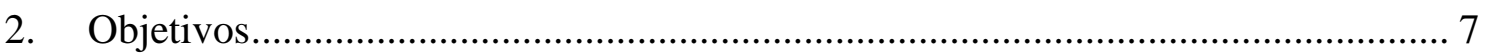

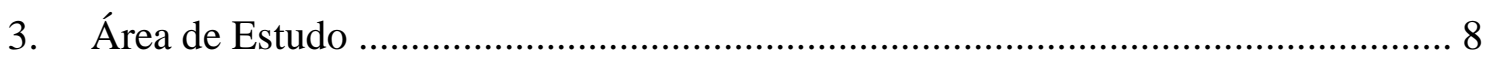

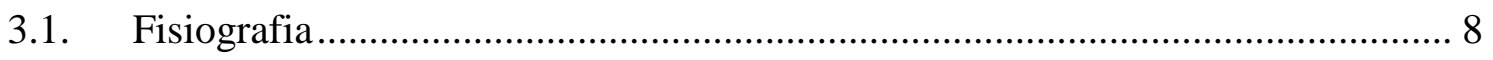

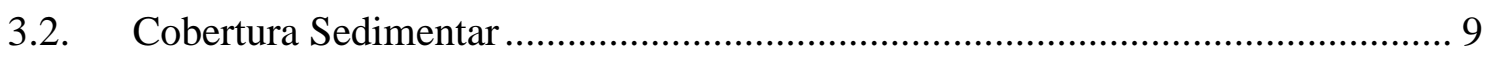

3.3. Massas de Água e Hidrodinâmica ................................................................. 10

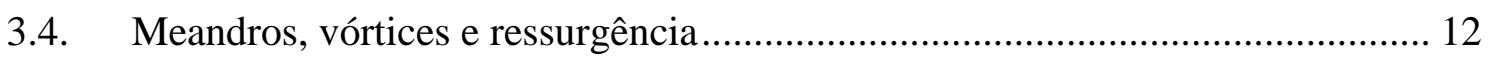

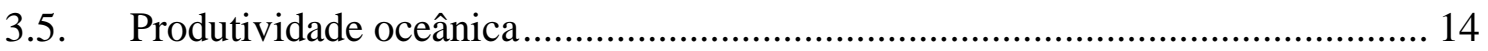

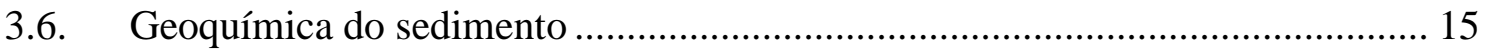

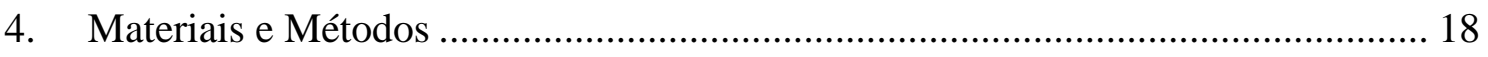

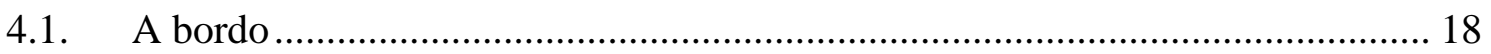

4.2. Análises sedimentológica e geoquímica...................................................... 19

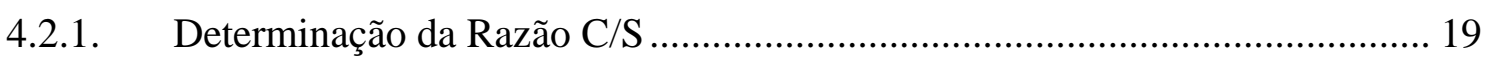

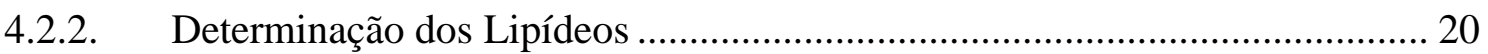

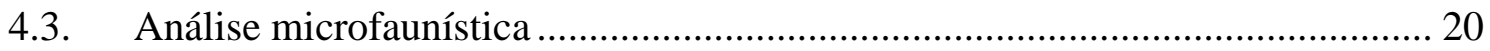

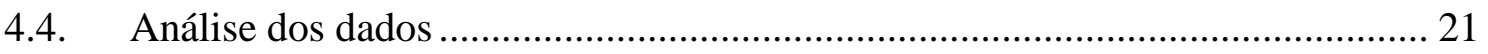

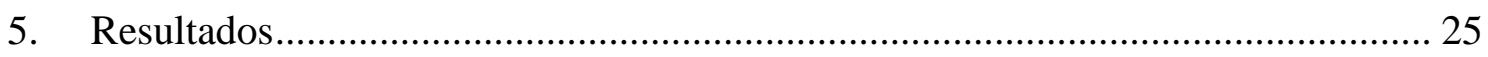


5.1. Estação I06

5.1.1. Dados bióticos

5.1.1.1. Descritores ecológicos (densidade, riqueza, diversidade ponderada, diversidade de Shannon, e equitabilidade de Pielou)

5.1.1.2. Espécies mais abundantes, perfil de distribuição vertical, $\mathrm{ALD}_{10}$ espécie, $\mathrm{ALD}_{10}$ fauna total, e porcentagem de microhábitat.

5.2.1.1. Descritores ecológicos (densidade, riqueza, diversidade ponderada, diversidade de Shannon e equitabilidade de Pielou)....

5.2.1.2. Espécies mais abundantes e perfil de distribuição vertical, $\mathrm{ALD}_{10}$ fauna total e para as espécies mais abundantes, e porcentagem de microhábitat.

6. Discussão

6.1. Talude Superior .

6.2. Talude Médio.

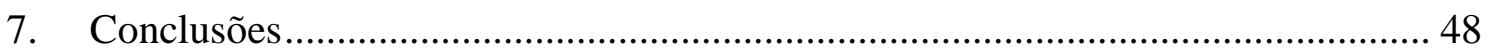

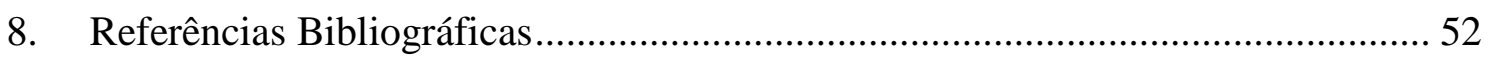

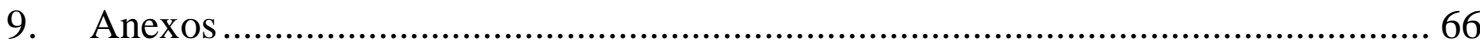

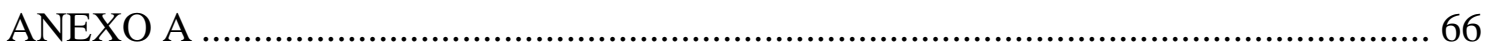

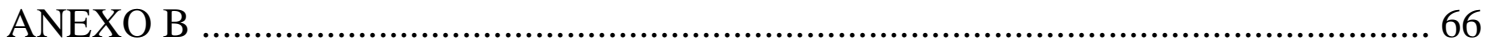

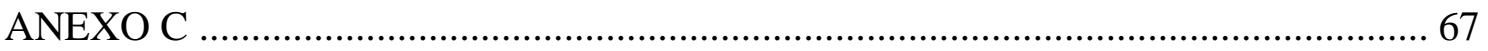

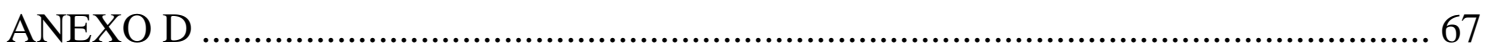

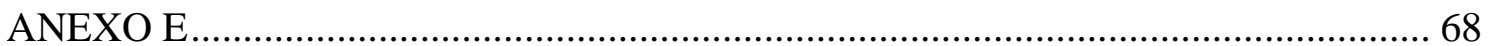

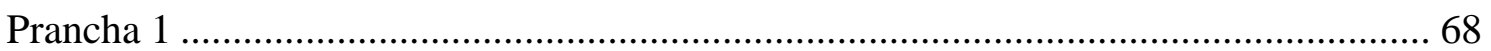


Prancha 2. 


\section{Lista de Figuras}

Figura 1: Modelo conceitual TROX explicando as profundidades em que os foraminíferos bentônicos podem habitar em função da disponibilidade de nutrientes e concentração de oxigênio. A esquerda, em ambiente oligotrófico o fator crítico determinante sobre a profundidade do habitat é o nutriente, à direita, em ambiente eutrófico a concentração de oxigênio é o fator limitante (JORISSEN et al. 1995).......... 3 Figura 2:Perfil batimétrico da porção norte (perfil A-B) da Bacia de Campos. Este perfil apresentaexagero vertical de $10 \mathrm{x}$ e tons de cinza com intensidade proporcional a declividade (ALMEIDA e KOWSMANN, 2014).

Figura 3 : Imagem 3D, em perspectiva, do relevo sombreado do fundo do mar da porção norte da bacia de Campos (exagero vertical $\times 5$, iluminação de $\mathrm{N}$, escala varia com a profundidade na imagem). Nesta figura pode ser observada a fisiografia submarina onde se destacam no talude continental os canais que integram os sistemas turbidíticos Itabapoana e Marataízes e o complexo de cicatrizes de remoção (ALMEIDA e KOWSMANN, 2014)

Figura 4: Esquema da circulação oceânica e costeira do sudeste do Brasil. Note a presença dos vórtices na região dos cabos: Cabo Frio (VF), vórtice de São Tomé (VCST) e vórtice de Vitória (VV). A Corrente do Brasil transporta para sul as massas de água AT e ACAS, enquanto a Corrente de Contorno Intermediária transporta a AIA em direção norte e a Corrente Contorno Profunda transporta a APAN em direção sul (Modificado de CALADO et al., 2008). 13

Figura 5: Localização da área de estudo e das estações oceanográficas I06 e I08. 18

Figura 6: Fotos da amostragem das estações I06 e I08 da Bacia de Campos utilizando box-corer.

Figura 7: Distribuição vertical da densidade, riqueza, diversidade e equitatividade dos foraminíferos bentônicos vivos, entre 0 e $10 \mathrm{~cm}$ de profundidade da coluna de sedimento na estação I06.

Figura 8: Distribuição vertical das espécies mais abundantes com frequência igual ou superior a $3 \%$, entre 0 e $10 \mathrm{~cm}$ de profundidade na coluna de sedimento, na estação I06. No eixo x está representada a densidade e o eixo y estão representadas as profundidades em $\mathrm{cm}$ (densidade e profundidade em $\mathrm{cm}$ ) devem estar anotadas nos gráficos. Note que 
a escala do eixo x da espécie Reophax caribensis é diferente das demais espécies por ter apresentado elevada densidade.

Figura 9: Profundidade média de habitat em $10 \mathrm{~cm}$ de sedimento $\left(\mathrm{ALD}_{10}\right)$ para as espécies mais abundantes bem como para o total de espécies da estação I06. 31 Figura 10: Distribuição vertical da densidade, riqueza, diversidade e equitatividade dos foraminíferos bentônicos vivos, entre 0 e $10 \mathrm{~cm}$ de profundidade na coluna de sedimento na estação I08. No eixo x mostra os descritores ecológicos e no eixo y as profundidades $(\mathrm{cm})$. 33

Figura 11: Distribuição vertical das espécies mais abundantes com abundância relativa igual ou superior a $3 \%$, entre 0 e $10 \mathrm{~cm}$ na coluna de sedimentona estação I08. No eixo x está representada a densidade e no eixo y estão representadas as profundidades em $\mathrm{cm}$. Note que a escala da espécie Reophax spiculotestus é diferente das demais espécies por ter apresentado elevada densidade. 36 Figura 12: Profundidade média de habitat em 10cm (ALD10) de sedimento (eixo x) para as espécies mais abundantes (>3\%) e para o total de espécies (eixo y) da estação I08. 38

Figura 13: A esquerda, perfil de distribuição vertical tipo A identificada por Jorissen (1999) e a direita, perfil de distribuição vertical da densidade dos foraminíferos bentônicos vivos da estação I06.

Figura 14: A esquerda, perfil de distribuição vertical tipo B identificada por Jorissen (1999), e a direita, perfil de distribuição vertical da densidade dos foraminíferos bentônicos vivos da estação I08. 45 


\section{Lista de Tabelas}

Tabela 1: Profundidade e localização das estações I06 e I08Erro! Indicador não definido.

Tabela 2: Valores de $\mathrm{ALD}_{\mathrm{x}}$ e suas respectivas classificações de microhábitats utilizadas neste trabalho.

Tabela 3: Valores de diâmetro médio, razão silte/argila, conteúdo de CaCO3 e COT, presença de pelotas fecais, bioturbação e profundidade de camada anóxica na estação I06.

Tabela 4: Valores de descritores ecológicos (densidade, riqueza, diversidade de Shannon e equitatividade Pielou) nas profundidades 0 à $10 \mathrm{~cm}$ de sedimento, e suas respectivas médias na estação I06. 26

Tabela 5: Porcentagem das espécies nos microhábitats na estação I06. EP/IR= epifaunal e/ou infaunal raso, IR= infaunal raso, IR/II= infaunal raso e/ou infaunal intermediário, $\mathrm{II}=$ infaunal intermediário, II/IP= infaunal intermediário e/ou infaunal profundo, e IP= infaunal profundo. Porcentagem das subordens das espécies da estação I06. 30 Tabela 6: Valores de diâmetro médio, razão silte/argila, porcentagem de conteúdo de $\mathrm{CaCO}_{3}$ e COT, pelotas fecais, bioturbação e profundidade da camada anóxica para a estação I08.

Tabela 7: Valores de descritores ecológicos (densidade, riqueza, diversidade de Shannon e equitatividade Pielou) nas profundidades 0 à $10 \mathrm{~cm}$ de sedimento, e suas respectivas médias na estação I08.

Tabela 8: Porcentagem das espécies nos microhábitats na estação I08. EP/IR= epifaunal e/ou infaunal raso, $I R=$ infaunal raso, $I R / I I=$ infaunal raso e/ou infaunal intermediário, $\mathrm{II}=$ infaunal intermediário, II/IP= infaunal intermediário e/ou infaunal profundo, e IP= infaunal profundo. Porcentagem das subordens das espécies na estação I08. 37 


\section{Agradecimentos}

A Deus, à minha família e aos meus amigos que sempre me apoiaram nos momentos difíceis com palavras de conforto e com pequenas ações, mas que são muito importantes para mim.

Agradeço à minha mãe por me fazer companhia, me ouvir e pelos inúmeros conselhos que mesmo a distância, sempre me ajudou, então, obrigada por me passar essa estrutura forte capaz de aguentar todas as dificuldades e principalmente por ser a minha mãe.

Ao meu pai, por me transmitir a inspiração e a determinação para cumprir meus objetivos e pela confiança na minha capacidade, gostaria de poder ser mais atenciosa e mais compreensiva, mas eu espero retribuir daqui em diante o que talvez deixei de fazer.

Ao meu irmão Rodrigo que sempre compreendeu a minha ausência e que sempre me apoiou para eu vencer todos os obstáculos, obrigada por cuidar dos nossos pais e por abrir mão de seus sonhos para eu poder estar aqui e poder cumprir mais uma meta, e ao meu irmão Thiago, por me fazer companhia, me ajudar e por cuidar de mim quando precisei.

À minha orientadora Silvia Helena de Mello e Sousa, por todo apoio, ensinamentos e muita paciência, além das várias conversas na Didi e aos vários bombons pra ajudar a dar aquele ânimo no trabalho.

Às minhas amigas Cintia, Renata, Thaisa, Nancy, Sayuri e Carla obrigada pelas incontáveis risadas na salinha e no laboratório. À minha amiga Cintia, por toda ajuda nesse processo de aprendizado, sempre muito prestativa, seja para esclarecer alguma dúvida, ou apenas para uma conversa. Obrigada por sua amizade, companhia e conselhos e por me fazer rir de suas peculiaridades "mundo da Cintia". A Renata por ser uma pessoa que eu admiro muito, e que considero como irmã juntamente com a Cintia, obrigada por toda ajuda para conclusão deste trabalho e por me fazer pensar mais sobre 
o assunto "e se você fizesse assim?", e obrigada por me ouvir quando precisei e por compreender as dificuldades que eu passei.

A Thaisa e Nancy pelas conversas mais engraçadas que me alegravam todos os dias no laboratório, o tempo passa super-rápido com vocês! Obrigada pelos conselhos e por dar aquela força quando estava pronta para desanimar.

À Sayuri e Carla pelas conversas na salinha, muitas das quais eram as conversas mais engraçadas que me fazia chorar de dar risada e mesmo que cada uma esteja seguindo o seu próprio caminho, vamos cultivar essa amizade em que uma vive zuando a outra.

Ao Wagner por sempre me ajudar desde a época da graduação, seja para me ajudar a procurar informações, ou pelos conselhos das melhores padarias da região que moramos!

Ao Instituto Oceanográfico e ao Programa de Pós-Graduação, pela infraestrutura e o apoio para realização do Mestrado.

À PETROBRAS pela idealização do projeto e a CAPES pelo auxílio financeiro. 


\section{Resumo}

Amostras de sedimento foram coletadas no talude superior e médio da Bacia de Campos para avaliar a quantidade e qualidade da matéria orgânica (MO) disponíveis no ambiente. A partir de dados geoquímicos, sedimentológicos (tamanho médio de grão e razão silte/argila), e microfaunísticos foi possível identificar diferenças no aporte de MO no talude. O talude superior apresentou valores maiores de conteúdo de carbono orgânico (COT) e lipídeos, elevados valores de densidade, baixos valores de diversidade, riqueza, equitatividade, $\mathrm{ALD}_{10}$, e perfil vertical com densidades maiores, predomínio de espécies epifaunais e/ou infaunais rasos, indicando ambiente com maior produtividade primária sobre maior influência de pulsos de fitodetrito, decorrente da influência do Vórtice de Vitória transportando nutrientes para o mar profundo. Já o talude médio, apresentou menores valores de COT, lipídeos e densidade, maiores valores de diversidade, riqueza, equitatividade, $\mathrm{ALD}_{10}$, predomínio de espécies aglutinantes, indicando condições com menor aporte de nutrientes lábeis. Pelos dados microfaunísticos obtidos, o modelo TROX não pode ser aplicado no talude da Bacia de Campos como avaliador de condições tróficas possivelmente pela não inclusão de fatores como disponibilidade de MO lábil, e bioturbação que influenciam na distribuição vertical dos foraminíferos bentônicos vivos no talude superior e médio da Bacia de Campos.

Palavras chaves: Foraminíferos bentônicos vivos, distribuição vertical, microhábitat, matéria orgânica, talude continental, Atlântico Sudoeste. 


\section{Abstract}

Sediment samples were collected in the upper and middle slope of Campos Basin to evaluate the quantity and quality of organic matter (OM) available in the environment. From geochemical, sedimentological (grain size, ratio and silt/clay), and microfaunistic data was possible to identify differences in the contribution of $\mathrm{OM}$ in slope. The upper slope had higher organic carbon content (TOC) and lipids, high density values, low values of diversity, richness, evenness, $\mathrm{ALD}_{10}$, and vertical profile with higher densities, predominance of epifaunal and/or shallow infaunal species, indicating higher primary productivity environment with greater influence on the pulse of phytodetritus, due to the influence of the Vitória Eddy carrying nutrients to the deep sea. The average slope had lower TOC values, lipids and density, higher values of diversity, richness, evenness, $\mathrm{ALD}_{10}$, predominant agglutinated species, indicating conditions with lower input of labile nutrients. Microfaunistic data obtained cannot be applied by the TROX model to the upper and middle slope of Campos Basin as an evaluator of trophic conditions due to non-inclusion of factors such as availability of labile OM, and bioturbation that influence the vertical distribution of living benthic foraminifera in the upper and middle slope of Campos Basin.

Keywords: Live benthic foraminifera, vertical distribution, microhabitat, organic matter, continental slope, Southwestern Atlantic Ocean. 


\section{Introdução}

Os foraminíferos pertencem ao Reino Protista, Filo Sarcodina, Classe Foraminífera (SEN GUPTA, 1999), e são encontrados principalmente no ambiente marinho.

Os foraminíferos bentônicos apresentam uma carapaça denominada teca ou testa (SEN GUPTA, 1999). A testa é uma carapaça que reveste o protoplasma, cuja função é proteger o organismo contra predadores, além de auxiliar na redução contra o stress físico como a turbulência da água e o atrito do ambiente, e o stress químico como $\mathrm{pH}$, conteúdos de $\mathrm{CO}_{2}$ e $\mathrm{O}_{2}$ na água. Morfologicamente, as testas dos foraminíferos podem apresentar uma câmara (unilocular) ou várias câmaras (multilocular), e de acordo com sua composição podem ser constituídas de matéria orgânica, minerais (calcita, aragonita ou sílica) ou até partículas aglutinadas (ARMSTRONG e BRASIER, 2005).

Os foraminíferos são considerados bons indicadores ambientais, pois são abundantes no sedimento, apresentam elevada diversidade de espécies, ciclo de vida relativamente curto, ampla distribuição geográfica, além de serem sensíveis às variações químicas e físicas do meio (BERNHARD e SEN GUPTA, 1999).

Em relação a alimentação, os foraminíferos possuem um hábito alimentar altamente diversificado (e.g. suspensívoro, detritívoros, carnívoros, omnívoros, etc.) e de acordo com a preferência pela fonte de nutrientes (e.g. matéria orgânica da zona eufótica, matéria orgânica produzida pelas bactérias, e dos nutrientes disponibilizados pelas correntes) e a disponibilidade de oxigênio, os foraminíferos bentônicos tendem a migrar verticalmente no sedimento entre os diferentes microhábitats (JORISSEN et al. 1995).

Segundo Jorissen (1999), o microhábitat é um microambiente caracterizado pela combinação de processos físicos, químicos, biológicos e são estas condições ambientais que permitem criar microhábitats distintos, tornando-os atrativos ou não à colonização das espécies. Assim, os foraminíferos bentônicos podem ocupar, de maneira generalizada, três microhábitats: interface sedimento-água, superfície do sedimento e dentro do sedimento.

Baseado na profundidade em que os foraminíferos bentônicos se encontram no sedimento, Corliss (1991) classificou os foraminíferos bentônicos em: epifauna, as 
espécies que são encontradas no primeiro $0,5 \mathrm{~cm}$ do sedimento; infaunais rasos, entre 0 $2 \mathrm{~cm}$; infaunais intermediárias, entre 1-4cm; e infaunais profundas, abaixo de $4 \mathrm{~cm}$.

A caracterização dos termos epifaunal e infaunal durante muito tempo tem gerado discussões sobre a delimitação da profundidade no sedimento. Enquanto alguns autores consideravam a posição estática dos foraminíferos bentônicos no sedimento (CORLISS, 1991), outros consideravam que a posição do foraminífero no sedimento é variável em função da otimização de alimento ao longo da coluna sedimentar (LINKE E LUTZE, 1993).

Em se tratando da distribuição espacial dos foraminíferos bentônicos vivos em mar profundo, tem-se como fatores controladores mais comumente citados a advecção das massas de água, produtividade primária e fluxo de $\mathrm{C}_{\text {org. }}$, corrosão do carbonato, velocidade de corrente no substrato (MACKENSEN et al. 1993, 1995; SCHMIEDL et al. 1997), dentre os quais os destacam-se oxigênio e nutrientes (BERNHARD, 1989; JORISSEN et al. 1995; RATHBURN et al. 1996; FARIDUDDIN e LOUBERE, 1997; JORISSEN, 1999; SCHMIEDL et al. 2000; MORIGI et al. 2001; FONTANIER et al. 2005; HEINZ e HEMLEBEN, 2006; GOODAY et al. 2009; entre outros).

Jorissen (1999) considera também a competição, predação e bioturbação como fatores controladores sobre a distribuição vertical dos foraminíferos bentônicos vivos. A competição ocorre por alimento e espaço no sedimento, já no caso da predação, a distribuição é alterada quando ocorre a diminuição da predação pela macrofauna resultando no aumento do número de espécies infaunais. E para complementar, a bioturbação altera a distribuição vertical transportando os foraminíferos para maiores profundidades no sedimento, e também facilita a entrada de matéria orgânica e oxigênio criando microambientes atrativos para a colonização e contribuindo no aumento do número de espécies infaunais (JORISSEN, 1999).

Segundo Jorissen (1999), o oxigênio limita a distribuição vertical das espécies dependentes do oxigênio forçando-as para ambientes óxicos, permanecendo apenas as espécies resistentes e adaptadas a habitar ambiente com menor concentração de oxigênio. Porém Jorissen (1999) e Fontanier et al. (2002, 2003) destacam que mesmo existindo espécies facultativas que podem sobreviver a ambiente anóxico (não dependem do oxigênio), a anoxidade inibe a reprodução e aliada a limitação dos nutrientes em maiores profundidades do sedimento, estas espécies tendem a desaparecer. Já o fator disponibilidade de nutrientes é considerado o principal fator que 
explica a abundância destes organismos e a ausência destes em maiores profundidades no sedimento (JORISSEN et al. 1995; JORISSEN, 1999).

Considerando apenas os fatores oxigênio e disponibilidade de nutrientes, Jorissen et al. (1995) desenvolveram um modelo para explicar o padrão de distribuição vertical dos foraminíferos bentônicos denominado modelo TROX (TR- tróficonutrientes; OX-Oxigênio) (Figura 1). Segundo este modelo, em ambientes oligotróficos, os foraminíferos são controlados em função da disponibilidade de nutrientes, predominando nessa situação espécies de epifauna ou infauna rasa, enquanto em ambientes eutróficos, o fator limitante na distribuição vertical dos organismos seria a disponibilidade de oxigênio, pois em condições extremamente eutróficas, os foraminíferos habitam próximo a superfície onde as condições são menos estressantes (JORISSEN et al. 1995).

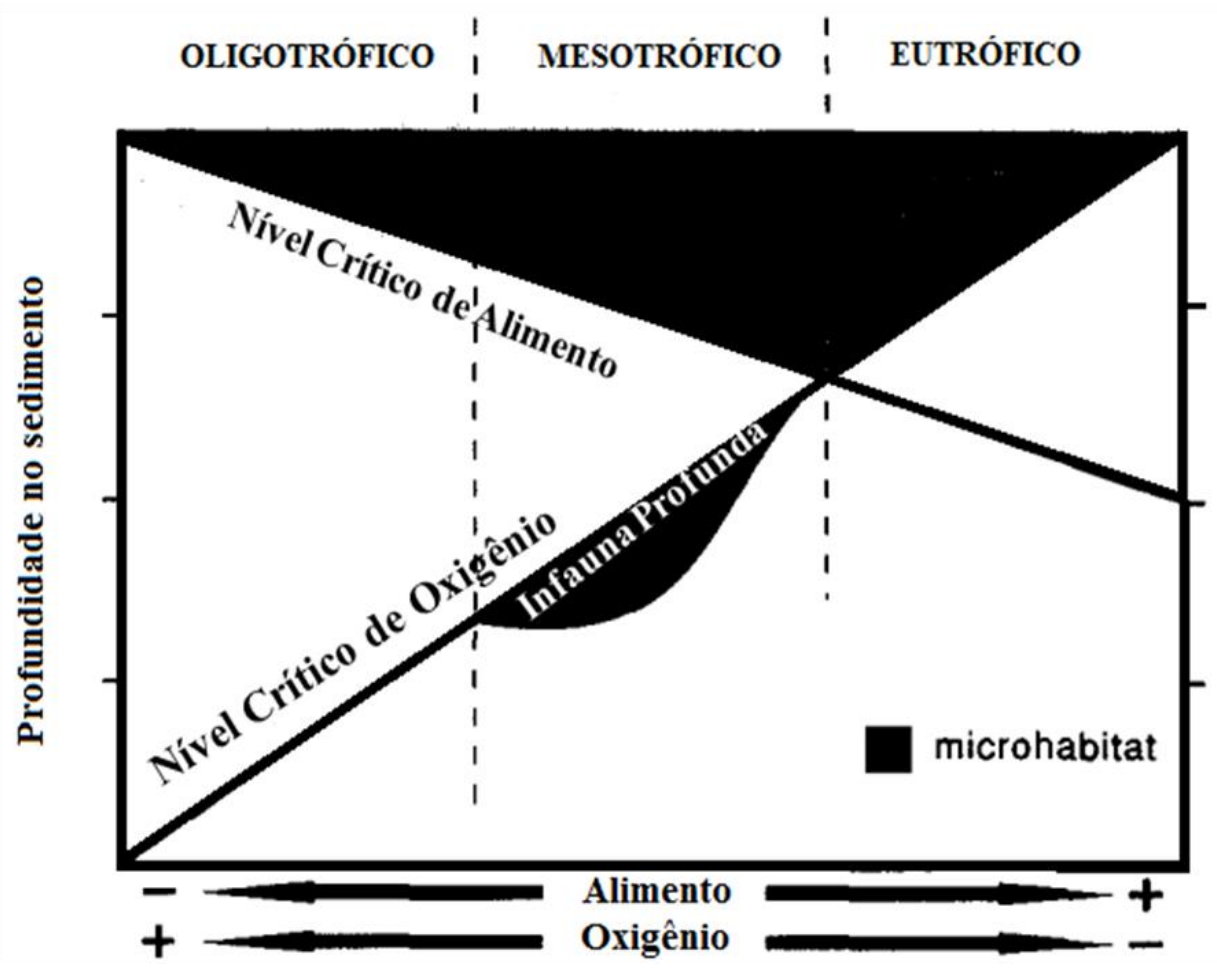

Figura 1: Modelo conceitual TROX explicando as profundidades em que os foraminíferos bentônicos podem habitar em função da disponibilidade de nutrientes e concentração de oxigênio. A esquerda, em ambiente oligotrófico o fator crítico determinante sobre a profundidade do habitat é o nutriente, à direita, em ambiente eutrófico a concentração de oxigênio é o fator limitante (JORISSEN et al. 1995).

Em ambientes com maior concentração de oxigênio e baixa disponibilidade de nutrientes (oligotrófico), trabalhos têm demonstrado que a matéria orgânica oriunda da 
produtividade primária da zona eufótica é o fator principal que controla a distribuição vertical dos foraminíferos na coluna sedimentar, enquanto os fatores como granulometria e a concentração de oxigênio parecem ser os fatores secundários controladores da distribuição vertical dos foraminíferos bentônicos (LOUBERE 1996; LOUBERE e FARIDUDDIN, 1999; BERNHARD e SEN GUPTA, 1999; JORISSEN et al. 1995; JORISSEN 1999; FONTANIER et al. 2008).

Em se tratando de disponibilidade de nutrientes, estes organismos respondem ao aporte de alimento com aumento em sua biomassa e abundância (GOODAY, 1988; MARTINS et al. 2006). Trabalhos realizados por Jorissen et al. (1998), Van Der Zwann et al. (1999), De Rijik et al. (2000), Fontanier et al. (2002, 2003), Martins et al. (2006) afirmam que a abundância e composição das espécies da fauna dos foraminíferos bentônicos vivos estão fortemente relacionadas ao fluxo de matéria orgânica para o fundo do oceano, que por sua vez varia em função da profundidade da coluna d'água e da produtividade superficial sazonal (LOUBERE, 1996; KUHNT et al. 1999).

A produtividade primária exerce um papel importante no fornecimento de matéria orgânica para o fundo do oceano, uma vez que parte desta produção é exportada ao longo da coluna d' água em forma de matéria orgânica particulada (MOP) (MURRAY, 2001; LUTZ et al. 2007). Esta matéria passa então a ser degradada ao longo da coluna d'água e apenas uma pequena parcela assenta no fundo do oceano. Esta matéria no sedimento é então parcial ou totalmente consumida pelos bentos ou passa a ser preservada em forma de carbono orgânico total (COT) no sedimento (LUTZ et al. 2007).

Segundo Sun et al. (2006), a MO oriunda da produtividade primária pode formar uma espessa camada de fitodetrito no assoalho oceânico, que pode ser utilizado tanto para alimentação para os organismos bentônicos quanto para formação de um possível local de colonização para as espécies. Assim, em locais onde há maior quantidade do fluxo de carbono orgânico no fundo do oceano, maior é a quantidade de matéria orgânica no sedimento depositada no assoalho permitindo assim, um aumento na profundidade do microhábitat (BERNHARD,1992), o inverso ocorre em locais com baixo fluxo de carbono orgânico com uma menor quantidade de matéria orgânica no sedimento resultando em um microhábitat restrito a interface sedimento-água (LOUBERE e FARIDUDDIN,1999).

Van der Zwann et al. (1999) discutem em seu trabalho que a quantidade do fluxo de $\mathrm{C}_{\text {org }}$ e a profundidade da coluna d'água altera não somente a profundidade do 
microhábitat, mas também no hábito alimentar das espécies. De acordo com estes autores, em águas rasas com maior fluxo de carbono orgânico, os organismos são detritívoros epifaunais e infaunais com mobilidade para se deslocar entre os microhábitats.

Trabalhos têm demonstrado que não apenas a quantidade da MO é o fator principal controlador sobre a distribuição vertical dos foraminíferos bentônicos na coluna sedimentar, mas também a qualidade desta matéria orgânica no sedimento (DE RIJIK et al. 2000; FONTANIER et al. 2002, 2008; KOHO et al. 2008). Enquanto algumas espécies preferem MO mais lábil (rápida degradação) e residem no topo do sedimento onde há maior quantidade de MO oriunda da produtividade primária de alta qualidade (lábil), outras espécies são menos competidoras e se alimentam de MO mais refratária (mais difícil de degradação, por exemplo, bactérias) situando-se em maiores profundidades no sedimento (MARTINS et al. 2006; FONTANIER et al. 2003) gerando assim, distribuições verticais diferentes entre as espécies na coluna de sedimento (JORISSEN et al. 1998).

Alve (2010) demonstrou que a qualidade da matéria orgânica exerce papel importante na composição e densidade dos foraminíferos bentônicos. Em seu estudo, a comunidade de espécies dependentes de matéria orgânica mais fácil de degradação (e.g. fitodetrito fresco) quando submetidas a uma ausência desta matéria orgânica, apresentam uma maior tendência a diminuição ou estagnação da comunidade, enquanto a comunidade de espécies que são menos dependentes da matéria orgânica lábil consumindo portanto a matéria orgânica refratária tendem a manter e/ou aumentar sua população.

Para Koho et al. (2008), a qualidade da matéria orgânica lábil é um fator estruturante sobre a comunidade dos foraminíferos bentônicos. De acordo com esses autores, as espécies calcáreas são mais sensíveis a entrada da matéria orgânica lábil e a necessitam para reprodução e sobrevivência. Já a maioria das espécies aglutinantes são menos dependentes da entrada da matéria orgânica lábil no sedimento, sugerindo que estas apresentam outros hábitos alimentares. Por exemplo: Rhabdammina abyssorum e Cribrostomoides subglobosus são espécies aglutinantes que sobrevivem por um longo tempo sem a entrada de matéria orgânica lábil metabolizando seu próprio protoplasma.

Fontanier et al. (2002); Eberwein e Mackensen (2006); Koho et al. (2007); Fontanier et al. (2008), reconhecem que os valores de densidade, diversidade e riqueza de espécies de foraminíferos bentônicos seguem padrão batimétrico, ocorrendo em 
geral, os maiores valores no talude superior, indicando maiores fluxos de $\mathrm{C}_{\text {org }}$ (matéria orgânica lábil) para o assoalho oceânico e menores valores em regiões mais profundas como no talude médio.

Burone et al. (2010) identificaram na plataforma e talude continental da margem sudeste Brasileira, setor Embaiamento de São Paulo (latitude 23.8 $\mathrm{S}-25.9^{\circ} \mathrm{S}$ e longitude $42.8^{\circ}-46.13^{\circ} \mathrm{W}$ ), distribuições verticais de densidade de foraminíferos bentônicos que se ajustam predominantemente com funções matemáticas de decaimento exponencial, característicos de condições oligotróficas, e reconheceram que a produtividade primária da coluna d'água e, consequentemente, o fluxo exportado para o assoalho oceânico é um dos principais fatores que controlam as associações nesse setor da margem do Brasil. Todavia, para os autores velocidades de correntes de fundo, substrato e profundidade da coluna d'água devem ser considerados em se tratando de variações das associações de espécies.

Sousa et al. (2006) demonstraram que o suprimento alimentar, a energia do ambiente, e a granulometria do substrato, os quais são controlados pelas massas de água Água Profunda do Atlântico Norte (APAN) e Água Intermediária Antártica (AIA) são também fatores responsáveis pela distribuição dos foraminíferos bentônicos no talude continental da Bacia de Campos (latitudes $20.5^{\circ} \mathrm{S}-24^{\circ} \mathrm{S}$ ).

Baseado nessas premissas vislumbrou-se a possibilidade de se aplicar pela primeira vez a metodologia de distribuição vertical dos foraminíferos bentônicos vivos no talude da Bacia de Campos no contexto de entendimento da quantidade e qualidade dos nutrientes disponíveis no ambiente, inserindo também novas informações ecológicas sobre as espécies da bacia tais como a profundidade média de habitat e a preferência das espécies pelos microhábitats.

O presente projeto está inserido no projeto HABITATS - Heterogeneidade Ambiental da Bacia de Campos, coordenado pelo CENPES/PETROBRÁS, que tem como objetivo a caracterização ambiental da Bacia de Campos e a obtenção de subsídios ao monitoramento ambiental dessa bacia, que há aproximadamente 4 décadas, vem sendo submetida a atividades de exploração e produção de óleo e gás. 


\section{Objetivos}

O presente trabalho tem como objetivo principal, avaliar a distribuição vertical dos foraminíferos bentônicos vivos no sedimento e descritores ecológicos para auxiliar na avaliação do aporte de matéria orgânica para o assoalho oceânico em estações localizadas no talude superior (417 $\mathrm{m}$ de profundidade) e médio (993 $\mathrm{m}$ de profundidade), setor norte da Bacia de Campos. Como objetivos específicos, tem-se:

- Realizar o levantamento de espécies infaunais e epifaunais de foraminíferos bentônicos para compreender os ambientes em termos de quantidade e qualidade da matéria orgânica no sedimento no talude superior e médio do setor norte da Bacia de Campos;

- Analisar as informações obtidas a partir de dados bióticos nas análises de foraminíferos bentônicos vivos obtidos como densidade, diversidade de Shannon, riqueza, e equitatividade para comparar com a disponibilidade de nutrientes na coluna d'água e sedimento no contexto de dados de circulação oceânica e de produção primária disponíveis na literatura;

- Avaliar a partir da profundidade média de microhábitat - Average Living Depth (ALDx) da comunidade de espécies de foraminíferos bentônicos e de espécies mais representativas a aplicação do modelo Trophic Oxygen (TROX) no entendimento da disponibilidade de nutrientes no talude do setor norte da Bacia de Campos. 


\section{3. Área de Estudo}

\subsection{Fisiografia}

A Bacia de Campos compreende uma área total de $100.000 \mathrm{~km}^{2}$ limitada ao norte pelo Alto da Vitória $20.5^{\circ} \mathrm{S}$ e ao sul pelo Alto de Cabo Frio $24^{\circ} \mathrm{S}$ (RANGEL et al. 1994). A Bacia de Campos apresenta uma plataforma com extensão média de $100 \mathrm{~km}$, sendo mais estreita e rasa no setor norte e mais larga e profunda no setor sul (FIGUEIREDO JR. et al. 2010), com a quebra da plataforma variando entre $80 \mathrm{~m}$ e 110m. O talude continental apresenta respectivamente extensão e declividade média de $40 \mathrm{~km}$ e $2.5^{\circ}$ (VIANA et al. 1998a), sendo que a passagem do talude para o sopé continental é marcada pela presença do Platô de São Paulo, situado entre as profundidades 1.500 a 2.300m (CORREA et al. 2009).

A Bacia de Campos é constituída por inúmeros cânions, no entanto, o único cânion que se mantém ativo é o Cânion Almirante Câmara (MACHADO et al. 2004), que está conectado ao Rio Paraíba do Sul e drena sedimentos da plataforma para águas profundas (VIANA et al. 1998a).

A área de estudo do presente trabalho compreende o talude superior e médio do setor norte da Bacia de Campos. A porção norte desta bacia compreende desde a margem esquerda do Cânion Almirante Câmara até o Arco de Vitória (RANGEL et al. 1994; WINTER et al. 2007). Neste setor há uma plataforma mais estreita e rasa com declividade suave que acompanha a linha de costa e um talude côncavo (FIGUEIREDO JR. et al. 2010). De acordo com Almeida e Kowsmann (2014), o talude superior no setor norte apresenta uma declividade elevada de $5^{\circ}$ a $10^{\circ}$ enquanto o talude médio, por sua vez, localizado entre 600 a $1100 \mathrm{~m}$ de profundidade, é menos íngreme ( $2^{\circ}$ a $\left.4^{\circ}\right)$ (Figura 2).

A declividade passa a ser ainda mais suave do talude inferior em direção ao Platô de São Paulo ( $2^{\circ}$ e $1^{\circ}$, respectivamente). Além destas características, este setor é composto por um sistema de canais submarinos denominados Sistemas Turbidíticos Itabapoana e Marataízes (Figura 3), que convergem no talude médio transportando sedimentos arenosos até o Platô de São Paulo (ALMEIDA e KOWSMANN, 2014). 


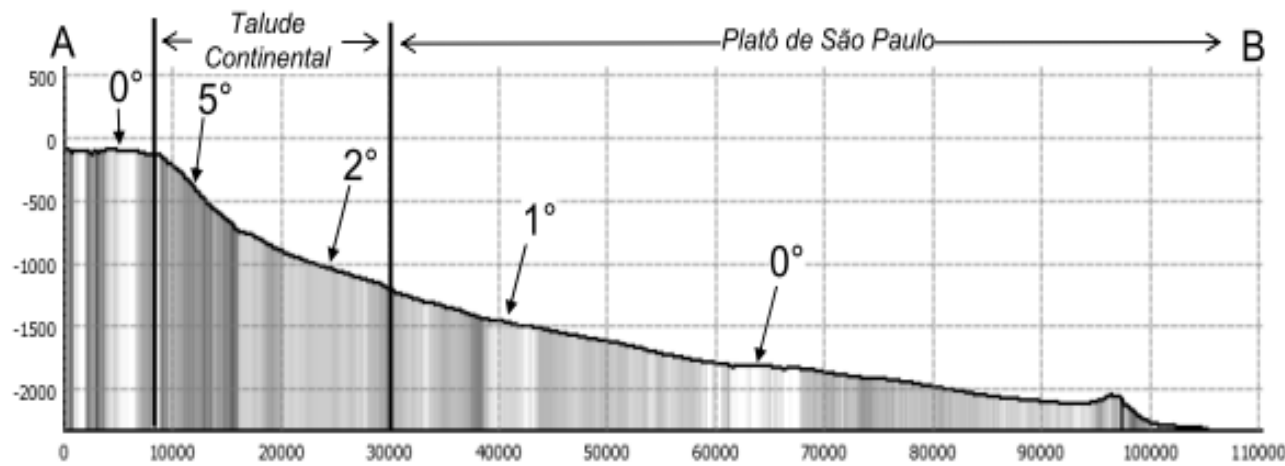

Figura 2: Perfil batimétrico da porção norte (perfil A-B) da Bacia de Campos. Este perfil apresenta exagero vertical de $10 \mathrm{x}$ e tons de cinza com intensidade proporcional a declividade (ALMEIDA e KOWSMANN, 2014).

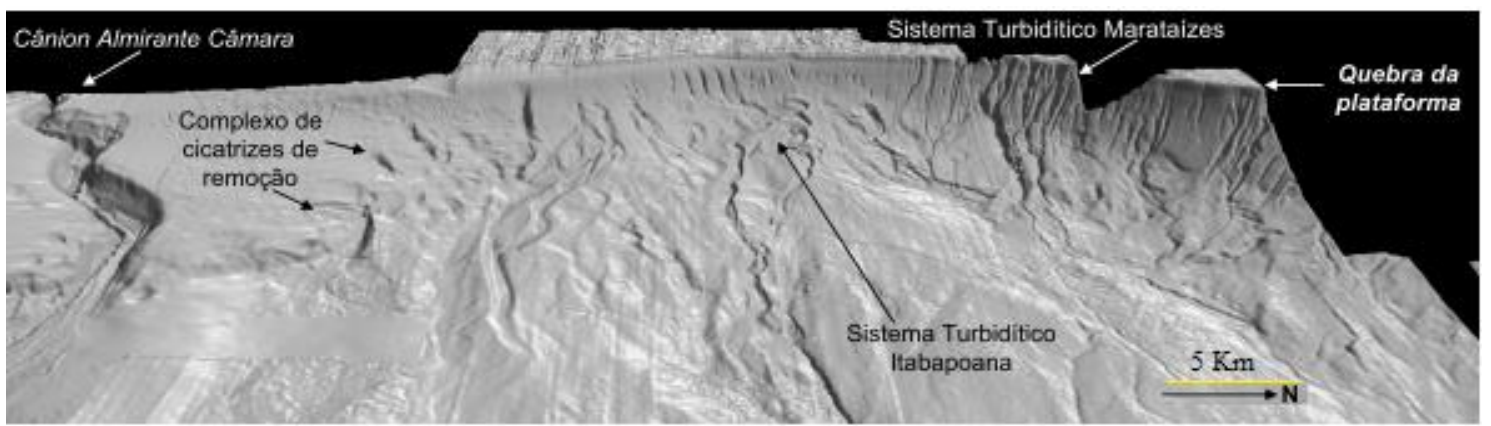

Figura 3: Imagem 3D, em perspectiva, do relevo sombreado do fundo do mar da porção norte da bacia de Campos (exagero vertical $\times 5$, iluminação de $\mathrm{N}$, escala varia com a profundidade na imagem). Nesta figura pode ser observada a fisiografia submarina onde se destacam no talude continental os canais que integram os sistemas turbidíticos Itabapoana e Marataízes e o complexo de cicatrizes de remoção (ALMEIDA e KOWSMANN, 2014).

\subsection{Cobertura Sedimentar}

O transporte, a deposição e o retrabalhamento dos sedimentos no mar profundo são controlados pela dinâmica das massas de água (VIANA et al. 1998a). Especificamente as areias depositadas no talude são retiradas da plataforma por inúmeros processos dinâmicos (corrente geostrófica, de maré e tempestade) e que posteriormente serão redistribuídas no talude pela Corrente do Brasil (CB) (VIANA, 2002).

Segundo Figueiredo Jr. e Madureira (2004), a plataforma da Bacia de Campos é composta por duas coberturas sedimentares distintas: o terrígeno e o carbonático, o primeiro encontra-se em áreas próximas a linha de costa enquanto o carbonático está situado em plataforma média e externa, como é observado ao norte do Cabo de São Tomé. 
No geral a plataforma é recoberta por areias siliciclásticas e bioclásticas, apresentando na plataforma externa o predomínio de sedimentos siliciclásticos (quartzofeldspato), seguido de sedimentos carbonáticos derivados de algas verdes e vermelhas (VIANA et al. 1998a). Em relação ao arredondamento e tamanho dos grãos da plataforma, as areias são bem arredondadas, e são finas em direção ao sul e na plataforma interna, e relativamente mais grossas na porção central e norte da Bacia de Campos (VIANA et al. 1998a).

No talude superior, ocorrem areias siliciclásticas e bioclásticas, que seguem padrão similar de distribuição de sedimentos da plataforma: areias finas ao sul e mais grossas ao norte do cânion de São Tomé. Ao sul do cânion de São Tomé, lamas arenosas com bioturbação misturadas a bioclastos (foraminíferos planctônicos) recobrem uma área maior que $100 \mathrm{~km}^{2}$ (VIANA et al. 1998a). No talude da porção norte da Bacia de Campos, as areias siliciclásticas são bem arredondadas apresentando nódulos de algas vermelhas, melhor seleção de grãos, sendo que esse grau de arredondamento dos sedimentos poderia ser reflexo da atuação da Corrente do Brasil, que apresenta maiores valores de velocidade neste setor norte (VIANA et al. 1998a).

No talude médio $(550 \mathrm{~m}$ a $1200 \mathrm{~m})$, a presença da Corrente de Contorno Intermediária (CCI) transportando a massa de água Água Intermediária Antártica rica em oxigênio oxida a superfície dos sedimentos do talude superior, resultando em uma superfície de areias finas enriquecidas de ferro intercalado com lama e silte (CADDAH et al. 1998). Essa camada de ferro apresenta espessura de $10 \mathrm{~cm}$, apresentando em composição sedimentos silicilásticos e biogênicos (VIANA et al. 1998a).

\subsection{Massas de Água e Hidrodinâmica}

A estrutura vertical de massas de água presentes na Bacia de Campos é: Água Tropical (AT), Água Central do Atlântico Sul (ACAS), Água Intermediária Antártica (AIA), Água Circumpolar Superior (ACS), e Água Profunda do Atlântico Norte (APAN) (Figura 4).

Na superfície do Atlântico Sul Tropical onde há uma elevada taxa de evaporação e forte radiação está situada a AT (<100m de profundidade) (CAMPOS, 2006), caracterizada por águas quentes $\left(>20^{\circ} \mathrm{C}\right)$ e salinas $(36)$, e com fluxo em direção sul. Esta massa de água assim que flui em direção ao sul mistura-se com águas costeiras 
e frias de baixa salinidade perdendo as características citadas acima (CAMPOS et al. 1995).

A ACAS está situada logo abaixo da AT (100-500m de profundidade) (CAMPOS, 2006) e apresenta temperatura entre $6^{\circ} \mathrm{C}$ a $20^{\circ} \mathrm{C}$ e salinidade entre 34.6 e 36. A sua origem está no afundamento das águas na região da convergência do Giro Subtropical e subsequente espalhamento ao longo da superfície na altura do Cabo de São Tomé fluindo em direção ao sul (SILVEIRA et al. 2000).

A AIA está situada entre 500-1200m de profundidade (CAMPOS, 2006) e apresenta temperatura e salinidade respectivamente de $3^{\circ} \mathrm{C}$ a $6^{\circ} \mathrm{C}$, e 34.2 a 34.6 . A AIA e ACS são massas de água inseridas na circulação profunda do Giro Subtropical, que penetram na bacia oceânica Brasileira sudeste e se dividem aproximadamente na latitude $28^{\circ} \mathrm{S}$ em dois braços, no talude da Bacia de Santos, com a AIA fluindo ao norte de $25^{\circ} \mathrm{S}$ em direção ao equador (MÜLLER et al. 1998).

Abaixo da AIA flui a ACS, que apresenta salinidade de 34,42 a 34,59 e temperatura $\left(3,46\right.$ a $\left.3,31^{\circ} \mathrm{C}\right)$, e é pobre em oxigênio dissolvido e rica em nutrientes (STRAMMA e ENGLAND, 1999, SILVEIRA, 2007).

Por último, situada entre 1500 e $3000 \mathrm{~m}$, a APAN (Figura 4), ao contrário da ACS, é uma água pobre em nutriente e rica em oxigênio (FOLONI-NETO, 2010). A APAN apresenta temperatura de $3^{\circ} \mathrm{C}$ a $4^{\circ} \mathrm{C}$ e salinidade 34.6 e 35 , e flui em direção sul (MÜLLER et al. 1998; SILVEIRA et al. 2000).

As correntes presentes na Bacia de Campos são da superfície do oceano para a assoalho oceânico: CB, CCI e Corrente de Contorno Profunda (CCP) (SILVEIRA 2007) (Figura 4).

A CB flui próxima a costa brasileira como uma corrente de contorno oeste em direção sul (SILVEIRA et al. 2000) e está situada acima de 500m de profundidade de coluna d'água (CALADO et al. 2010). Na latitude $10^{\circ} \mathrm{S}$, a Corrente Sul Equatorial (CSE) se bifurca originando duas correntes: ao norte flui a Corrente Norte do Brasil (CNB) e ao sul a CB (PETERSON e STRAMMA 1991). A CB é uma corrente superficial e rasa razão pela qual apresenta temperatura e salinidade relativamente altas (SILVEIRA et al. 2000), e é responsável pelo transporte das massas de águas: AT e ACAS (Figura 4).

Até a latitude $20^{\circ} \mathrm{S}$, a $\mathrm{CB}$ é rasa e transporta apenas a massa de água AT na quebra da plataforma, mas após esta latitude, recebe contribuição da ACAS tornando-se profunda e crescendo em seu transporte. 
Abaixo da CB flui em direção oposta a CCI (Figura 4), situada a 500 e 1200m de profundidade de coluna d'água, que transporta as massas de água AIA e ACS, ocupando porções intermediárias do talude continental (SILVEIRA et al. 2004). Por sua vez, a CCP presente no sopé, flui em direção ao sul e transporta a massa de água APAN (SILVEIRA, 2007).

\subsection{Meandros, vórtices e ressurgência}

Vórtices (ciclônicos e anticiclônicos) e meandros são observados na $\mathrm{CB}$, de acordo com inúmeros trabalhos como Campos et al. (1995, 2000), Calado (2001), Rodrigues e Lorenzzetti (2001), Silveira (2004), Palóczy et al. (2013). Os meandros têm sua origem na combinação da topografia de fundo e orientação da linha de costa, porém para o crescimento do meandro é necessário a ocorrência da instabilidade baroclínica provocada pelo cisalhamento entre a $\mathrm{CB}$ e a CCI. Após o crescimento do meandro formam-se os vórtices que muitas vezes são reabsorvidos pela própria $\mathrm{CB}$ ou são emitidos (CALADO, 2006).

Na Bacia de Campos são observados três vórtices: vórtice de Cabo Frio (VCF), vórtice do Cabo de São Tomé (VCST) e vórtice de Vitória (VV) (SILVEIRA, 2004) (Figura 4). O VCF e VCST tem sua origem a partir da mudança abrupta da orientação da linha de costa (de NE-SO para E-O) e do estiramento da coluna d'água gerado pela instabilidade do fluxo da $\mathrm{CB}$, que antes centrado em águas mais rasas atinge maiores profundidades no talude continental. A instabilidade da $\mathrm{CB}$ cria meandros, os quais crescem em tamanho e se fecham formando os vórtices (CAMPOS et al.1995; CALADO, 2001).

O VV apresenta diâmetro de $50 \mathrm{~km}$ e situa-se na latitude $20.3^{\circ} \mathrm{S}$ e longitude $38.9^{\circ} \mathrm{W}$ perto do Porto de Vitória (Gaeta et al. 1999) e abaixo da cadeia de Vitória Trindade. A possível origem deste VV, segundo Schmid et al. (1995) estaria associado a um forte processo de ressurgência costeira, levando a formação de um meandro na Corrente do Brasil na quebra da plataforma, e que teria evoluído para um vórtice ciclônico. 


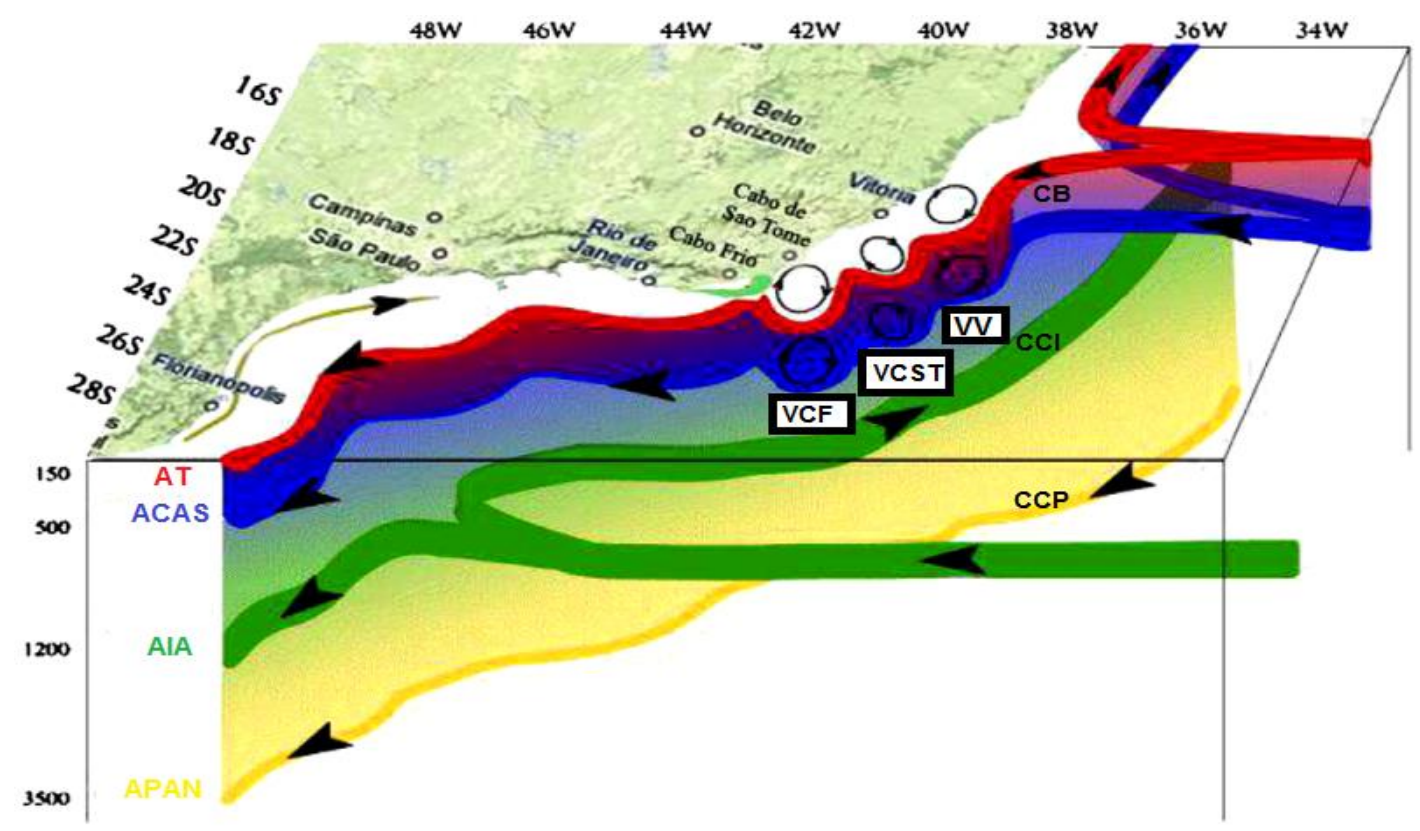

Figura 4: Esquema da circulação oceânica e costeira do sudeste do Brasil. Note a presença dos vórtices na região dos cabos: Cabo Frio (VF), vórtice de São Tomé (VCST) e vórtice de Vitória (VV). A Corrente do Brasil transporta para sul as massas de água AT e ACAS, enquanto a Corrente de Contorno Intermediária transporta a AIA em direção norte e a Corrente Contorno Profunda transporta a APAN em direção sul (Modificado de CALADO et al. 2008).

A importância dos vórtices e meandros, é que estes contribuem para o aumento da produtividade primária local e contribuindo para a deposição de matéria orgânica no fundo do oceano na margem sudeste Brasileira (MAHIQUES et al. 2002).

A ressurgência de águas ricas na área de estudo pode ocorrer de diferentes maneiras como: soerguimento da nutriclina, bombeamento de Ekman, e movimento dos vórtices em direção ao mar profundo conforme relatado por Siegel et al. (2008) e Vicente (2012). No primeiro caso, a ressurgência acontece pela ocorrência dos VF e VCST que soerguem a picnoclina movendo a nutriclina em direção a zona eufótica disponibilizando uma maior quantidade de nutrientes, enquanto os vórtices anticiclônicos desloca para baixo a nutriclina e consequentemente diminuindo a produtividade primária.

Quanto ao Bombeamento de Ekman, há nesse caso a interação entre o vento e o vórtice. Os vórtices anticilônicos teriam por função a diminuição da força do vento necessária para geração do stress na superfície d'água e empurramento das águas costeiras, facilitando assim, o afloramento da água rica em nutrientes (CAMPOS et al. 2000; PALÓCZY et al. 2013). O inverso ocorre com os vórtices ciclônicos gerando a subsidência e diminuição da produtividade primária (MCGILLICUDDY JR. et al. 2007; VICENTE, 2012). 
Por sua vez, o movimento do vórtice ciclônico em direção à águas mais profundas resulta no aumento da produtividade primária, o inverso ocorre com o movimento do vórtice anticiclônico em direção oeste/costa diminuindo a produtividade primária (KAMPEL, 2003; VICENTE, 2012). Tanto os VCST quanto os VCF aumentariam a produtividade primária pelo soerguimento da nutriclina e movimento do vórtice em direção às águas profundas (VICENTE, 2012).

Os vórtices apresentam diferenças na dimensão (VICENTE, 2012), no fator condicionante (RODRIGUES e LORENZETTI, 2001) e na direção (CALADO, 2006). O VCF é mais "restrito" enquanto o VCST é mais amplo latitudinalmente (VICENTE, 2012), Por outro lado, o VV e VCST apresentam como fator condicionante à sua formação a topografia de fundo, enquanto o VCF tem sua origem principalmente na geometria mais brusca da linha de costa de Cabo Frio comparativamente a uma geometria mais suave da linha de costa em Cabo de São Tomé (RODRIGUES e LORENZZETTI, 2001). No que se refere às diferenças quanto à direção de desenvolvimento dos vórtices, o VCF tende a fluir em direção sul, o VCST move-se em direção ao mar profundo (CALADO, 2006), e o VV se desloca paralelamente em direção à quebra da plataforma (direção nordeste) e posteriormente muda a sua direção para o sul (SCHMID et al. 1995).

A água que ressurge em Vitória em torno da latitude $20-21^{\circ} \mathrm{S}$, inicialmente flui paralelamente a costa, porém parte desta água flui por advecção em direção à quebra da plataforma do Cabo de São Tomé, já a ressurgência no Cabo de São Tomé (22S) movese rapidamente em direção à quebra da plataforma em Cabo Frio, e por fim a água que ressurge em Cabo Frio é transportada até distâncias maiores que $100 \mathrm{~km}$ em direção oeste - sudoeste (RODRIGUES e LORENZZETTI, 2001).

\subsection{Produtividade oceânica}

Segundo Ciotti e Kampel (2001), em regiões onde predominam condições oligotróficas a produtividade primária tende a ser baixa. Porém isso é alterado em locais onde ocorrem processos oceanográficos como meandros e vórtices, que auxiliam a inserção de águas mais ricas em nutrientes na zona eufótica, resultando no incremento dos valores da produtividade primária. Ciotti e Kampel (2001) consideram a Bacia de Campos oligotrófica, com valores de clorofila-a variando entre 0-25.5 mg.m ${ }^{-3}$ (GAETA e BRANDINI, 2006). Kampel (2003) e Vicente (2012) a partir de sensoriamento 
remoto, obtiveram dados de valores médios de clorofila-a respectivamente de 0,13 mg.m ${ }^{-3}$ e 0,22 mg.m $\mathrm{m}^{-3}$.

Ciotti e Kampel (2001) observaram no VCST, valores de clorofila-a variando entre 0,16 e 0,24 mg.m ${ }^{-3}$ e perto de Cabo Frio, Cabo de São Tomé e Vitória (quebra da plataforma), Kampel (2003) observou plumas de águas frias apresentando temperatura entre $14^{\circ}$ e $22.5^{\circ} \mathrm{C}$.

Vicente (2012) estimou para o setor norte da Bacia de Campos, valor de 0,28 $\mathrm{mg} \cdot \mathrm{m}^{-3}$ de clorofila-a e valores de produtividade primária variável entre 738,2 e 739,3 $\mathrm{mgCm}^{-2}$. $\mathrm{dia}^{-1}$. Os valores de fluxo de produtividade primária (ppm) no setor norte apresentaram valores de 134,6 e 63,6 $\mathrm{mgCm}^{-2}$. $\mathrm{dia}^{-1}$. Para Vicente (2012), o alto valor encontrado neste setor estaria associado à presença de vórtices que aumentam a produtividade primária através do soerguimento da nutriclina e do movimento do vórtice em direção às águas profundas.

\subsection{Geoquímica do sedimento}

Compreender a composição, distribuição e origem da matéria orgânica (MO) presente no sedimento é de fundamental importância para a sobrevivência da comunidade bentônica, pois grande parte dos organismos bentônicos (e.g. herbívoros, omnívoros) se alimentam da matéria orgânica derivado da produtividade primária, enquanto outros foraminíferos se alimentam do acúmulo e deposição de matéria orgânica não necessariamente derivados da produtividade primária (e.g. matéria orgânica transportada por advecção lateral) (OLIVEIRA et al. 2013; PUSCEDDU et al. 2010).

Estudos recentes mostram que a ecologia bentônica depende principalmente da qualidade da MO que atinge o assoalho oceânico (PUSCEDDU et al. 2009). Segundo estes autores, a qualidade da MO presente no sedimento é determinada pela sua composição, de modo que, determinados componentes podem torná-la mais lábil ou mais refratária. Assim, para avaliar a labilidade, Gremaré et al. (2003) analisaram diversos parâmetros bioquímicos (e.g. carbono orgânico, carboidratos, aminoácidos e lipídios), e mostraram que os lipídios e os aminoácidos correspondem a fração mais lábil da MO.

Segundo Volkman (2006), os lipídios agrupam um grande número de compostos químicos (e.g. alcanos, esteróis, ácidos graxos, etc.) que apresentam 
diferentes estruturas químicas. Através destas estruturas pode-se determinar o organismo que produziu a MO no sedimento, por exemplo, alcanos de cadeias curtas (e.g. n-C15, n-C17 e n-C19) indicam presença de MO oriunda de algas, enquanto longas cadeias (e.g. n-C20 à C-35) representam fontes terrestres como, plantas vasculares (VOLKMAN, 2006).

Os esteróis, outra classe de lipídio, são componentes das membranas das células e também refletem especificamente a origem da MO, marinha ou terrestre (e.g. microalga, planta terrestre ou animal) (LIBES, 1992). Os esteróis são responsáveis por armazenar energia (VOLKMAN, 2006), regular hormônios de crescimento, respiração e reprodução em organismos marinhos (DUURSMA e DAWSON, 1981). Além disto, possuem a característica em manter sua estrutura química mesmo sob condições ambientais não favoráveis de preservação (EMERSON e HEDGES, 2008).

Ácidos graxos são compostos abundantes no sedimento do fundo do oceano, estão relacionados a bactérias, microalgas e fauna marinha e são importantes como reservatório de energia (VOLKMAN, 2006), reguladores de hormônios de crescimento e reprodução (DUURSMA e DAWSON, 1981). Os ácidos graxos produzidos por diferentes comunidades bióticas apresentam estrutura química específica que permitem a sua utilização como indicadoras de fonte de MO (e.g. o ácido graxo poli-insaturado (PUFA) é produzido principalmente por organismos fitoplanctônicos e os foraminíferos bentônicos selecionam fitodetrito contendo PUFA para sua alimentação) (VOLKMAN, 2006).

Assim, os lipídios são um dos inúmeros marcadores moleculares utilizados para a caracterização da composição MO e na análise da proporção relativa de aporte de MO autóctone e alóctone no sistema aquático (CARREIRA et al. 2010). Uma das principais diferenças entre os lipídios e os outros marcadores é a sua elevada resistência à degradação, o que permite sua preservação no sedimento por mais tempo (VOLKMAN, 2006).

Carreira et al. (2010) utilizaram lipídios para identificar a composição e origem da MO (i.e. autóctone e alóctone) em sedimentos superficiais do talude continental (750-1950m de profundidade de coluna d'água) da Bacia de Campos, avaliando também a distribuição da MO com o aumento da profundidade de coluna d'água. Segundo esses autores, no talude superior (750-1050m) do setor norte da bacia, a MO mostrou elevada proporção de lipídios derivados de produtividade primária marinha e fauna 
zooplanctônica sugerindo maior contribuição autóctone com diminuição desses valores de lipídios autóctones com o aumento da profundidade.

Estudo realizado por Oliveira et al. (2013) sobre a qualidade da MO na Bacia de Campos utilizando os lipídios oriundos da produtividade primária marinha (origem autóctone, lábil) e de origem alóctone (refratária), permitiu verificar que a MO presente no sedimento da plataforma e o talude superior e médio da Bacia de Campos é derivado dos produtores autóctones primários e secundários, disponibilizando uma alta fração de MO lábil para os organismos bentônicos. Por sua vez, em regiões mais profundas (1900-3000m profundidade) a MO mostrou ter maiores valores de fração refratária e, portanto com menor valor nutricional. 


\section{Materiais e Métodos}

O presente trabalho foi realizado no Laboratório de Bioindicadores Ambientais do Instituto Oceanográfico da USP (LBA - IOUSP) e utilizou as amostras de sedimento e dados sedimentológicos e geoquímicos obtidos no Projeto HABITATS. As amostras deste estudo foram coletadas nas estações oceanográficas I06 e I08 da Bacia de Campos. A estação I06 está situada a profundidade de $417 \mathrm{~m}$ e está localizada na latitude $21^{\circ} 13,5644^{\prime}$ S e longitude $40^{\circ} 15,0731^{\prime}$ W. Por sua vez, a estação I08 está situada em $993 \mathrm{~m}$ de profundidade, e localizada na latitude $21^{\circ} 11,0026^{\prime} \mathrm{S}$ e longitude $40^{\circ} 9,2774^{\prime} \mathrm{W}$ (Figura 5).

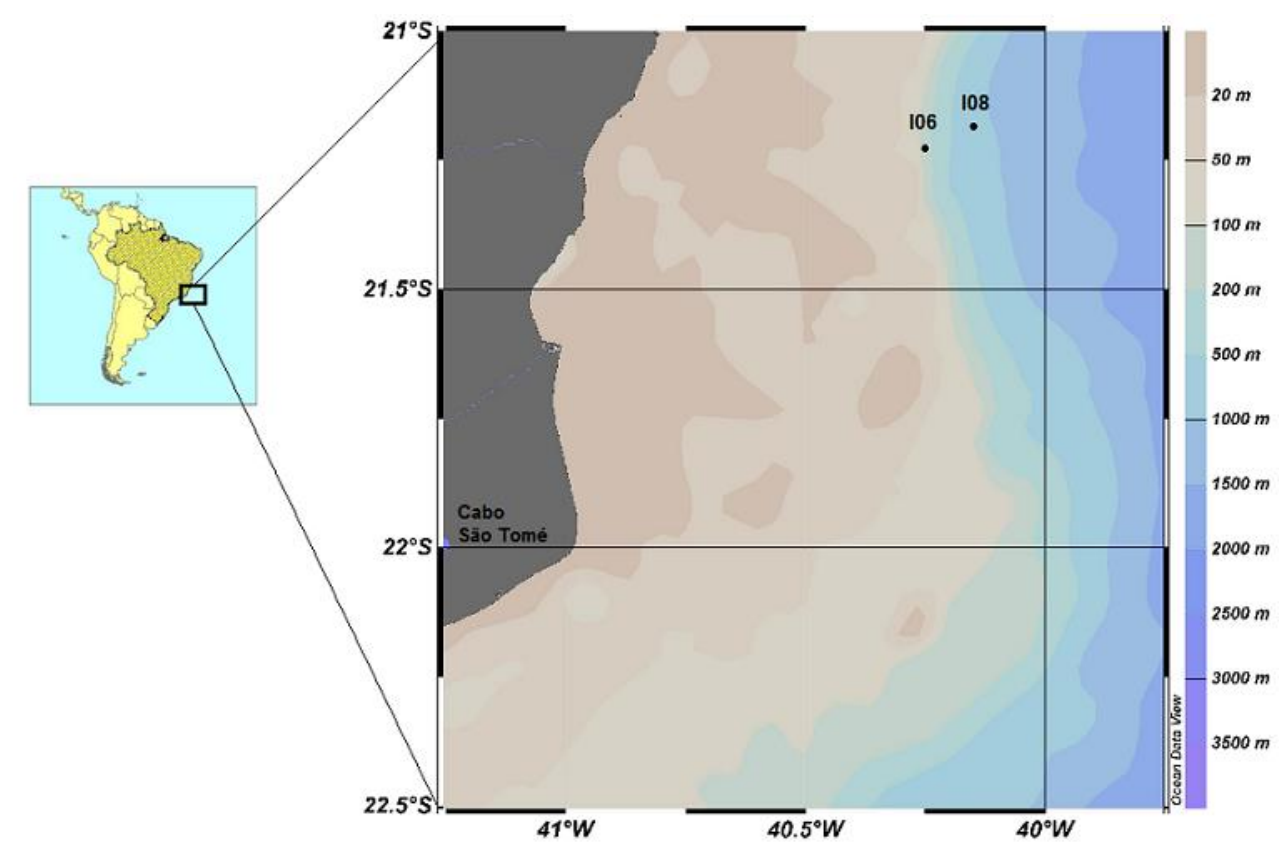

Figura 5: Localização da área de estudo e das estações oceanográficas I06 e I08.

\subsection{A bordo}

As amostras das estações I06 e I08 foram coletadas com um testemunhador de fundo do tipo box corer com dimensão de 50x50cm (Figura 6), a bordo do N.Oc Miss Emma McCall, entre os dias 03 e 04 de fevereiro de 2009. Estas amostras foram subamostradas em seções menores, com dimensões de $10 \mathrm{~cm}$ x $10 \mathrm{~cm}$ x $50 \mathrm{~cm}$, onde a cada intervalo de $1 \mathrm{~cm}$ foram coletadas amostras, até atingir $10 \mathrm{~cm}$ de profundidade na 
coluna de sedimento, resultando em um total de 20 amostras para as duas estações. Posteriormente, as amostras foram colocadas em recipientes plásticos contendo solução de álcool a $70 \%$ para a preservação do protoplasma dos foraminíferos bentônicos que estavam vivos no momento da coleta.
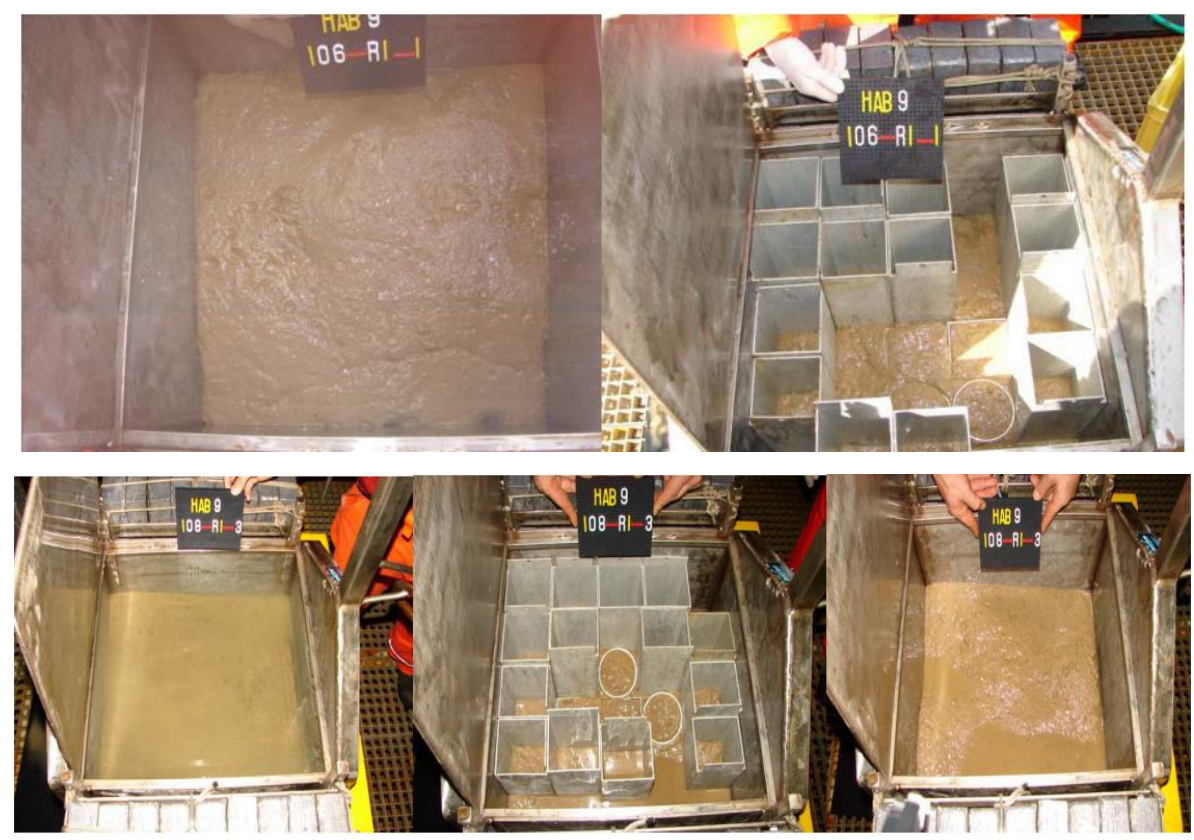

Figura 6: Fotos da amostragem das estações I06 e I08 da Bacia de Campos utilizando box-corer.

\subsection{Análises sedimentológica e geoquímica}

A granulometria do sedimento foi determinada após a retirada de carbonato das amostras utilizando o analisador Malvern Masterizer 2000. A razão silte/argila foi calculada segundo Pjerup (1988). Esta razão permite inferir níveis energéticos do ambiente, onde os maiores valores representam ambiente relativamente mais energético. O carbonato total foi determinado por diferença de peso, após tratamento das amostras de sedimento com $\mathrm{HCl}$ 1,0 M (1 g: $20 \mathrm{~mL})$ à temperatura ambiente. O conteúdo de carbonato foi calculado pela diferença entre o peso inicial e final da amostra.

\subsubsection{Determinação da Razão $C / S$}

Os dados de $\mathrm{C}_{\text {org }}$ e enxofre total (Stotal) foram realizados no Laboratório de Ciências Ambientais da Universidade Estadual do Norte Fluminense - UENF, sob coordenação do Prof. Dr. Carlos E. Rezende. 
Os dados de $\mathrm{C}_{\text {org }}$ foram obtidos através do Analisador Elementar CHNS/O Perkin Elmer (2.400 Series II). A massa de material utilizada para as determinações analíticas foi de aproximadamente $10 \mathrm{mg}$, tendo-se efetuado a descarbonatação, através da adição de $\mathrm{HCl}$ 1,0 mol L ${ }^{-1}$ diretamente nas amostras dentro dos recipientes de prata. Posteriormente as amostras foram secas em estufa a $60^{\circ} \mathrm{C}$ por $12 \mathrm{~h}$ e os valores obtidos foram expressos em percentual (\%).

Para a análise do Stotal, 0,5 g (peso seco) de amostra foi inserida em tubos de teflon (X-press), nos quais foram adicionados ácidos concentrados (9 $\mathrm{ml}$ de $\mathrm{HNO}_{3}+4$ $\mathrm{ml}$ de $\mathrm{HF}+2 \mathrm{ml}$ de $\mathrm{HCl}$ ). Os extratos foram mantidos em repouso a noite em temperatura ambiente e em seguida, levados ao microondas, por 40 minutos a temperatura de $175{ }^{\circ} \mathrm{C}$ e potência de 1600 w, (adaptado de US-EPA 1996). Após o resfriamento (30 min.), o extrato final foi filtrado e aferido a um volume final de $50 \mathrm{ml}$ com $\mathrm{HNO}_{3}$ 0,5 $\mathrm{N}$ em balão volumétrico. A determinação dos metais foi realizada posteriormente no equipamento IPC-AES (Varian-Liberty Series II).

\subsubsection{Determinação dos Lipídeos}

O processo analítico foi desenvolvido no Laboratório de Geoquímica Orgânica Marinha (LaGOM) / Faculdade de Oceanografia da UERJ e seguiu metodologia adaptada de trabalhos da literatura (e.g. Readman et al.1986; Canuel e Martens, 1993; Yunker et al. 1995; Carreira et al. 2002; Wakeham et al. 2002).

Os lipídios foram extraídos de aproximadamente $5 \mathrm{~g}$ de sedimento seco (precisão $\pm 0,1 \mathrm{mg}$ ) por refluxo em aparelho Soxhlet, usando mistura de solventes (diclorometano: metanol, 9:1) (Readman et al. 1986).

As determinações quali-quantitativas foram feitas por cromatografia em fase gasosa acoplada à espectrometria de massas (CG/EM) para os esteróis e n-alcoois (fração sap-N, ou seja, fração da fase superior recuperada da reação entre n-hexano e água purificada); e por cromatografia em fase gasosa acoplada a detector de ionização por chama (CG/DIC) para os ácidos graxos (fração sap-A, ou seja, fração resultante do extrato residual que foi acidificado e extraído com n-hexano para a recuperação da fase inferior denominada de fração sap-A).

\subsection{Análise microfaunística}


De cada sub-amostra, um volume de $50 \mathrm{~cm}^{3}$ de sedimento foi corado com o corante Rosa de Bengala e homogeneizado por um período de $72 \mathrm{~h}$, com o intuito de identificar os foraminíferos bentônicos que estavam vivos durante a coleta. Após esse procedimento, as amostras foram submetidas a peneiramento úmido, utilizando para isso, peneiras com malhas de $0,063 \mathrm{~mm}$ e $0,125 \mathrm{~mm}$. O sedimento retido nessas frações foi posteriormente seco em estufa na temperatura de $40^{\circ} \mathrm{C}$ por cerca de 24 horas.

Com o auxílio de um estereomicroscópio foi realizada a triagem dos foraminíferos bentônicos vivos de ambas as malhas, onde foram posteriormente colocados em lâminas micropaleontológicas. Ao final deste processo, restringiu-se a quantificação e identificação dos foraminíferos bentônicos vivos pertencentes à malha $0,125 \mathrm{~mm}$, em função do consumo demasiado de tempo e a dificuldade na identificação das espécies presentes na malha $0,063 \mathrm{~mm}$, tendo em vista o tamanho reduzido dos espécimes. Na identificação das espécies de foraminíferos bentônicos foram utilizados como referências Boltovskoy et al. (1980), Van Morkoven et al. (1986), Loeblich e Tappan (1988), Jones (1994), Barbosa (2002), Kaminsky e Gradstein (2005), entre outros. Por sua vez, a classificação dos microhábitats das espécies de foraminíferos bentônicos foi baseada em Corliss (1991): epifaunal (0-1 cm), infaunal raso $(0-2 \mathrm{~cm})$, infaunal intermediário (1-4 cm) e infaunal profundo $(>4 \mathrm{~cm})$.

Para a fotomicrografia das espécies mais abundantes, utilizou-se a Microscopia Eletrônica de Varredura (MEV) do Laboratório de Microscopia Eletrônica de Varredura do Instituto de Geociências da Universidade de São Paulo e, posteriormente, as fotomicrografias foram editadas no programa Adobe Photoshop CS5®.

\subsection{Análise dos dados}

Foram calculados os índices ecológicos como densidade (ind. $/ 50 \mathrm{~cm}^{3}$ ), riqueza (número de espécies presentes na amostra), equitabilidade de Pielou (J), diversidade de Shannon (H'), diversidade ponderada e a profundidade média de habitat $\left(A L D_{x}\right)$, sendo este $\mathrm{ALD}_{\mathrm{x}}$ calculado tanto para as espécies mais abundantes quanto para a comunidade de foraminíferos bentônicos vivos.

Para a elaboração da curva de distribuição vertical de foraminíferos bentônicos vivos no sedimento foi considerada a densidade dos foraminíferos bentônicos vivos da fração 0,125mm. Todavia, foram excluídos os indivíduos de espécies tubulares, em 
razão de sua intensa fragmentação, resultando na impossibilidade de sua identificação e contabilização.

O Índice de Diversidade de Shannon (H') é um índice que leva em consideração o número dos indivíduos assim como o número de espécies e sua unidade é bits-indíviduos ${ }^{-1}$. O valor zero significa que a comunidade contém apenas uma única espécie, enquanto os valores elevados representam uma comunidade com várias espécies. H' foi calculada com o objetivo de comparar e mostrar as diferenças das composições faunísticas ao longo da coluna sedimentar $(0-10 \mathrm{~cm})$, entre as estações I06 e I08, tendo-se utilizado a seguinte fórmula (1):

$\mathrm{H}^{\prime}=-\Sigma((\mathrm{ni} / \mathrm{n}) \ln (\mathrm{ni} / \mathrm{n}))(1)$

Onde:

ni= número de indivíduos da espécie $\mathrm{i}$;

$\mathrm{n}=$ número total de indivíduos;

O Índice de equitatividade Pielou ( $\mathrm{J}$ ) mede a regularidade com que os indivíduos estão distribuídos entre as espécies presentes, ou seja, em uma comunidade onde há dominância de uma determinada espécie, a equitatividade apresentará valores menores, enquanto altos valores de equitavidade indicam sem dominância de espécies (MAGURRAN, 2004). Para o cálculo do índice de equitatividade foi aplicada a seguinte fórmula (2):

$$
\mathrm{J}=\mathrm{H}^{\prime} / \operatorname{lnS}(2)
$$

Onde:

$\mathrm{S}=$ Riqueza;

$H^{\prime}=$ Índice de Diversidade de Shannon;

O Índice de diversidade ponderada foi calculado para cada estação segundo Burone e Pires-Vanin, (2006), com o objetivo de ressaltar diferenças na composição faunística e sintetizar as condições ecológicas ao longo da distribuição vertical, permitindo desta forma, comparar a diversidade entre as estações I6 e I8. Este índice de diversidade ponderada é representado pela fórmula (3): 


$$
\overline{H^{\prime}}=\sum_{k=1}^{X} \frac{H_{k}^{\prime} R_{k}}{n}
$$

Onde:

$\mathrm{H}_{\mathrm{k}}=$ é o índice de diversidade específica de Shannon na profundidade k;

$\mathrm{k}=$ profundidade;

$\mathrm{R}_{\mathrm{k}}=$ Riqueza;

$\mathrm{x}=$ número de profundidades;

n= número total de espécimes na profundidade.

A profundidade média do microhábitat - Average Living Depth $\left(\mathrm{ALD}_{\mathrm{x}}\right)$ foi calculada para toda a comunidade microfaunística de foraminíferos bentônicos, bem como para cada espécie mais abundante (abundância relativa igual ou superior a 3\%). O $\mathrm{ALD}_{\mathrm{x}}$ para toda a comunidade microfaunística tem por objetivo identificar a profundidade média em que a comunidade de foraminíferos habita nas estações analisadas, por sua vez o $A L D_{x}$ para cada espécie abundante tem a função de identificar a seleção de cada espécie por microhábitat como uma estratégia de otimizar a aquisição por alimento e sua reprodução. $\mathrm{O}$ cálculo do $A L D_{\mathrm{x}}$ dos foraminíferos bentônicos vivos foi calculado de acordo com Jorissen et al. (1995) pela seguinte fórmula (4):

$$
\operatorname{ALD}_{x}=\sum_{i=0, x}\left(n_{i} D_{i}\right) / N,
$$

Onde:

$\mathrm{i}=$ intervalo/ profundidade;

ni= número de indivíduos no intervalo i;

$\mathrm{Di}=$ ponto médio do intevalo $\mathrm{i}$;

$\mathrm{N}=$ número total de indivíduos de todas as profundidades.

Com os valores do $\mathrm{ALD}_{\mathrm{x}}$ gerados, calcularam-se as porcentagens de espécimes consideradas epifauna e/ou infauna rasa (EP/IR), infauna rasa (IR), infauna rasa e/ou infauna intermediária (IR/II), infauna intermediária (II) e infauna intermediária e/ou infauna profunda (II/IP), infauna profunda (IP). Corliss (1991) classificou em epifauna os organismos que habitam $0-1 \mathrm{~cm}$, infauna rasa $(0-2 \mathrm{~cm})$, infauna intermediária (1-4 $\mathrm{cm})$, e infauna profunda $(>4 \mathrm{~cm})$, porém para o presente estudo, alguns destes valores 
foram alterados em busca de melhores limites de classificação de profundidade e estão apresentados na Tabela 2 .

Tabela 1: Valores de $\mathrm{ALD}_{\mathrm{x}}$ e suas respectivas classificações de microhábitats utilizadas neste trabalho.

Microhabitat

Epifauna e/ou Infauna Rasa (EP/IR)

Infauna Rasa (IR)

Infauna Rasa e/ou Infauna Intermediária (IR/II)

Infauna Intermediária (II)

Infauna Intermediária e/ou Infauna Profunda (II/IP)

Infauna Profunda (IP)
ALD (Corliss, 1991 modificado)

0.5

$>0.5-2.0$

2

$>2.0-4.0$

4

$>4.0$

Por fim, os perfis de distribuição vertical gerados para as estações analisadas foram classificados de acordo com os tipos de distribuição vertical apresentado por Jorissen et al. (1995), e juntamente com os dados da profundidade média de habitat $\left(A L D_{X}\right)$ da microfauna total, as condições tróficas nas estações foram interpretadas segundo o Modelo TROX (TR-trófico; OX- oxigênio) de Jorissen et al. (1995). 


\section{Resultados}

\subsection{Estação I06}

Os sedimentos foram lamosos com diâmetro médio $(\Phi)$ de 6,70, e o valor obtido da razão silte/ argila foi de 2,03 e da razão C/S foi de 11,06. Os valores obtidos de conteúdo de $\mathrm{CaCO}_{3}$ e carbono orgânico total (COT) foram 44,41 \% e 1,88\%, respectivamente. Na estação I06, mudança na coloração dos sedimentos foi observada a $13 \mathrm{~cm}$ de profundidade no sedimento, sugerindo a ocorrência de mudanças na condição redox (camada anóxica) nessa profundidade. Nessa coluna sedimentar não foram observadas estruturas de bioturbação, tendo-se observado a ocorrência de pelotas fecais nas amostras. Os valores de diâmetro médio $(\Phi)$, razão silte/ argila, razão $\mathrm{C} / \mathrm{S}$, conteúdos de $\mathrm{CaCO}_{3}$ e COT (\%), profundidade da camada anóxica (cm), presença e/ou ausência de pelotas fecais e bioturbação estão apresentados na Tabela 3.

Tabela 2: Valores de diâmetro médio, razão silte/argila, conteúdo de CaCO3 e COT, presença de pelotas fecais, bioturbação e profundidade de camada anóxica na estação I06.

\begin{tabular}{|c|c|}
\hline \multicolumn{2}{|l|}{ Dados abióticos } \\
\hline Diâmetro médio $(\Phi)$ & 6.7 \\
\hline Silte/Argila & 2.03 \\
\hline $\mathrm{C} / \mathrm{S}$ & 11.06 \\
\hline $\mathrm{CaCO}_{3}(\%)$ & 44.41 \\
\hline COT (\%) & 1.88 \\
\hline Pelotas fecais (presença $=1$; ausência $=0$ ) & 1 \\
\hline Bioturbação (presença $=1$; ausência $=0$ ) & $\mathbf{0}$ \\
\hline Camada anóxica $(\mathrm{cm})$ & 13 \\
\hline
\end{tabular}

\subsubsection{Dados bióticos}

5.1.1.1.Descritores ecológicos (densidade, riqueza, diversidade ponderada, diversidade de Shannon, e equitabilidade de Pielou)

Os valores de densidade variaram de 1140 ind. $/ 50 \mathrm{~cm}^{3}$ na profundidade $0-1 \mathrm{~cm}$ à 31 ind. $/ 50 \mathrm{~cm}^{3}$ na profundidade $9-10 \mathrm{~cm}$, observando uma diminuição progressiva da 
densidade da profundidade superior $(0-1 \mathrm{~cm})$ com 1140 ind. $/ 50 \mathrm{~cm}^{3}$ para a profundidade inferior (1-2 cm) com 143 ind./50 $\mathrm{cm}^{3}$ (Tabela 4 e Figura 7). O valor da densidade média obtido foi de 167 ind. $/ 50 \mathrm{~cm}^{3}$

Tabela 3: Valores de descritores ecológicos (densidade, riqueza, diversidade de Shannon e equitatividade Pielou) nas profundidades 0 à $10 \mathrm{~cm}$ de sedimento, e suas respectivas médias na estação I06.

\begin{tabular}{ccccc}
\hline Profundidade $(\mathrm{cm})$ & Densidade (ind./50cc.) & Riqueza (R) & Diversidade de Shannon $\left(\mathrm{H}^{\prime}\right)$ & Equitatividade $(\mathrm{J})$ \\
\hline $0-1$ & 1140 & 59 & 2.6 & 0.65 \\
$1-2$ & 143 & 25 & 2.0 & 0.61 \\
$2-3$ & 76 & 24 & 2.6 & 0.83 \\
$3-4$ & 76 & 22 & 2.3 & 0.73 \\
$4-5$ & 51 & 21 & 2.6 & 0.85 \\
$5-6$ & 44 & 13 & 2.1 & 0.80 \\
$6-7$ & 29 & 12 & 2.1 & 0.85 \\
$7-8$ & 49 & 14 & 2.1 & 0.81 \\
$8-9$ & 34 & 15 & 2.3 & 0.85 \\
$9-10$ & 31 & 7 & 1.4 & 0.72 \\
Média & 167.3 & 21.2 & 2.2 & 0.77 \\
\hline
\end{tabular}



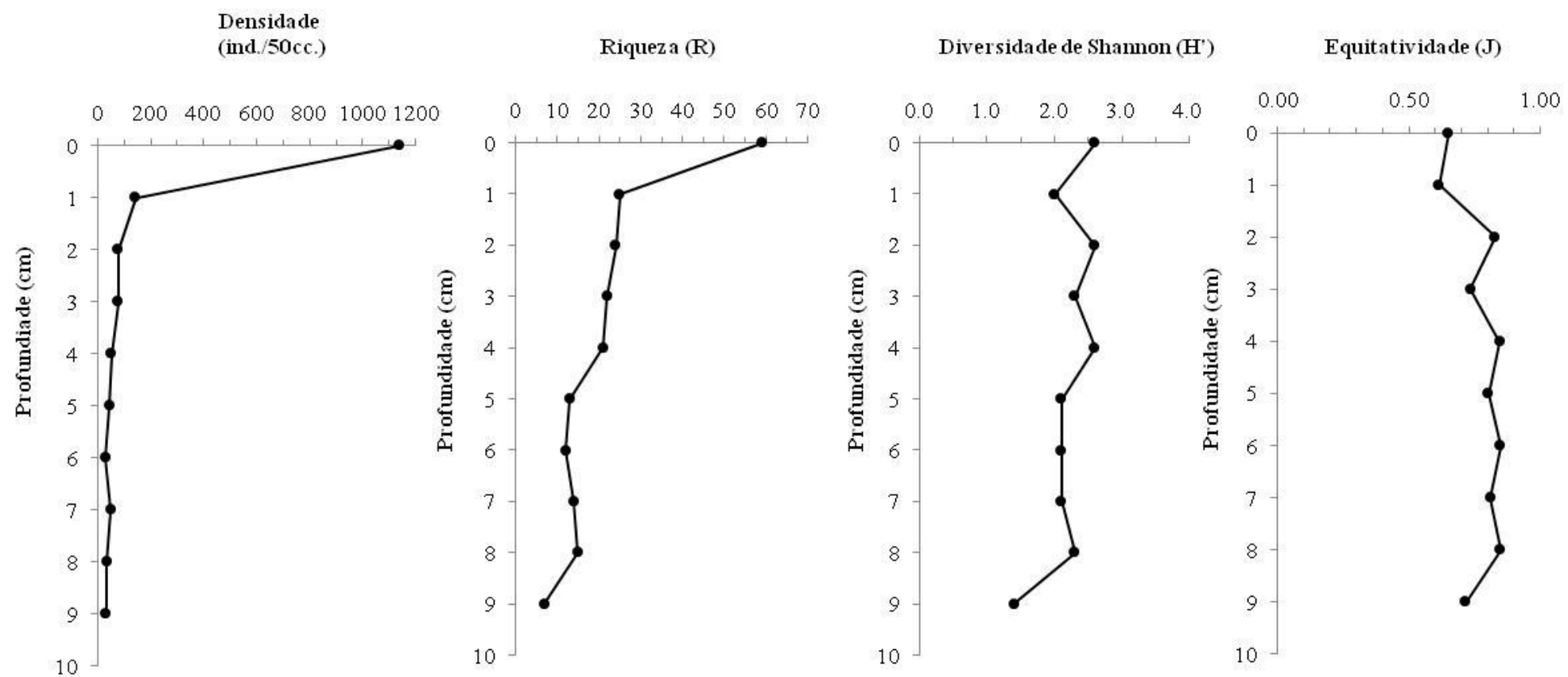

Figura 7: Distribuição vertical da densidade, riqueza, diversidade e equitatividade dos foraminíferos bentônicos vivos, entre 0 e $10 \mathrm{~cm}$ de profundidade da coluna de sedimento na estação I06. 
Os valores de riqueza variaram de 59 espécies na profundidade $0-1 \mathrm{~cm}$ para 7 espécies na profundidade $9-10 \mathrm{~cm}$. Os valores de riqueza decaem da profundidade $0-1 \mathrm{~cm}$ até a profundidade $6-7 \mathrm{~cm}$ (12 espécies), no entanto, a riqueza aumenta nas profundidades $7-8 \mathrm{~cm}$ (14 espécies) e 8-9 cm (15 espécies), voltando a decair na profundidade 9-10 cm (7 espécies). A média dos valores de riqueza obtida foi de 21 espécies na estação I06 (Tabela 4).

O maior valor de diversidade observado foi de 2,6 em profundidades intercalados (e.g. profundidades $0-1,2-3$ e 4-5 cm) e o menor valor $(1,4)$ foi constatado na profundidade 9$10 \mathrm{~cm}$ de sedimento (Tabela 4). O valor médio da diversidade de Shannon foi de 2,2, e o valor de diversidade ponderada para a estação I06 foi de 2,35.

Os valores calculados da Equitatividade de Pielou (J) da estação I6 mostram os menores valores nas duas primeiras profundidades $(0-1$ e $1-2 \mathrm{~cm})$, respectivamente de 0,65 e 0,61, aumentando nas profundidades seguintes (e.g. profundidade $8-9 \mathrm{~cm}$ com valor 0,85 ). $\mathrm{O}$ valor médio da equitatividade foi de 0,77 (Tabela 4).

5.1.1.2. Espécies mais abundantes, perfil de distribuição vertical, ALD $D_{10}$ espécie, $A L D_{10}$ fauna total, e porcentagem de microhábitat

As espécies mais abundantes (abundância relativa >3\%) encontradas na estação I06 foram: Reophax caribensis (35\%), Reophax minimus (8\%), Lagenammina diffugiformis (6\%), Pyrgo nasuta (5\%), Pyrgo insularis (4\%), Uvigerina parvula (4\%), Uvigerina peregrina (4\%), Globocassidulina minuta (3\%), Pullenia bulloides (3\%), e Reophax calcareus (3\%).

No geral, à exceção das espécies Reophax minimus, que apresentou o maior valor de densidade 30 ind./50 $\mathrm{cm}^{3}$ na profundidade $3-4 \mathrm{~cm}$ e a espécie Lagenammina diffugiformis, que apresentou um leve aumento no valor de densidade de $10 \mathrm{ind} . / 50 \mathrm{~cm}^{3}$ na profundidade 9$10 \mathrm{~cm}$, as espécies mais abundantes da estação I06 apresentaram perfil de distribuição vertical semelhante, com elevada densidade na primeira profundidade $(0-1 \mathrm{~cm})$ e diminuição nos valores de densidade nas profundidades seguintes (Figura 8). 

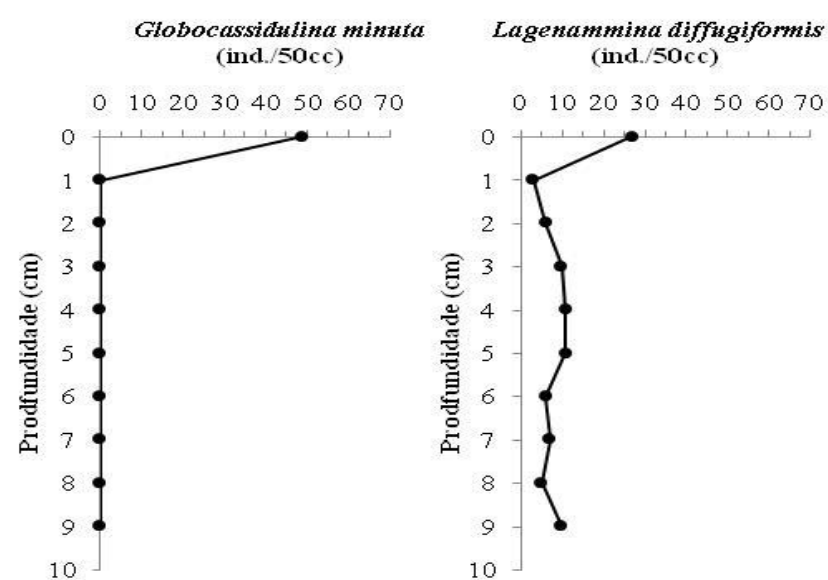
(ind. $/ 5 \mathrm{Occ}$ )

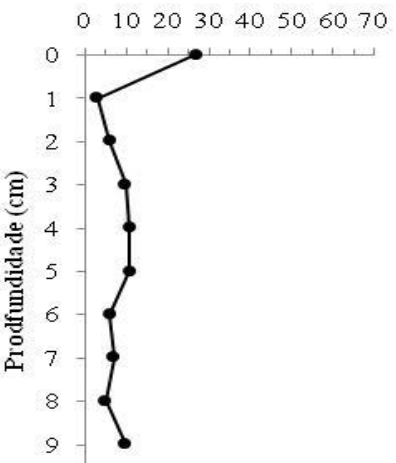

Reophax calcareus (ind $/ 50 \mathrm{cc}$ )

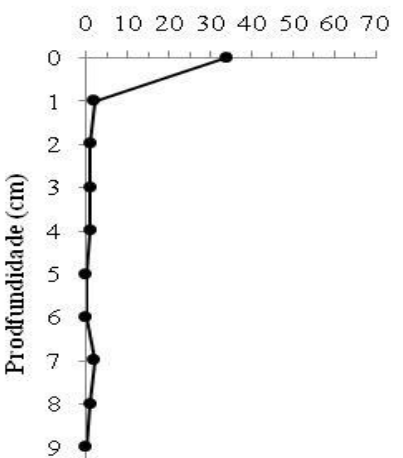

10
10

Reophax caribensis (ind $/ 50 \mathrm{cc}$ )

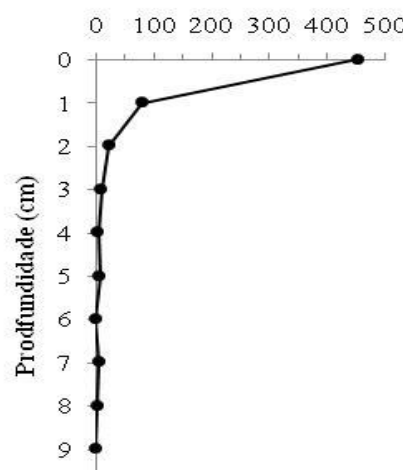

10

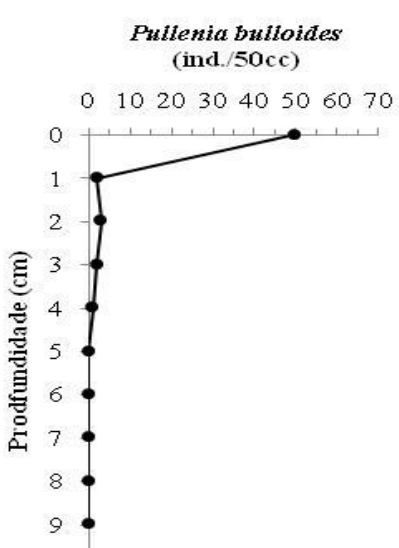

Reophax minimus (ind. $/ 50 \mathrm{cc}$ )

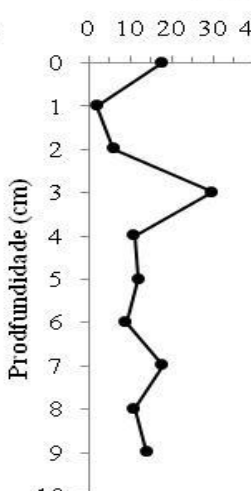

Pyrgo insularis

o 10203040506070

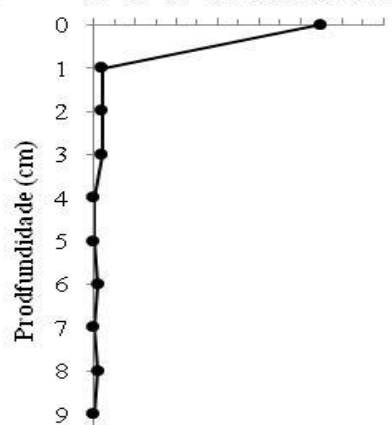

10

Uvigerina parvula (ind / $/ 50 \mathrm{cc}$ )

o 10203040506070

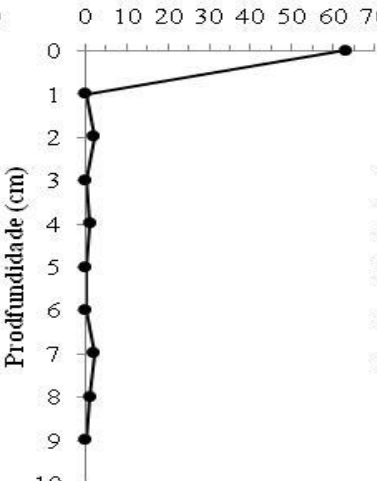

Pyrgo nasuta
(ind $/ 50 \mathrm{ccc}$ )

o 10203040506070

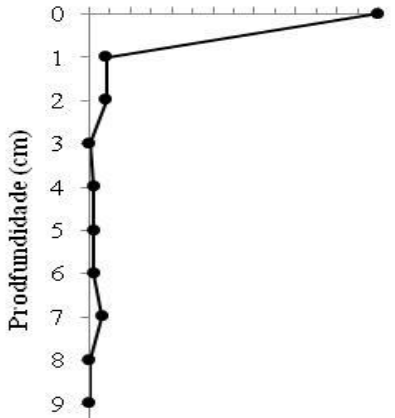

10

Uvigerina peregrina (ind $/ 50 \mathrm{cc}$ )

Figura 8: Distribuição vertical das espécies mais abundantes com frequência igual ou superior a 3\%, entre 0 e $10 \mathrm{~cm}$ de profundidade na coluna de sedimento, na estação I06. No eixo x está representada a densidade e o eixo y estão representadas as profundidades em $\mathrm{cm}$ (densidade e profundidade em cm) devem estar anotadas nos gráficos. Note que a escala do eixo x da espécie Reophax caribensis é diferente das demais espécies por ter apresentado elevada densidade.

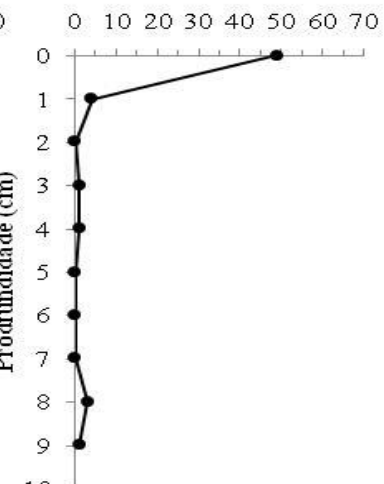


A profundidade média de hábitat $\left(\mathrm{ALD}_{10}\right)$ para a fauna total, ou seja, considerando todas as espécies da estação I06 apresentou o valor de $1,7 \mathrm{~cm}$. Os valores de $\mathrm{ALD}_{10}$ para as espécies mais abundantes estão apresentados na Figura 9. Na estação I06, com exceção das espécies Reophax minimus e Lagenammina diffugiformis que apresentaram ALD $_{10}$, respectivamente, de 5 e $4 \mathrm{~cm}$, no geral, as espécies apresentaram valor de $\mathrm{ALD}_{10}$ variáveis entre 1 e 0,5cm. Na estação I06, 31\% das espécies estão presentes no microhábitat epifaunal e/ou infaunal raso (EP/IR) e $25 \%$ das espécies ocorrem no microhábitat infaunal raso (IR), com $65 \%$ de espécies aglutinantes e porcentagem de espécies hialinas e porcelanáceas respectivamente de $26 \%$ e $9 \%$ (Tabela 5).

Tabela 4: Porcentagem das espécies nos microhábitats na estação I06. EP/IR= epifaunal e/ou infaunal raso, IR= infaunal raso, $\mathrm{IR} / \mathrm{II}=$ infaunal raso e/ou infaunal intermediário, $\mathrm{II}=$ infaunal intermediário, $\mathrm{II} / \mathrm{IP}=$ infaunal intermediário e/ou infaunal profundo, e IP= infaunal profundo. Porcentagem das subordens das espécies da estação I06.

\begin{tabular}{lc}
\hline \multicolumn{1}{c}{ Microhabitat } & $(\boldsymbol{\%})$ \\
\hline EP/IR (\%) & 31 \\
IR (\%) & 25 \\
IR/II (\%) & 10 \\
II (\%) & 8 \\
II/IP (\%) & 8 \\
IP(\%) & 18 \\
\hline \multicolumn{1}{c}{ Subordens } & $\mathbf{( \% )}$ \\
\hline Textulariina (Aglutinante) & 65 \\
Rotaliina (Hialino) & 26 \\
Miliolina (Porcelanáceo) & 9 \\
\hline
\end{tabular}




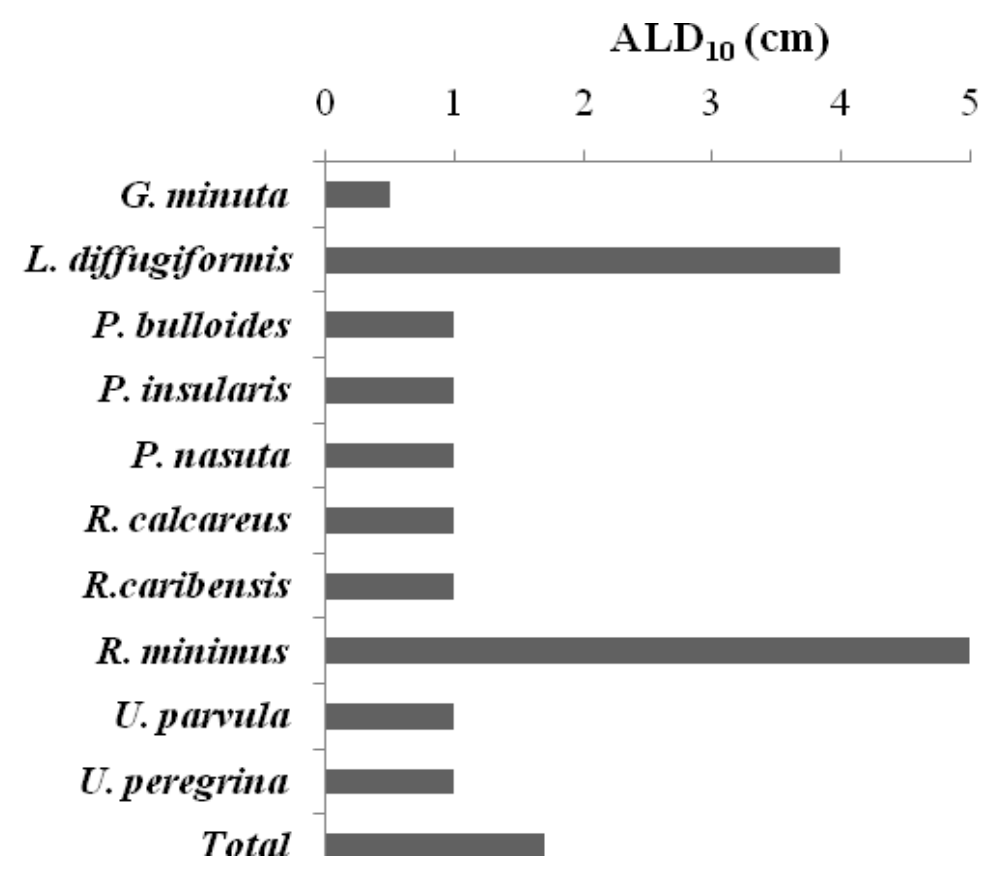

Figura 9: Profundidade média de habitat em $10 \mathrm{~cm}$ de sedimento $\left(\mathrm{ALD}_{10}\right)$ para as espécies mais abundantes bem como para o total de espécies da estação I06.

\subsection{Estação I08}

Os sedimentos foram lamosos na estação I08 com valor de diâmetro médio $(\Phi)$ de 6.97. O valor obtido da razão silte/ argila foi de 1.75 e da razão C/S foi de 9.07. Os valores obtidos de conteúdo de $\mathrm{CaCO}_{3}$ e COT foram $36.55 \%$ e $1.36 \%$, respectivamente. Na estação I08, mudança na coloração dos sedimentos foi observada a $7 \mathrm{~cm}$ de profundidade no sedimento, sugerindo a ocorrência de mudanças na condição redox (camada anóxica) nessa profundidade. Nessa coluna sedimentar, foram observadas estruturas de bioturbação, e ausência de pelotas fecais nas amostras. Os valores de diâmetro médio $(\Phi)$, razão silte/ argila, razão $\mathrm{C} / \mathrm{S}$, conteúdos de $\mathrm{CaCO}_{3}$ e COT $(\%)$, profundidade da camada anóxica $(\mathrm{cm})$, presença e/ou ausência de pelotas fecais e bioturbação, estão apresentados na Tabela 6. 
Tabela 5: Valores de diâmetro médio, razão silte/argila, porcentagem de conteúdo de $\mathrm{CaCO}_{3}$ e COT, pelotas fecais, bioturbação e profundidade da camada anóxica para a estação I08.

\begin{tabular}{|c|c|}
\hline \multicolumn{2}{|l|}{ Dados abióticos } \\
\hline Diâmetro médio ( $\Phi)$ & 6.97 \\
\hline Silte/Argila & 1,75 \\
\hline $\mathrm{C} / \mathrm{S}$ & 9.07 \\
\hline $\mathrm{CaCO}_{3}(\%)$ & 36.55 \\
\hline COT (\%) & 1.36 \\
\hline Pelotas fecais (presença $=1$; ausência $=0$ ) & 0 \\
\hline Bioturbação (presença $=1$; ausência $=0$ ) & 1 \\
\hline Camada anóxica $(\mathrm{cm})$ & 7 \\
\hline
\end{tabular}

\subsubsection{Dados bióticos}

5.2.1.1. Descritores ecológicos (densidade, riqueza, diversidade ponderada, diversidade de Shannon e equitabilidade de Pielou)

Os valores de densidade variaram de 353 ind. $/ 50 \mathrm{~cm}^{3}$ na profundidade $1-2 \mathrm{~cm}$ a 8 ind. $/ 50 \mathrm{~cm}^{3}$ na profundidade $8-9 \mathrm{~cm}$, observando uma diminuição progressiva da densidade da profundidade superior $(1-2 \mathrm{~cm}) \mathrm{com} 353 \mathrm{ind} . / 50 \mathrm{~cm}^{3}$, passando a apresentar $210 \mathrm{ind} . / 50 \mathrm{cc}$, na profundidade de $2-3 \mathrm{~cm}$ (Tabela 7 e Figura 10). No entanto, na profundidade 9-10 $\mathrm{cm}$ o valor de densidade aumenta em relação à profundidade anterior $(8-9 \mathrm{~cm})$ (e.g. densidade de 8 ind./50 cc na profundidade $8-9 \mathrm{~cm}$ para 14 ind./50 cc na profundidade $9-10 \mathrm{~cm}$ ) (Tabela 7). $\mathrm{O}$ valor médio da densidade obtido foi de 107 ind./50cc (Tabela 7).

Tabela 6: Valores de descritores ecológicos (densidade, riqueza, diversidade de Shannon e equitatividade Pielou) nas profundidades 0 à $10 \mathrm{~cm}$ de sedimento, e suas respectivas médias na estação $\mathrm{I} 08$.

\begin{tabular}{ccccc}
\hline Profundidade (cm) & Densidade (ind./50cc.) & Riqueza (R) & Diversidade de Shannon $\left(\mathrm{H}^{\prime}\right)$ & Equitatividade $(\mathrm{J})$ \\
\hline $0-1$ & 196.00 & 49 & 3.0 & 0.77 \\
$1-2$ & 353 & 63 & 3.6 & 0.88 \\
$2-3$ & 210 & 55 & 3.5 & 0.88 \\
$3-4$ & 102 & 37 & 3.3 & 0.91 \\
$4-5$ & 73 & 36 & 3.3 & 0.91 \\
$5-6$ & 67 & 23 & 2.8 & 0.90 \\
$6-7$ & 27 & 14 & 2.4 & 0.91 \\
$7-8$ & 18 & 9 & 2.1 & 0.95 \\
$8-9$ & 8 & 7 & 1.9 & 0.98 \\
$9-10$ & 14 & 8 & 2.0 & 0.95 \\
Média & 106.80 & 30.10 & 2.79 & 0.90 \\
\hline
\end{tabular}



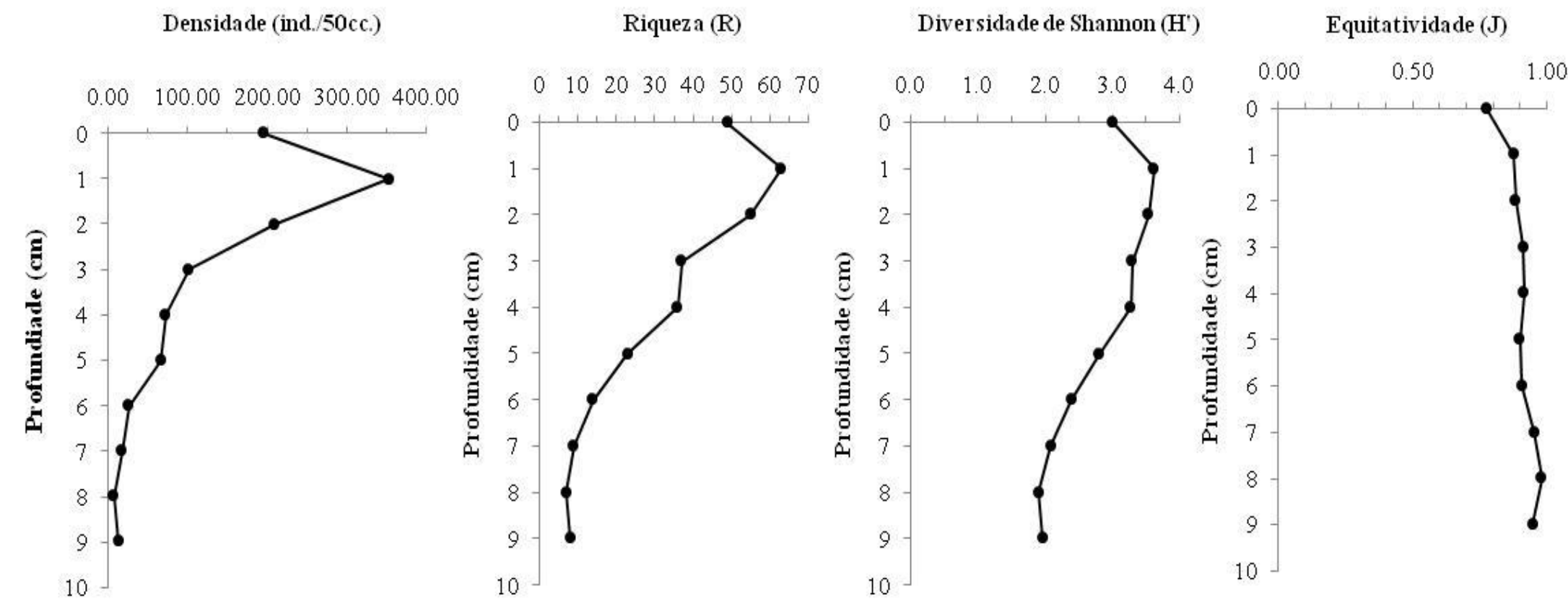

Figura 10: Distribuição vertical da densidade, riqueza, diversidade e equitatividade dos foraminíferos bentônicos vivos, entre 0 e 10 cm de profundidade na coluna de sedimento na estação I08. No eixo x mostra os descritores ecológicos e no eixo y as profundidades $(\mathrm{cm})$. 
Os valores de riqueza variaram de 63 espécies na profundidade $1-2 \mathrm{~cm}$ para 7 espécies na profundidade $8-9 \mathrm{~cm}$. Os valores de riqueza decaem da profundidade $1-2 \mathrm{~cm}$ até a profundidade 8-9 cm (7 espécies), porém na profundidade 9-10 cm o valor aumenta novamente (e.g. profundidade 8-9 cm com o valor de 7 espécies e profundidade $9-10 \mathrm{~cm}$ com o valor de 8 espécies) (Tabela 7 e Figura 10). O valor médio da riqueza foi de 30 espécies.

Os valores calculados de diversidade de Shannon apresentaram valor máximo de 3,6 na profundidade 1-2 cm, e valor mínimo de 1,9 na profundidade $8-9 \mathrm{~cm}$ de sedimento (Tabela 7). Os valores de diversidade decaem progressivamente da profundidade $1-2 \mathrm{~cm}(3,6)$ até a profundidade 8-9 cm (1,9), com exceção da profundidade 9-10 cm, que apresenta maior valor de diversidade comparado a profundidade anterior 8-9 cm (e.g. profundidade 9-10 cm com o valor de diversidade 2, e profundidade $8-9 \mathrm{~cm}$ com valor de diversidade 1,9) (Tabela 7). O valor médio da diversidade de Shannon foi de 2,28 e o valor de diversidade ponderada para a estação I08 foi de 3,18.

O valor calculado de equitatividade de Pielou (J) da estação I8 apresentou o menor valor $(0,77)$ na profundidade $0-1 \mathrm{~cm}$, com aumento dos valores em direção a maiores profundidades no sedimento (e.g. profundidade $8-9 \mathrm{~cm}$ com valor de 0,98). Porém na profundidade 9-10 $\mathrm{cm}$ o valor volta a diminuir comparativamente à profundidade anterior (e.g. de 0,98 a 0,95) (Tabela 7). O valor médio da equitatividade foi de 0,90 (Tabela 7).

5.2.1.2. Espécies mais abundantes e perfil de distribuição vertical, ALD ${ }_{10}$ fauna total e para as espécies mais abundantes, e porcentagem de microhábitat

As espécies mais abundantes (abundância relativa >3\%) encontradas na estação I8 estão apresentadas a seguir: Reophax spiculotestus (18\%), Karrerulina conversa (4\%), Reophax sp1. (4\%), Ammobaculites agglutinans (3\%), Ammodiscus planorbis (3\%), Discammina compressa (3\%), Hoeglundina elegans (3\%), Recurvoidella bradyi (3\%), Reophax scorpiurus (3\%) e Repmanina charoides (3\%).

A Figura 11 mostra os perfis de distribuição vertical em $10 \mathrm{~cm}$ de sedimento das espécies mais abundantes da estação I08. Pode-se notar com exceção das espécies Reophax sp1. e Reophax spiculotestus, que apresentaram as maiores densidades (16 e 63 ind./50cc, respectivamente) na primeira profundidade $(0-1 \mathrm{~cm})$, no geral, as espécies apresentaram a maior densidade na profundidade $1-2 \mathrm{~cm}$. 
A distribuição da espécie Repmanina charoides é um exemplo do perfil de distribuição vertical das espécies abundantes da estação I08, apresentando baixa densidade na primeira profundidade $(0-1 \mathrm{~cm})$ com apenas 2 ind. $/ 50 \mathrm{~cm}^{3}$ aumentando na profundidade $1-2 \mathrm{~cm}$ com valor máximo de densidade 12 ind. $/ 50 \mathrm{~cm}^{3}$ Nas profundidades inferiores a $2 \mathrm{~cm}$, a densidade dessa espécie diminui, ocorrendo 10 ind. $/ 50 \mathrm{~cm}^{3}$ na profundidade $2-3 \mathrm{~cm}$ e 6 ind. $/ 50 \mathrm{~cm}^{3}$ na profundidade 3-4 cm (Figura 11). 

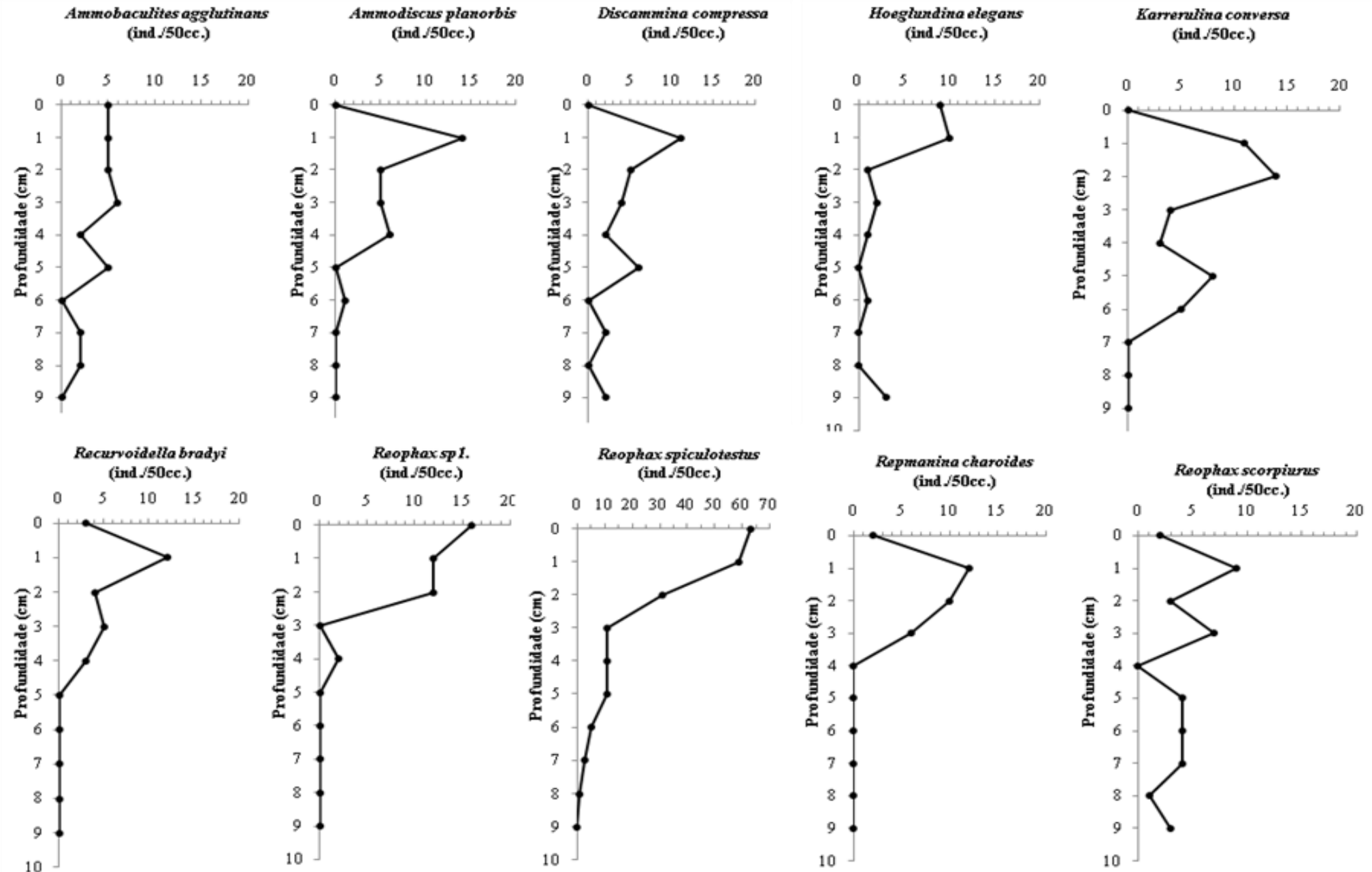

Figura 11: Distribuição vertical das espécies mais abundantes com abundância relativa igual ou superior a 3\%, entre 0 e 10 cm na coluna de sedimento na estação I08. No eixo $\mathrm{x}$ está representada a densidade e no eixo y estão representadas as profundidades em $\mathrm{cm}$. Note que a escala da espécie Reophax spiculotestus é diferente das demais espécies por ter apresentado elevada densidade. 
Na estação I08, a profundidade média de hábitat para fauna total $\left(\mathrm{ALD}_{10}\right)$ apresentou o valor de $2,5 \mathrm{~cm}$. O ALD 10 das espécies mais abundantes mostraram o valor máximo de $4 \mathrm{~cm}$ para as espécies Ammobaculites agglutinans, Discammina compressa e Reophax scorpiurus. Por sua vez, as espécies Ammodiscus planorbis, Hoeglundina elegans, Karrerulina conversa, apresentaram $\mathrm{ALD}_{10}$ com valor de $3 \mathrm{~cm}$ e as espécies Reophax sp1., Reophax spiculotestus, Repmanina charoides, e Recurvoidella bradyi apresentaram o menor valor de $\mathrm{ALD}_{10}$ de $2 \mathrm{~cm}$ (Figura 12). Na estação I08, 27\% das espécies ocorrem como infaunal rasa e/ou infaunal intermediária (IR/II) e 20\% das espécies estão presentes como infaunal intermediária (II), com $85 \%$ das espécies aglutinantes e espécies hialinas e porcelanáceas com 13\% e 2\% (Tabela 8).

Tabela 7: Porcentagem das espécies nos microhábitats na estação I08. EP/IR= epifaunal e/ou infaunal raso, IR= infaunal raso, IR/II= infaunal raso e/ou infaunal intermediário, II= infaunal intermediário, II/IP= infaunal intermediário e/ou infaunal profundo, e IP= infaunal profundo. Porcentagem das subordens das espécies na estação I08.

\begin{tabular}{lc}
\hline \multicolumn{1}{c}{ Microhabitat } & $(\boldsymbol{\%})$ \\
\hline EP/IR (\%) & 17 \\
IR (\%) & 5 \\
IR/II (\%) & 27 \\
II (\%) & 20 \\
II/IP (\%) & 15 \\
IP(\%) & 16 \\
\hline \multicolumn{1}{c}{ Subordens } & $\mathbf{( \% )}$ \\
\hline Textulariina (Aglutinante) & 85 \\
Rotaliina (Hialino) & 13 \\
Miliolina (Porcelanáceo) & 2 \\
\hline
\end{tabular}




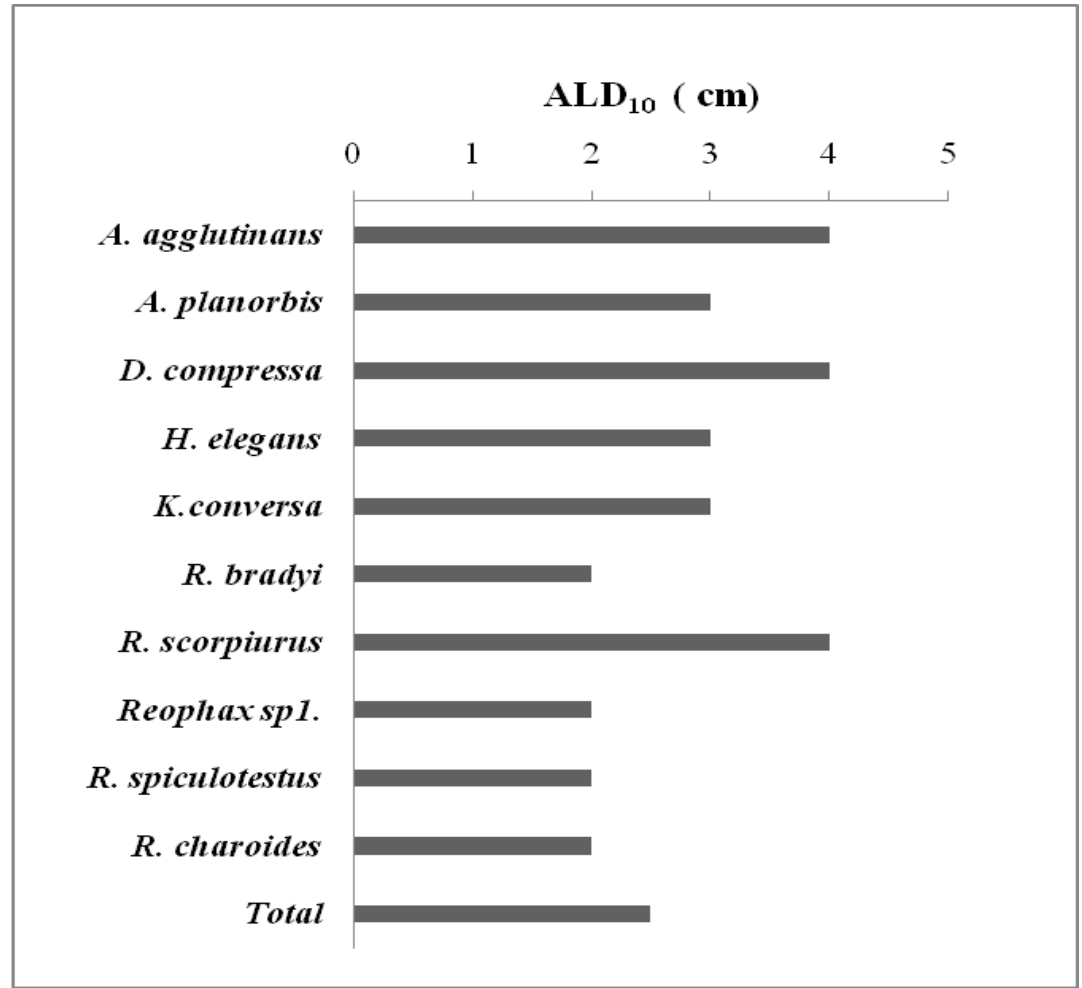

Figura 12: Profundidade média de habitat em $10 \mathrm{~cm}$ (ALD10) de sedimento (eixo $\mathrm{x}$ ) para as espécies mais abundantes (>3\%) e para o total de espécies (eixo y) da estação I08. 


\section{Discussão}

Dados sedimentológicos, geoquímicos e de foraminíferos bentônicos vivos permitiram identificar diferentes condições hidrodinâmicas e de aporte de nutrientes no talude superior e médio da Bacia de Campos.

A morfologia da bacia exerce um papel fundamental na dinâmica das correntes que por sua vez, atua na transferência, deposição e retrabalhamento dos sedimentos no mar profundo (VIANA et al. 1998a). A deposição dos sedimentos é controlada pela variação da velocidade da corrente que por outro lado, é influenciada pela fisiografia da margem (VIANA, 2002). Segundo Viana et al. (1998a) essa variação de velocidade pode ser observada próximo ao Cabo de São Tomé onde a projeção da plataforma resulta no expandimento do fluxo da $\mathrm{CB}$ e consequentemente na diminuição da velocidade.

A maior velocidade da CB (1.2.m.s $\mathrm{s}^{-1}$ ) (VIANA, 2002) favorece a deposição de lama arenosa no talude superior, enquanto no talude médio a presença da CCI, que flui em direção norte, com velocidades não superiores a $0,30 \mathrm{~m} \cdot \mathrm{s}^{-1}$, promove a deposição de sedimentos hemipelágicos (VIANA, 2002).

A diminuição dos valores de tamanho de grão e na velocidade de corrente com o aumento profundidade da lâmina de água foi observada para o talude continental da Bacia de Campos (ALMEIDA e KOWSMANN, 2014). No presente estudo, este mesmo padrão foi observado apresentando valores de diâmetro médio $(\Phi)$ e razão silte/argila para a estação I06 de 6,70 e 2,03, respectivamente. Por sua vez, na estação I08 foram observados valores menores de diâmetro médio (6.97) e razão silte/argila (1.75), corroborando as estimativas de velocidades de corrente de fundo estabelecidas por Silveira (2007) para a CB $\left(0,4-0,7 \mathrm{~m} . \mathrm{s}^{-1}\right) \mathrm{e}$ Silveira et al. (2004) para a CCI (não superior a 0,30 m.s.15).

Os altos valores da razão C/S obtidos (11,06 e 9,07 respectivamente nas estações I06 e I08), refletem que a disponibilidade de oxigênio não é limitada no talude superior e médio da Bacia de Campos. Segundo Berner e Raiswell, (1984) o limite entre anóxico e óxico apresenta valor $\mathrm{C} / \mathrm{S}=2,8$, basicamente este valor representa a conversão do carbono orgânico em enxofre, indicando indiretamente todo o consumo do oxigênio.

\subsection{Talude Superior}

Eberwein e Mackensen (2006) e Koho et al. (2007) mostraramque há um padrão de diminuição nos valores da densidade de foraminíferos bentônicos vivos com o aumento da 
profundidade da coluna d'água. Segundo Jorissen (1999), o padrão de distribuição vertical dos foraminíferos bentônicos vivos nos sedimentos reflete a tolerância ou preferência das espécies por um ou mais fatores como disponibilidade de nutrientes, concentração de oxigênio, bioturbação, competição e predação. Considerando estes fatores, Jorissen (1999) gerou 4 perfis de distribuições verticais onde dentre estes, o perfil tipo A de distribuição vertical é semelhante ao perfil de distribuição vertical dos foraminíferos bentônicos da estação I06.

Na estação I06 a distribuição vertical da densidade dos foraminíferos bentônicos vivos apresentou um perfil de decaimento exponencial acentuado com o maior valor de densidade de 1140 ind./50 cc na profundidade $0-1 \mathrm{~cm}$ semelhante ao perfil tipo A identificado por Jorissen (1999) apresentando valores máximos de densidade na profundidade $0-1 \mathrm{~cm} \mathrm{e}$ valores mínimos em maiores profundidades (Figura 13).
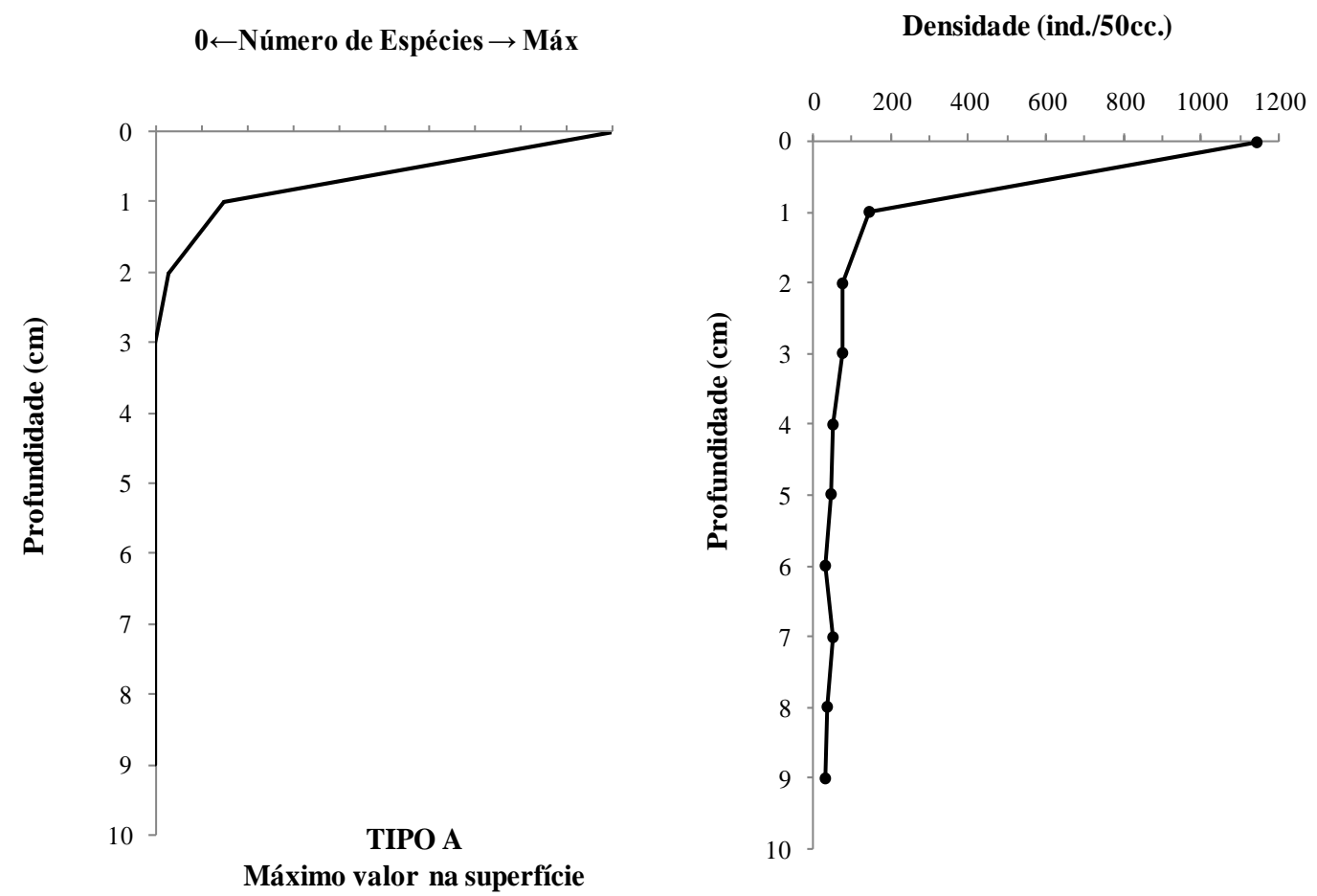

Figura 13: À esquerda, perfil de distribuição vertical tipo A identificada por Jorissen (1999) e a direita, perfil de distribuição vertical da densidade dos foraminíferos bentônicos vivos da estação I06.

O tipo de distribuição vertical do tipo A é caracterizado pelo predomínio de espécies oportunistas epifaunais ou infaunal raso que possuem preferência pelo topo do sedimento para se alimentar da matéria orgânica lábil ou que não toleram as condições em maiores 
profundidades, sendo este perfil associado a maior disponibilidade de MO lábil no ambiente (JORISSEN, 1999).

Burone et al. (2010) também observaram este perfil de decaimento exponencial na plataforma e talude superior (400m) entre as latitudes $23.8^{\circ}-25.9^{\circ} \mathrm{S}$ do setor do Embaimento de São Paulo, desde Cabo Frio até Cabo de Santa Marta (latitudes $23^{\circ}-28^{\circ}$ S), atribuindo este perfil a condições oligotróficas.

Dados de fluxos de carbono orgânico e conteúdo de carbonato de cálcio no sedimento podem refletir a produtividade primária (BRUMMER E EIJDEN, 1992). No entanto variações na porcentagem de $\mathrm{CaCO}_{3}$ ocorrem em função do balanço entre a produtividade primária da zona eufótica, sua dissolução e diluição, ocasionada pelo aumento do fluxo de sedimentos terrígenos (DITTERT et al. 1999). No talude superior do setor norte, o aumento nos valores de porcentagem de carbonato deve-se provavelmente além do maior fluxo de produtividade primária, à presença de pelotas fecais, que atuam como membranas orgânicas protetoras na preservação e transporte do carbonato da zona fótica até o assoalho oceânico (DITTERT et al. 1999) bem como ao transporte de sedimentos terrígenos resultado de uma plataforma estreita e de uma elevada declividade do talude superior 5 a $10^{\circ}$ (ALMEIDA e KOWSMANN, 2014).

Em áreas oligotróficas onde não há influência da lisoclina gerando dissolução do carbonato, o conteúdo de carbonato pode ser um indicador de produtividade. Por sua vez, em áreas eutróficas o uso do carbonato como indicador de produtividade torna-se restritivo, pois os maiores valores de conteúdo de carbono orgânico no sedimento contribui para o processo de dissolução através da reação do $\mathrm{CO}_{2}$ gerado a partir da degradação da $\mathrm{MO}$ pelos organismos bentônicos (DITTERT et al. 1999).

A constatação na estação I06 de valores relativamente maiores de conteúdos de COT (1,88\%), lipídeos autóctones (628,4 ng/mg), e de $\mathrm{CaCO}_{3}(44,41 \%)$ (Tabela 3), parece indicar que o talude superior na Bacia de Campos é um local com maior fluxo de produtividade primária, e consequentemente, maior deposição da MO lábil. Essa constatação corrobora dados obtidos por Vicente (2012), que estima produção primária nessa região da estação em 134,6 $\mathrm{mgCm}^{-2} \cdot$ dia $^{-1}$, e são argumentos importantes na confirmação da hipótese de que o aporte de matéria orgânica para o talude continental na margem sudeste Brasileira é proveniente principalmente da exportação de produtividade primária nas águas superficiais.

A labilidade representada pelo lipídeos autóctones e a quantidade relativamente maior de MO oriunda de pulsos de fitodetritos no talude superior é também indicada, pela presença 
na estação I06, de espécies oportunistas como G. minuta (ALTEBANCH, 2003; MARTINS et al. 2006), L. diffugiformis (KURBEJEWEIT et al. 2000; LICARI e MACKENSEN, 2005; DUROS et al. 2011) e P. bulloides (GUPTA, 2010).

Os pulsos esporádicos de MO no talude superior favorecem as espécies com estratégia de vida oportunista, que residem nos primeiros centímetros do sedimento, promovendo seu crescimento e reprodução, resultando no incremento de sua abundância (JORISSEN, 1999; FONTANIER et al. 2003, 2005; MOJTAHID et al. 2009). Esta estratégia oportunista também resulta, segundo Jorissen et al. (1992), Garcia et al. (2013), em valores menores de diversidade, riqueza, e equitatividade, que são observados na estação I06 (Tabela 4), quando comparados aos altos valores observados destes mesmos descritores ecológicos na estação I08 (Tabela 7).

Segundo Koho et al. (2008), as espécies com paredes cálcareas ao contrário das espécies com paredes aglutinantes, são mais sensíveis à entrada de MO lábil e dependem desta matéria orgânica para sobreviverem e para reprodução. Gooday e Rathburn, (1999) e Kitazato et al. (2000) sugerem que o aumento da abundância das espécies calcáreas ocorre posteriormente a deposição de blooms de fitoplâncton. Valores maiores de porcentagem de espécies calcárias constatados para o talude superior (9\% calcário porcelanáceo e $26 \%$ calcário hialino, Tabela 5) corroboram a maior incidência de blooms de fitoplâncton nessa porção do talude da Bacia de Campos.

Sousa et al. (submetido) na Bacia de Campos também já demonstravam a influência do aporte alimentar na comunidade de foraminíferos bentônicos, seja pela qualidade de MO demonstrada pelos valores obtidos de correlação positiva significativa $(r=0.74)$ entre fitopigmento e densidade, e pela quantidade de MO (COT) e densidade ( $r=0,434)$. Deste modo, apesar de não ser possível no presente estudo a realização de uma análise de correlação estatística pelo baixo número de estações, o trabalho prévio de Sousa et al. (submetido) para a mesma área de estudo, já indicava correlação entre os parâmetros bióticos (descritores ecológicos) e abióticos (MO lábil e quantidade de COT), corroborando os trabalhos de Schmiedl et al. (1997), De Stigter et al. (1998), Jorissen et al. (1998), Schmiedl et al. (2000); Licari et al. 2003, entre outros, que relacionam a qualidade e quantidade da MO oriunda do fluxo de MO da produtividade primária com a distribuição dos foraminíferos bentônicos em mar profundo.

Segundo Vicente (2012), os altos valores de fluxo e produtividade primária observados no setor norte da Bacia de Campos estaria associado ao sistema de meandros e 
vórtices da Corrente do Brasil, especificamente o vórtice de Vitória, que transportaria nutrientes para o mar profundo a partir do seu movimento em direção offshore, aumentando dessa maneira a produtividade primária, e consequentemente, gerando maior fluxo de carbono orgânico para o fundo oceânico.

A ocorrência das espécies G. minuta e U. peregrina (ALTEBANCH et al. 2003; MARTINS et al. 2006; GARCIA et al. 2013), L. diffugiformis (Kurbejeweit et al. 2000) parece indicar que no talude superior há uma forte corrente de fundo ressuspendendo e redisponibilizando esta $\mathrm{MO}$ em superfície explicando a elevada presença de espécies epifaunais e ou infaunais rasos (31\%) (Tabela 5) e ao elevado valor de densidade (e.g. valor de densidade 1140 ind. $/ 50 \mathrm{~cm}^{3}$ ) na profundidade 0-1 cm (JORISSEN et al. 1995; LINKE e LUTZE 1993). Esta preferência pela profundidade 0-1 cm também pode ser observado pelo baixo valor de $\mathrm{ALD}_{10}$ com $1,7 \mathrm{~cm}$ (Tabela 5) onde os menores valores de $\mathrm{ALD}_{10}$ indicam um microhábitat menos profundo do sedimento.

Para compreender a preferência ecológica das espécies pelos microhábitats, foram comparados os microhábitats das espécies mais abundantes do presente estudo com os microhábitats da literatura (ANEXO C). Deste modo, os dados de microhábitat do presente estudo mostram que entre as dez espécies mais abundantes da estação I06, quatro espécies não são coerentes com a classificação da literatura. Por exemplo, as espécies $L$. diffugiformis, $P$. insularis e $P$. nasuta apresentaram um microhábitat mais profundo quando comparados com o da literatura, e o inverso ocorreu para G. minuta, apresentando um microhábitat aparentemente mais raso do que a literatura indicando que as espécies podem alterar o microhábitat em função de sua preferência ecológica para ambientes mais favoráveis onde há menor competição por nutrientes.

A elevada porcentagem de microhábitat epifaunal e ou infaunal raso, assim como o baixo valor de $\mathrm{ALD}_{10}$ e a camada anóxica profunda de $13 \mathrm{~cm}$ observada na estação I06 do talude superior corrobora com as descrições sugeridas pelo modelo TROX. No entanto, a constatação de elevados valores de densidade (1140 ind./50 $\mathrm{cm}^{3}$ profundidade $0-1 \mathrm{~cm}$ ), coloca-nos algumas dúvidas sobre a aplicação desse modelo na avaliação de condições tróficas da área de estudo.

\subsection{Talude Médio}


Trabalhos como Alve e Bernhard (1995); Jorissen et al. (1998); De Stigter et al. (1998); Bernhard e Sen Gupta, (1999); De Rijk et al. (2000); Schmiedl et al. (2000); Kitazato et al. (2000); Morigi et al. (2001); Fontanier et al. (2002, 2003, 2005, 2008); Eberwein e Mackensen (2006); Koho et al. (2007); Jorissen et al. (2007) têm mostrado que diminuição nos valores da densidade de foraminíferos bentônicos vivos ocorre com o aumento da profundidade da coluna d'água, em resposta a diminuição nos valores na quantidade e qualidade de MO no sedimento. No presente estudo, este mesmo padrão também foi verificado para a distribuição vertical, onde ocorre diminuição no valor da densidade dos foraminíferos bentônicos vivos da estação I06 (1140 ind./50 $\mathrm{cm}^{3}$ profundidade $0-1 \mathrm{~cm}$ ) mais rasa $(417 \mathrm{~m})$ para a estação I08 (353 ind./50cc profundidade $1-2 \mathrm{~cm})$, mais profunda $(993 \mathrm{~m})$.

Segundo Morigi (2009), a diversidade é controlada pela estabilidade do ambiente. Em ambientes como plataforma e talude superior onde há flutuações no fluxo de matéria orgânica ou na disponibilidade do oxigênio, predominam espécies oportunistas, que habitam os primeiros centímetros do sedimento (SCHMIEDL et al. 2000), resultando deste modo, em menores valores de diversidade. Por outro lado, em ambiente estável, a diversidade da fauna tende a ser elevada.

Schmiedl et al. (1997) avaliaram a diversidade dos foraminíferos bentônicos na margem Sudoeste Africana, e observaram valores relativamente menores (2,09) em áreas com maior produtividade como na plataforma e talude superior $(400 \mathrm{~m})$, e valores maiores de diversidade $(3,82)$, em áreas oligotróficas situadas entre 2000 e 3000m de profundidade. No presente estudo, padrão semelhante foi encontrado, onde se constatou aumento nos valores de diversidade do talude superior para o talude médio.

Em relação ao perfil de distribuição vertical da densidade dos foraminíferos bentônicos na estação I08, o maior valor de densidade (353 ind. $150 \mathrm{~cm}^{3}$ ) é observado em subsuperfície (1-2 cm), apresentando diminuição progressiva com o aumento da profundidade no sedimento desta estação (Tabela 7 e Figura 10). O padrão do perfil da distribuição vertical da estação I08 é semelhante ao perfil tipo B identificado por Jorissen (1999), onde os maiores valores já não estão mais na primeira profundidade e sim em subsuperfície (Figura 14) (JORISSEN, 1999). 

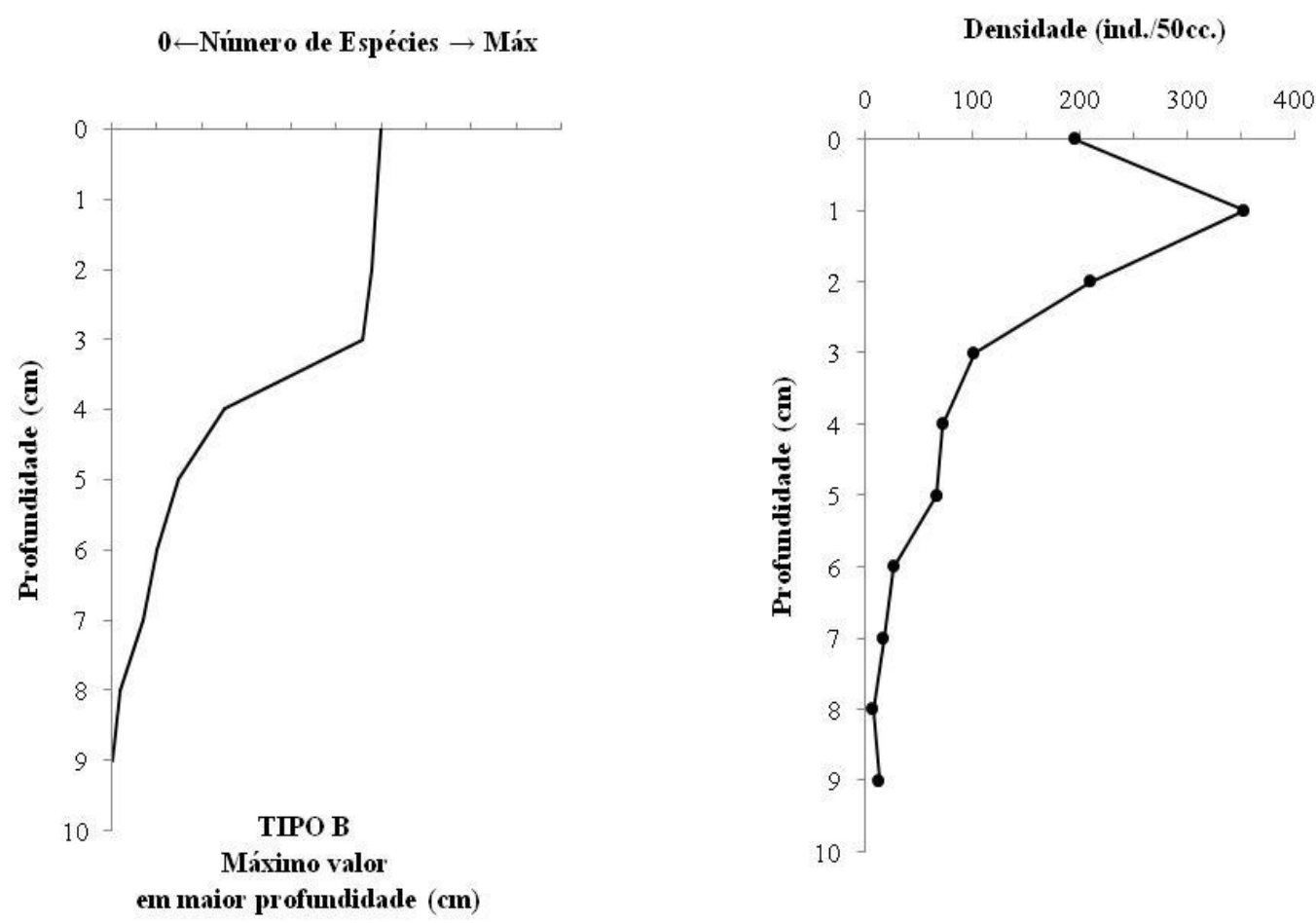

Figura 14: À esquerda, perfil de distribuição vertical tipo B identificada por Jorissen (1999), e a direita, perfil de distribuição vertical da densidade dos foraminíferos bentônicos vivos da estação I08.

Segundo Jorissen et al. (1995), o perfil de distribuição vertical tipo B não é característico de áreas oligotróficas. De acordo com Jorissen et al. (1995), Jorissen (1999), Fontanier et al. (2003), o aumento dos valores de densidade de foraminíferos bentônicos em subsuperfície (e.g. 1-2cm) do sedimento é atribuído a espécies facultativas anaeróbicas que se alimentam de específica fonte de MO perto da zona redox (e.g. bactérias ou dos produtos gerados por ela.).

Todavia, valor obtido de C/S $(9,07)$ reflete alta disponibilidade de oxigênio no ambiente e associado à constatação da camada anóxica situada a $7 \mathrm{~cm}$ de profundidade (Tabela 6), que mesmo se tratando de um dado qualitativo, confirma a não restrição de oxigênio a profundidades superiores a $7 \mathrm{~cm}$ no sedimento. Além disso, dados obtidos sobre a MO no talude médio demonstram menor quantidade de MO no sedimento, representada pelos valores de porcentagem de COT $(1,36 \%)$. Por sua vez, valores relativamente menores de lipídeos autóctones $(442,1 \mathrm{ng} / \mathrm{mg})$ são indicativos da diminuição do aporte de MO lábil, proveniente de produção primária. Valores relativamente menores de fluxo de carbono orgânico $\left(63,6 \mathrm{mgCm}^{-2} \cdot\right.$ dia $\left.^{-1}\right)$ na estação I08, obtidos por Vicente (2012) confirmam para o 
talude médio a condição de um ambiente com menor disponibilidade de nutrientes que o talude superior.

Essa diminuição no aporte de MO lábil é acompanhada de valores relativamente menores de $\mathrm{CaCO}_{3}$ (36,55\%), observados no talude médio. Essa diminuição no conteúdo de $\mathrm{CaCO}_{3}$ poderia indicar dissolução do carbonato pela proximidade da lisoclina que poderia promover a corrosão do carbonato. Todavia, essa situação não é observada nessa região do talude. Por outro lado, não se deve descartar a possibilidade da diminuição nos valores de $\mathrm{CaCO}_{3}$ ser decorrente de diluição por aporte de terrígenos.

No perfil vertical da estação I08, constata-se a ocorrência, de espécies tolerantes a uma MO de menor qualidade (JORISSEN, 1999), tais como, R. spiculotestus (GOODAY, 1996) e A. planorbis (SZAREC et al. 2007). Além disso, a presença das espécies H. elegans (FARIDUDDIN e LOUBERE, 1997; SCHMIEDL et al. 1997; FONTANIER et al. 2002; MORIGI et al. 2001; EBERWEIN e MACKENSEN, 2006; KOHO et al. 2008; MOJTAHID et al. 2010; GARCIA et al. 2013), $K$. conversa (KAMINSKY e GRADSTEIN, 2005), $R$. scorpiurus (HARLOFF e MACKENSEN, 1997; SCHMIEDL et al. 1997; KURBJEWEIT et al. 2000; HEINZ e HEMLEBEN, 2003; LICARI e MACKENSEN, 2005; DUROS et al. 2011) ), R. charoides (DE RIJIK et al. 2000; SCHMIEDL et al. 2000) corrobora condições relativamente mais oligotróficas no talude médio da bacia.

O perfil tipo B pode também ser observado em ambiente raso com bioturbação (JORISSEN, 1999). Neste perfil segundo Jorissen (1999), predominam espécies infaunais rasas, ocorrendo os máximos valores de densidade nos dois primeiros centímetros de profundidade. Ao contrário do tipo A, as espécies encontradas no perfil vertical tipo B não apresentam preferência pelo topo do sedimento (ou possivelmente não conseguem competir com outras espécies) e são tolerantes as condições estressantes (e.g. diminuição de quantidade e qualidade de MO e/ou concentração de oxigênio) (JORISSEN et al. 1998; JORISSEN, 1999).

Deve-se também considerar que estruturas figurativas de bioturbação observadas na coluna de sedimento da estação I08 poderiam ter facilitado a entrada de MO e oxigênio bem como o transporte de espécies para maiores profundidades no sedimento, e de acordo com Jorissen (1999), permitindo a sobrevivência das espécies infaunais (valores de porcentagem de microhábitat infaunal raso e/ ou intermediário e intermediário de respectivamente $27 \%$ e $20 \%$, promovendo assim aumento nos valores de $\operatorname{ALD}_{10}(2,5 \mathrm{~cm})$ (Tabela 8 e Figura 12), e 
consequentemente aumento nos valores de diversidade e riqueza, como também constatado por Jorissen et al. 1995, Fontanier et al. 2002, 2008.

À semelhança do que foi feito para a estação I06, dados de microhábitats observados para a estação I08 foram comparados com dados de literatura, com o intuito de melhor compreender a preferência ecológica das espécies na região, principalmente considerando o aumento da porcentagem de espécies infaunais na estação I08. Nesta estação, nota-se que entre as dez espécies mais abundantes, quatro espécies (A. planorbis, D. compressa, $H$. elegans, e $R$. charoides) apresentaram microhábitat mais profundo (ANEXO D). Essas diferenças podem ser explicadas em razão da classificação dos microhábitats a partir do gênero ou morfotipo da espécie, ou mesmo pela aplicação diferenciada do ALDx, calculado em alguns casos até profundidades inferiores a $10 \mathrm{~cm}$ (e.g. Szarec et al. 2007 utilizaram valores de $\mathrm{ALD}_{5}$ para classificar os microhábitats, e em seu trabalho valor de $\mathrm{ALD}_{5}>2.5 \mathrm{~cm}$ foi considerado como infauna profunda). Não se deve, todavia, descartar a possibilidade do aumento da profundidade do microhábitat das espécies na estação I08 ser decorrente de bioturbação, que promoveria o transporte das espécies e alimento rumo a maiores profundidades no sedimento, criando condições favoráveis de sobrevivência e resultando assim na alteração do microhábitat da espécie.

Apesar da falta de controle no comportamento das espécies infaunais na estação I08 em função da bioturbação, dados como baixo valor de densidade de indivíduos e a maior porcentagem de espécies aglutinantes (85\% Tabela 8) indicam que no talude médio as espécies são menos dependentes da MO oriunda de produtividade primária (FONTANIER et al. 2003, 2005). A menor contribuição de matéria orgânica lábil no talude médio da bacia deve ser provavelmente resultado do maior tempo de degradação da MO ao longo da coluna d' água.

Estes menores valores de densidade na estação I08 estão coerentes com as condições oligotróficas sugeridas pelo modelo TROX. Porém outros dados previstos deste modelo como: profundidade da camada anóxica profunda, baixa diversidade, e maiores porcentagens de espécies epifaunais ou infaunais rasos (JORISSEN et al. 1995), não foram observados para a estação I08 do talude médio, o que dificulta a aplicação do modelo TROX na avaliação das condições tróficas do talude médio. 


\section{Conclusões}

Os dados obtidos de distribuição vertical dos foraminíferos bentônicos vivos no sedimento e descritores ecológicos permitiram identificar condições diferenciadas no talude superior e médio do setor norte da Bacia de Campos, no que se refere à quantidade e qualidade da MO.

A elevada densidade de indivíduos, composição de espécies (e.g. L. diffugiformis, G. minuta, e $P$. bulloides), baixa diversidade, perfil de distribuição vertical dos foraminíferos bentônicos tipo A, predomínio de espécies epifaunais/infaunais rasos, revelado por valores menores de $\mathrm{ALD}_{10}$ juntamente com os valores relativamente maiores de conteúdos de COT e lipídeos autóctones, indicam que a estação I06 é um ambiente com maior disponibilidade de nutrientes de alta labilidade. A presença de espécies oportunistas associada à ocorrência de espécies calcárias revela para o talude superior do setor norte da Bacia de Campos ambiente de pulsos de fitodetritos, provenientes do incremento da produtividade primária nessa região. Esse cenário é corroborado por valores relativamente maiores de fluxo de carbono constatados para essa porção do talude da bacia.

Por sua vez, o menor valor de densidade de indivíduos, perfil de distribuição vertical dos foraminíferos bentônicos tipo B, composição de espécies (e.g. R. scorpiurus, K. conversa, e $R$. charoides), aumento nos valores de diversidade, predomínio de espécies infaunais, representados pelo aumento nos valores de $\mathrm{ALD}_{10}$ e os menores valores de conteúdo de COT e lipídeos autóctones, indicam que a estação I08 do talude médio é um ambiente com menor disponibilidade de nutrientes lábeis. A presença de espécies $R$. spiculotestus e A. planorbis associados ao aumento da porcentagem de aglutinantes indicam que o talude médio é um ambiente sob menor influência de pulso de fitodetrito, o que é corroborado pelo menor valor de fluxo de carbono constatado para o talude médio.

Dados como elevada porcentagem de microhábitat epifaunal e ou infaunal raso, baixo valor de $\mathrm{ALD}_{10}$ e a camada anóxica profunda na estação I06 do talude superior e os menores valores de densidade da estação I08 corroboram com as descrições sugeridas pelo modelo TROX, no entanto, outros dados no talude médio como aumento no valor de $\mathrm{ALD}_{10}$, maior porcentagem de espécies infaunais, aumento nos valores de diversidade, profundidade de camada anóxica rasa, e a elevada densidade de indivíduos do talude superior contradizem ao modelo, gerando dúvidas sobre a aplicabilidade na avaliação de condições tróficas da área de estudo. 
Possivelmente a contradição do modelo TROX para a área de estudo deve-se ao fato do modelo desconsiderar fatores importantes como as preferências e tolerâncias de cada espécie pelo microhábitat; a existência de espécies tolerantes a ambientes disóxicos; a influência da qualidade da MO (Fontanier et al. 2002) e a influência da bioturbação (Fontanier et al. 2008, Hess e Jorissen 2009, Duros et al. 2011) sobre a distribuição vertical dos foraminíferos bentônicos vivos do talude superior e médio do setor norte da Bacia de Campos. 


\section{Referências Bibliográficas}

ALMEIDA, A.G.; KOWSMANN, R.O. 2014. Geomorfologia do Talude Continental e do Platô de São Paulo. In: Kowsmann, R.O., editor. Caracterização Ambiental Regional da Bacia de Campos, Atlântico Sudoeste: Geologia e Geomorfologia. Rio de Janeiro: Elsevier, v.1, 33-66 (Série Habitats). In press.

ALTENBACH, A. V.; LUTZE, G.F.; SCHIEBEL, R.; SCHÖNFELD, J. 2003. Impact of interrelated and interdependent ecological controls on benthic foraminifera: an example from the Gulf of Guinea. Palaeogeogr. Palaeocl., 197, p. 213-238.

ALVE, E. 2010. Benthic foraminiferal responses to absence of fresh phytodetritus: A two-year experiment. Mar. Micropaleontol., v. 76, p. 67-75.

ALVE, E.; BERNHARD, J.M. 1995. Vertical migratory response of benthic foraminifera to controlled oxygen concentrations in an experimental mesocosm. Mar. Ecol. Prog. Ser.-, v. 116,p. 137-151.

ARMSTRONG, H.A.; BRASIER, M.D. 2005. Microfossils. 2. ed. Oxford: Blackwell Publishing, 296p.

BARBOSA, V. P. 2002. Sistemática, bioestratigrafia e paleoceanografia de foraminíferos do quaternário do talude continental das bacias de Santos Campos. Tese de pós-graduação em Geologia para obtenção do grau de doutor em Ciências. Universidade Federal do Rio de Janeiro, 247p.

BERNER, R.; RAISWELL, R. 1984. C/S method for distinguishing freshwater from marine sedimentary rocks. Geology, v.12, p. 365-368.

BERNHARD, J.M. 1992. Benthic foraminiferal distribution and biomass related to pore-water oxygen content: Central California continental slope and rise. Deep.-Sea Res., v. 39, p. 585-605.

BERNHARD, J.M. 1989. The distribution of benthic Foraminifera with respect to oxygen concentration and organic carbon levels in shallow-water Antarctic sediments. Liminol. Oceanogr., v. 34, n. 6, p. 1131-1 141.

BERNHARD, J.M.; SEN GUPTA, B.K. 1999. Foraminifera of oxygen-depleted environments. In: SEN GUPTA, B.K. (ed.). Modern Foraminifera. London: Kluwer Academic Publishers. cap.12, p. 201-216. 
BOLTOVSKOY, E.; GUISSANI, G.; WATANABE, S.; WRIGHT, R. 1980. Atlas of benthic shelf foraminifera of the southwest Atlantic. Dr W. Junk by Publishers. The Hague.147p.

BRUMMER, G.J.A.; VAN EIJDEN, A.J.M. 1992. Blue-Ocean Paleoproductivity estimates from pelagic carbonate mass accumulation rates. Mar. Micropaleontol., v.19, p. $99-117$.

BURONE, L.; PIRES-VANIN, A. M. S. 1986. Foraminiferal assemblages in Ubatuba Bay, south-eastern Brazilian coast. Scientia Marina. v. 70, n.2, p. 203-217.

BURONE, L.; SOUSA, S.H.M.; MAHIQUES, M. M.; VALENTE, P.; CIOTTI, A.; YAMASHITA, C. 2010. Benthic foraminiferal distribution on the southeastern Brazilian shelf and upper slope. Mar. Biol. (Berlin), p. 1-21.

BUZAS, M.A.; CULVER, S.J.; JORISSEN, F.J. 1993. A statistical evaluation of the microhabitats of living (stained) infaunal benthic foraminifera. Mar. Micropaleontol., v.20, p. 311-320.

CADDAH, L.F.G.; KOWSMANN, R. O.; VIANA, A. R. 1998. Slope sedimentary facies associated with Pleistocene and Holocene sea-level changes, Campos Basin, southeast Brazilian Margin. Sediment. Geol., v. 115, p.159-174.

CALADO, L. Dinâmica da formação dos meandros e vórtices da Corrente do Brasil ao largo do Sudeste Brasileiro. 2001. f. 112. Dissertação (Mestrado em Oceanografia Física) - Instituto Oceanográfico, Universidade de São Paulo, São Paulo 2001.

CALADO, L. Dinâmica da interação da atividade de meso-escala da Corrente do Brasil com o fenômeno da ressurgência costeira ao largo de Cabo Frio e Cabo de São Tomé, RJ. 2006. f. 184. Tese (Doutorado em Oceanografia Física- Instituto Oceanográfico), Universidade de São Paulo, São Paulo 2006.

CALADO, L.; GANGOPADHYAY, A.; SILVEIRA, I.C.A. 2008. Feature-oriented regional modeling and simulations (FORMS) for the western South Atlantic: Southeastern Brazil region. Ocean. Model. (Oxford), v.25, p.48-64.

CALADO, L.; SILVEIRA, I.C.A.; GANGOPADHYAY, A.; CASTRO, B.M. 2010. Eddy-induced upwelling off Cape São Tomé ( $22^{\circ}$ S, Brazil). Cont. Shelf Res., v.30, n. 10-11, p.1181-1188. 
CAMPOS, E.J.D. 2006. Equatorward translation of the Vitoria Eddy in a numerical simulation. Geophys. Res. Lett., v. 33, L22607, doi: 10.1029/2006GL026997

CAMPOS, E.J.D.; PIOLA, A.R.; MILLER, J.L. 1995. Water mass distribution on the shelf and shelf-break upwelling in the southeast Brazil Bight. 10 $^{\text {th }}$ Symposium on global change studies. p. 446-449.

CAMPOS, E. J. D.; VELHOTE, D.; SILVEIRA, I. C. A. 2000.Shelf break upwelling driven by Brazil Current cyclonic meanders. Geophys. Res. Lett., Washington, D.C., USA, v. 27, n. 6, p. 751-754.

CANUEL, E.A.; MARTENS, C.S. 1993. Seasonal variations in the sources and alteration of organic matter associated with recently-deposited sediments. Org. Geochem., v. 20, n. 5, p. 563-577.

CARREIRA, R. S.; ARAÚJO, M. P.; COSTA, T. L.F.; ANSARI, N. R.; PIRES, L. C.M. 2010. Lipid biomarkers in deep sea sediments from the Campos Basin, SE Brazilian continental margin. Org. Geochem., v. 41, p. 879-884.

CARREIRA, R.S.; WAGENER, A.L.R.; READMAN, J.W.; FILEMAN, T.W.; MACKO, S.A.; VEIGA, I. 2002. Changes in the sedimentary organic carbon pool of a fertilized tropical estuary, Guanabara Bay, Brazil: an elemental, isotopic and molecular marker approach. Mar. Chem., v. 79, p. 207-227.

CIOTTI, A.M.; KAMPEL, M. 2001 Concurrent observations of ocean color and sea surface temperature between Cabo Frio e Cabo São Tomé. Anais X SBSR, p.785-791.

CORLISS, B.H. 1991. Morphology and microhabitat preferences of benthic foraminifera from the northwest Atlantic Ocean. Mar. Micropaleontol., v.17, p.195236.

CORLISS, B. H., CHEN, C.1988. Morphotype patterns of Norwegian Sea deep-sea benthic foraminifera and ecological implications. Geology, v.16, p. 716-719.

CORRÊA, I.C.S.; TOLDO JR., E.E.; TOLEDO, F.A.L. 2009. Seafloor geological impacts associated with drilling disturbance. Deep.-Sea Res. II, v. 56, p. 4-11.

DE RIJK, S.; JORISSEN, F.J.; ROHLING, E.J.; TROELSTRA, S.R. 2000. Organic flux control on bathymetric zonation of Mediterranean benthic foraminifera. Mar. Micropaleontol., v.40, p.151-166. 
DE STIGTER, H. C.; JORISSEN, F. J.; VAN DER ZWAAN, G. J. 1998. Bathymetric Distribution and Microhabitat Partitioning of Live (Rose Bengal Stained) Benthic Foraminifera Along a Shelf to Bathyal Transect in the Southern Adriatic Sea. J. Foramin. Res., v. 28, no. 1, p. 40-65.

DITTERT, N.; BAUMANN,K.H.; BICKERT, T.; HENRICH, R.; HUBER, R.; KINKEL, H.; MEGGERS, H. 1999. Carbonate Dissolution in the Deep-Sea: Methods, Quantification and Paleoceanographic Application. In: FISCHER, G.; WEFER, G. (ed.). Use of Proxies in Paleoceanography: Examples from the South Atlantic. Berlin, Springer, 255-284.

DUROS, P.; FONTANIER C.; METZGER, E.; PUSCEDDU, A.; CESBRON, F.; DE STIGTER, H.C.; BIANCHELLI S.; DANOVARO, R.; JORISSEN, F.J. 2011. Live (stained) benthic foraminifera in the Whittard Canyon, Celtic margin (NE Atlantic). Deep.-Sea Res. I, v.58, p.128-146.

DUURSMA, E. K.; DAWSON, R. 1981. Marine organic chemistry. Elsevier Oceanogr. Ser. No. 31. Elsevier Sci. Publ. Co., Amsterdam, Oxford, and New York. $521 \mathrm{p}$.

EBERWEIN, A.; MACKENSEN, A. 2006. Regional primary productivity differences off Morocco (NW-Africa) recorded by modern benthic foraminifera and their stable carbon isotopic composition. Deep.-Sea Res. I, v. 53, p.1379-1405.

EMERSON, S.R.; HEDGES J.I. 2008. Chemical Oceanography and the Marine Carbon Cycle. Cambridge University Press, Cambridge U.K. p.453.

FARIDUDDIN, M.; LOUBERE, P. 1997.The surface ocean productivity response of deep water benthic foraminifera in the Atlantic Ocean. Mar. Micropaleontol., v.32, p.289-310.

FIGUEIREDO JR., A.G.; MADUREIRA, L. S. P. 2004. Topografia, composição, refletividade do substrato marinho e identificação de províncias sedimentares na região Sudeste-Sul do Brasil. São Paulo, Instituto Oceanográfico, USP. Série Documentos Revizee - Score Sul. p.46-55.

FIGUEIREDO JR., A.G.; PACHECO, C.E.P.; VASCONCELOS, S.C. 2010. Geomorfologia da plataforma continental da Bacia de Campos. XIII ABEQUA Congress - The South American Quaternary: Challenges and Perspectives. 
FOLONI-NETO, H. As massas de água na Bacia de Campos, RJ. 2010. 119f. Dissertação (Mestrado em Oceanografia Física) - Instituto Oceanográfico, Universidade de São Paulo, São Paulo, 2010.

FONTANIER, C.; JORISSEN, F.J.; CHAILLOU, G.; ANSCHUTZ, P.; GRÉMARE, A.; GRIVEAUD, C. 2005. Live foraminiferal faunas from a $2800 \mathrm{~m}$ deep lower canyon station from the Bay of Biscay: Faunal response to focusing of refractory organic matter. Deep.-Sea Res. I, v. 52, p. 1189-1227.

FONTANIER, C.; JORISSEN, F.J.; CHAILlOU, G.; DAVID, C.; ANSCHUTZ, P.; LAFON, V. 2003. Seasonal and interannual variability of benthic foraminiferal faunas at $550 \mathrm{~m}$ depth in the Bay of Biscay. Deep.-Sea Res. I, v. 50 p.457-494.

FONTANIER, C.; JORISSEN, F.J.; LANSARD, B.; MOURET, A.; BUSCAIL, R.; SCHMIDT, S.; KERHERVE, P.; BURON, F.; ZARAGOSI, S.; HUNAULT, G.; ERNOULT, E.; ARTERO, C.; ANSCHUTZ, P.; RABOUILLE, C. 2008.Live foraminifera from the open slope between Grand Rhône and Petit Rhône Canyons (Gulf of Lions, NW Mediterranean). Deep.-Sea Res. I, v.55, p.1532-1553.

FONTANIER, C.; JORISSEN, F.J.; LICARI, L.; ALEXANDRE, A.; ANSCHUTZ, P.; CARBONEL, P. 2002. Live benthic foraminiferal faunas from the Bay of Biscay: faunal density, composition, and microhabitats. Deep.-Sea Res., v.49, p.751-785.

GAETA, S. A.; BRANDINI, F.P. Produção Primária do Fitoplâncton entre o Cabo de São Tomé (RJ) e o Chuí (RS). In: Rossi-Wongtschowski. C.L.D.B. e Madureira, L.S.P. (Org.), 2006, O ambiente da Plataforma Continental e do Talude na região sudeste sul do Brasil- São Paulo: Editora da Universidade de São Paulo. 2006, p. 219-264.

GAETA, S. A.; LORENZZETTI, J. A.; MIRANDA, L. B.; RIBEIRO, S. M. S.; POMPEU, M.; ARAUJO, C. 1999. The Vitória eddy and its relation to the phytoplankton biomass and primary productivity during the austral fall of 19951. Arch. Fishery Mar. Res., Alemanha, v. 47, n. 2/3, p. 253-270.

GARCÍA, B.M.; PASCUAL, A.; LÁZARO, J.R.; BODEGO, A. 2013. Recent benthic foraminifers of the Basque continental shelf (Bay of Biscay, northern Spain): Oceanographic implications. Cont. Shelf Res., v. 66, p. 105-122.

GOODAY, A. J. 1988. A response by benthic foraminifera to the deposition of phytodetritus in the deep sea. Nature, v.332, p. 70-73. 
GOODAY, A.J. 1996. Epifaunal and shallow infaunal foraminiferal communities at three abyssal NE Atlantic sites subject to differing phytodetritus input regimes. Deep.Sea Res. I, v. 43, no 9, p.1395-1421.

GOODAY, A.J.; LEVIN, L.A.; DA SILVA, A. A.; BETT, B.J.; COWIE, G.L.; DISSARD, D.; GAGE, J.D., HUGHES, D.J.; JEFFREYS, R.; LAMONT, P.A.; LARKIN, K.E.; MURTY, S.J.; SCHUMACHER, S.; WHITCRAFT, C.; WOULDS, C. 2009. Faunal responses to oxygen gradients on the Pakistan margin: A comparison of foraminifera, macrofauna and megafauna. Deep.-Sea Res. II, v. 56, p. 488-502.

GOODAY, A.J.; RATHNURN, A.E. 1999. Temporal variability in living deep-sea benthic foraminifera: a review. Earth-Sci. Rev., v. 46, p. 187-212.

GRÉMARE, A.; MEDERNACH, L.; DEBOVÉE, F.; AMOUROUX, J. M.; CHARLES, F.; DINET, A.; VÉTION, G.; ALBERT, P.; COLOMINES, J. C. 2003. Relationship between sedimentary organic matter and benthic fauna within the Gulf of Lion: synthesis on the identification of new biochemical descriptors of sedimentary organic nutritional value. Oceanol. Acta, v. 26, p. 391-406.

GUPTA, K.A. 2010. Deep-sea faunal provinces and their inferred environments in the Indian Ocean based on distribution of recent benthic foraminifera. Palaeogeogr. Palaeocl., v. 291, p.429-442.

HARLOFF, J.; MACKENSEN, A. 1997. Recent benthic foraminiferal associations and ecology of the Scotia Sea and Argentine Basin. Mar. Micropaleontol., v. 31, p. 1-29.

HEINZ, P.; HEMLEBEN, C.H. 2003.Regional and seasonal variations of recent benthic deep-sea foraminifera in the Arabian Sea. Deep.-Sea Res. I, v. 50, p.435-447.

HEINZ, P.; HEMLEBEN, C. 2006. Foraminiferal response to the Northeast Monsoon in the western and southern Arabian Sea. Mar. Micropaleontol., v. 58, p.103-113.

HESS, S., JORISSEN, F.J., 2009. Distribution patterns of living benthic foraminifera from Cap Breton canyon, Bay of Biscay: faunal response to sediment instability. DeepSea Res. I, v. 56, p. 1555-1578.

JONES, R.W. 1994. The Challenger Foraminifera. Oxford science publications. The nature history museum, $150 \mathrm{p}$. 
JORISSEN, F.J. 1999. Benthic foraminiferal microhabitats below the sediment waterinterface. In: SEN GUPTA, B.K. (ed.). Modern Foraminifera. London: Lower Academic Publishers, cap.10, 161-179.

JORISSEN, F.J.; BARMAWIDJAJA, D.M.; PUSKARIC, S.; VAN DER ZWAAN, G.J. 1992. Vertical distribution of benthic foraminifera in the northern Adriatic Sea: The relation with the organic flux. Mar. Micropaleontol., v. 19, p.131-146.

JORISSEN, F. J.; DE STIGTER, H. C.; WIDMARK, J. G. V. 1995. A conceptual model explaining benthic foraminiferal microhabitats. Mar. Micropaleontol., v.26, p.315.

JORISSEN, F. J.; FONTANIER, C.; THOMAS, E. 2007 Paleoceanographical proxies based on deep-sea benthic foraminiferal assemblage characteristics. In: Proxies in Late Cenozoic Paleoceanography (Pt. 2): Biological tracers and biomarkers, (ed.) C. HillaireMarcel e A. de Vernal, Elsevier, p. 263-313.

JORISSEN， F.J.; WITTLING， I.; PEYPOUQUET， J.P.; RABOUILLE， C.; RELEXANS, J.C. 1998. Live benthic foraminiferal faunas off Cape Blanc, NW-Africa: community structure and microhabitats. Deep.-Sea Res. I, v.45, p.2157-2188.

KAMINSKI, M.A., BOERSMA, A., TYSZKA, J., HOLBOURN, A.E.L. 1995. Response of deep water agglutinated foraminifera to dysoxic conditions in the California Borderland basins. In: Kaminski, M.A., Geroch, S. and Gasinski, M.A. (Eds.), Proceedings of the Fourth International Workshop on Agglutinated Foraminifera. Grzybowski Foundation Special Publication 3, p.131-140.

KAMINSKI, M.A.; GRADSTEIN, F.M. 2005. Atlas of Paleogene Cosmopolitan deepwater Agglutinated Foraminifera. Grzybownski Foundation Special Publication. $\mathrm{n}^{\circ} 10 ., 547 \mathrm{p}$.

KAMPEL, M. Estimativa da produção primária e biomassa fitoplanctônica através de sensoriamento remoto da cor do oceano e dados in situ. 2003. 311f. Tese (Doutorado em Ciências Área de Oceanografia Biológica) - Instituto Oceanográfico, Universidade de São Paulo, São Paulo, 2003.

KITAZATO, H.; SHIRAYAMA, Y.; NAKATSUKA, T.; FUJIWARA, S.; SHIMANAGA, M.; KATO, Y.; OKADA, Y.; KANDA, J.; YAMAOKA, A.; MASUZAWA, T.; SUZUKI, K. 2000. Seasonal phytodetritus deposition and responses of bathyal benthic foraminiferal populations in Sagami Bay, Japan: preliminary results from “Project Sagami 1996-1999”. Mar. Micropaleontol., v.40, p. 135-149. 
KOHO, K.A.; GARCÍA, R.; DE STIGTER, H.C.; EPPING, E.; KONING, E.; KOUWENHOVEN, T.J.; VAN DER ZWAAN, G.J. 2008. Sedimentary labile organic carbon and pore water redox control on species. Prog. Oceanogr. , v. 79, p. 55-82.

KOHO, K.A.; KOUWENHOVEN, T.J.; DE STIGTER, H.C.; VAN DER ZWAAN, G.J. 2007. Benthic foraminifera in the Nazaré Canyon, Portuguese continental margin: Sedimentary environments and disturbance. Mar. Micropaleontol., v.66, p. 27 - 51.

KUHNT, W. 1992. Abyssal recolonization by benthic foraminifera after the Cenomanian/Turonian boundary anoxic event in the North Atlantic. Mar. Micropaleontol., v.19, p. 257-274.

KUHNT, W.; HESS, S.; JIAN, Z. 1999. Quantitative composition of benthic foraminiferal assemblages as a proxy indicator for organic carbon flux rates in the South China Sea. Mar. Geol., v. 156, p. 123-157.

KURBJEWEIT, F.; SCHMIEDL， G.; SCHIEBEL,R.; HEMLEBEN， C.; PFANNKUCHE,O.; WALLMANN,K.; SCHÄFER, P. 2000. Distribution, biomass and diversity of benthic foraminifera in relation to sediment geochemistry in the Arabian Sea. Deep.-Sea Res. II, v. 47, p. 2913-2955

LIBES, S., M. 1992. An Introduction to Marine Biogeochemistry. Wiley \& Sons, New. York. 733p.

LICARI, L.; MACKENSEN, A. 2005. Benthic foraminifera off West Africa (18N to 328S): Do live assemblages from the topmost sediment reliably record environmental variability?. Mar. Micropaleontol., v.55, p. 205-233.

LICARI, L. N., SCHUMACHER S., WENZHOFER, F., ZABEL, M., MACKENSEN, A. 2003. COMMUNITIES AND MICROHABITATS OF LIVING BENTHIC FORAMINIFERA FROM THE TROPICAL EAST ATLANTIC: IMPACT OF DIFFERENT PRODUCTIVITY REGIMES. J. Foramin. Res., v. 33, nº 1, p. 10-31.

LINKE, P.; LUTZE, G.F. 1993. Microhabitat preferences of benthic foraminifera a static concept or a dynamic adaptation to optimize food acquisition?. Mar. Micropaleontol., v. 20, p. 215-234.

LOEBLICH, A.R.; TAPPAN, H. 1988. Foraminiferal genera and their classification

- PLATES. Van Nostrand Reinhold, New York. v. 2, p. 970. 
LOUBERE, P. 1996. The surface ocean productivity and bottom water oxygen deep water benthic foraminiferal assemblages. Mar. Micropaleontol., v. 28, p. 247-261.

LOUBERE, P.; FARIDUDDIN, M. 1999. Benthic Foraminifera and the flux of organic carbon to the seabed. In: SEN GUPTA, B.K. (ed.). Modern Foraminifera. London: Kluwer Academic Publishers. cap.11, p.181-199.

LUTZ, M.J.; CALDEIRA, K.; DUNBAR, R.B.; BEHREFEND, M.J. 2007. Seasonal rhythms of net primary production and particulate organic carbon flux to depth describe the efficiency of biological pump in the global ocean. J. Geophys. Res., 112, C10011.

MACHADO, L. C. R.; KOWSMANN, R. O.; DE ALMEIDA JR., W.; MURAKAMI, C. Y.; SCHREINER, S.; MILLER, D. J.; ORLANDO, P.; PIAUILINO, V. 2004. Geometria da porção proximal do sistema deposicional turbidítico moderno Formação Carapebus, Bacia de Campos; modelo para heterogeneidades de reservatório. B. Geoci. PETROBRAS. Rio de Janeiro, v. 12, n. 2, p. 287-315.

MACKENSEN, A.; FIITTERER, D.K.; GROBE, H.; SCHMIEDL, G. 1993. Benthic foraminiferal assemblages from the eastern South Atlantic Polar Front region between $35^{\circ}$ and $57^{\circ} \mathrm{S}$ : Distribution, ecology and fossilization potential. Mar. Micropaleontol., v. 22 , p. 33-69.

MACKENSEN, A.; SCHMIEDL, G.; HARLOFF J.; GIESE, M. 1995. Deep-sea foraminifera in the South Atlantic Ocean: ecology and assemblage generation. Micropaleontology, v. 41, p. 342-358.

MAGURRAN, A.E. 2004. Measuring Biological Diversity, Blackwell Publishing, Oxford. $256 \mathrm{p}$.

MAHIQUES, M. M.; SILVEIRA, I.C.A.; SOUSA, S. H. M.; RODRIGUES, M. 2002. Post-LGM sedimentation on the outer shelf upper slope of the northernmost part of the São Paulo Bight, southeastern Brazil. Mar. Geol., v.181, p. 387-400.

MARTINS, V.; JOUANNEAU, J.M.; WEBER, O.; ROCHA, F. 2006. Tracing the late Holocene evolution of the NW Iberian upwelling system. Mar. Micropaleontol., v. 59, p. $35-55$.

MCGILLICUDDY Jr., D.J.; ANDERSON, L. A.; BATES, N. R.; BIBBY, T.; BUESSELER, K.O.; CARLSON, C.A.; DAVIS, C.S.; EWART, C.; FALKOWSKI, P.G.; GOLDTHWAIT, S.A.; HANSELL, D.A.; JENKINS, W.J.; JOHNSON, R.; KOSNYREV,V.K.; LEDWELL, J.R.; LI, Q.P.; SIEGEL, D.A.; STEINBERG, D.K. 
2007. Eddy/Wind Interactions Stimulate Extraordinary Mid-Ocean Plankton Blooms. Science, v. 316, p. 1021-1026.

MOJTAHID, M.; JORISSEN, F.; LANSARD, B.; FONTANIER, C.; BOMBLED, B.; RABOUILLE, C. 2009. Spatial distribution of live benthic foraminifera in the Rhône prodelta: Faunal response to a continental-marine organic matter gradient. Mar. Micropaleontol., v. 70, p.177-200.

MOJTAHID, M.; GRIVEAUD, C.; FONTANIER, C.; ANSCHUTZ, P.; JORISSEN, F.J. 2010. Live benthic foraminiferal faunas along a bathymetrical transect (140-4800m) in the Bay of Biscay (NE Atlantic). Rev. Micropaleontol., v.53, p. 39-162.

MORIGI, C. 2009. Benthic environmental changes in the Eastern Mediterranean Sea during sapropel S5 deposition. Palaeogeogr. Palaeocl., v. 273 p. 258-271.

MORIGI, C.; JORISSEN, F. J.; GERVAIS, A.; GUICHARD, S.; BORSETTI, A. M. 2001. BENTHIC FORAMINIFERAL FAUNAS IN SURFACE SEDIMENTS OFF NW AFRICA: RELATIONSHIP WITH ORGANIC FLUX TO THE OCEAN FLOOR. J. Foramin. Res., v. 31, nº . 4, p. 350-368.

MÜLLER, T.J.; IKEDA, Y.; ZANGENBERG, N.; NONATO, L.V. 1998. Direct measurements of western boundary currents off Brazil between $20^{\circ} \mathrm{S}$ and $28^{\circ} \mathrm{S}$. J. Geophys. Res. , v. 103, n.C3, p. 5429-5437.

MURRAY, J.W. 1991. Ecology and palaeoecology of benthic Foraminifera. New York: Longman Scientific and Technical, 402p.

MURRAY, J.W. 2001. The niche of benthic foraminifera, critical thresholds and proxies. Mar. Micropaleontol., v. 41, p.1-7.

OLIVEIRA, D.R.P.; CORDEIRO, L.G.M.S.; CARREIRA, R.S. 2013. Characterization of organic matter in cross-margin sediment transects of an upwelling region in the Campos Basin (SW Atlantic, Brazil) using lipid biomarkers. Biogeochemistry, v.112, p. 311-327.

PALÓCZY, A.; SILVEIRA, I.C.A.; CASTRO, B.M.; CALADO, L. 2013. Coastal upwelling off Cape São Tomé $\left(22^{\circ} \mathrm{S}\right.$, Brazil): The supporting role of deep ocean processes. Cont. Shelf Res., http://dx.doi.org/10.1016/j.csr.2013.09.005. 
PEJRUP, M. 1988. The triangular diagram used for classification of estuarine sediments: a new approach. In: Boer, P.L.; van Gelder, A. e Nio, S.D. (Ed). Tideinfluenced Sedimentary Environments and Facies. D. Reidel, Dordrecht., p.289-300.

PETERSON, R.G.; STRAMMA, L. 1991. Upper-level circulation in the South Atlantic Ocean. Prog. Oceanog., v. 26, p. 1-73.

PUSCEDDU, A.; BIANCHELLI, S.; CANALS, M.; SANCHEZ-VIDAL,A.; DE MADRON, X. D.; HEUSSNER, S.; LYKOUSIS,V.; DE STIGTER, H.; TRINCARDI, F.; DANOVARO, R. 2010. Organic Matter in sediments of canyons and open slopes of the Portuguese, Catalan, Southern Adriatic and Cretan Sea margins. Deep.-Sea Res. I, v.57, p. 441-457.

PUSCEDDU, A.; DELL'ANNO, A.; FABIANO, M.; DANOVARO, R. 2009. Quantity and bioavailability of sediment organic matter as signatures of benthic trophic status. Mar. Ecol. Prog. Ser., v. 375, p. 41-52.

RANGEL, H.D.; MARTINS, F.A.L.; ESTEVES, F.R.; FEIJÓ, F.J. 1994. BACIA DE CAMPOS. B. Geoci. PETROBRAS, Rio de Janeiro, v. 8, n.1, p. 203-217.

RATHBURN, A. E.; CORLISS, B. H.; TAPPA, K. D.; LOHMANN, K. C. 1996. Comparisons of the ecology and stable isotopic compositions of living (stained) benthic foraminifera from the Sulu and South China Seas. Deep.-Sea Res. I, v. 43, $\mathrm{n}^{\circ} .10$, p. 1617-1646.

READMAN, J.W., MANTOURA, R.F.C., LLEWELLYN, C.A., PRESTON, M.R.,REEVES, A.D., 1986. The use of pollutant and biogenic markers as source discriminants of organic inputs to estuarine sediments. International Journal of Environmental Analytical Chemistry, v. 27, p.29 - 54.

REOLID, M.; TOVAR, F.J.R.; NAGY, J. 2012. Ecological replacement of Valanginian agglutinated foraminifera during a maximum flooding event in the Boreal realm (Spitsbergen). Cretaceous Res., v. 33, p. 196-204.

RODRIGUES, R.R.; LORENZZETTI, J.A. 2001. A numerical study of the effects of bottom topography and coastline geometry on the Southeast Brazilian coastal upwelling. Cont. Shelf Res., v. 21, 371-394.

SCHMID, C.; SCHÄFER, H.; PODESTÁ, G.; ZENK, W. 1995. The Vitória Eddy and Its Relation to the Brazil Current. J. Phys. Oceanogr., v. 25, p. 2532-2546. 
SCHMIEDL, G.; DE BOVÉE, F.; BUSCAIL, R.; CHARRIÈRE, B.; HEMLEBEN, C.; MEDERNACH L.; PICON, P. 2000. Trophic control of benthic foraminiferal abundance and microhabitat in the bathyal Gulf of Lions, western Mediterranean Sea. Mar. Micropaleontol., v. 40, p.167-188.

SCHMIEDL, G.; MACKENSEN, A.; MIILLER, P.J. 1997. Recent benthic foraminifera from the eastern South Atlantic Ocean: Dependence on food supply and water masses. Mar. Micropaleontol., v. 32, p. 239-287.

SEN GUPTA, B.K. 1999. Modern Foraminifera. London: Kluwer Academic Publishers, 388p.

SETOYAMA, E.; RADMACHER, W.; KAMINSKI, M.A.; TYSZKA, J. 2013. Foraminiferal and palynological biostratigraphy and biofacies from a Santonian e Campanian submarine fan system in the Vøring Basin (offshore Norway). Mar. Petrol. Geol., v. 43, p. 396-408.

SIEGEL, D.A.; COURT, D.B.; MENZIES, D.W.; PETERSON, P.; MARITORENA, S.; NELSON, N.B. 2008. Satellite and in situ observations of the bio-optical signatures of two mesoscale eddies in the Sargasso Sea. Deep.-Sea Res. II, v. 55, p. 1218-1230.

SILVEIRA, I. C. A.; SCHMIDT, A. C. K.; CAMPOS, E. J. D.; GODOI, S. S.; IKEDA, Y. 2000. A corrente do Brasil ao Largo da Costa Leste Brasileira. Rev. bras. oceanogr., v.48, n. 2, p. 171-183.

SILVEIRA, I. C. A., 2007. 160f. O Sistema Corrente do Brasil na Bacia de Campos, RJ. Tese de Livre de Livre Docência, Instituto Oceanográfico Universidade de São Paulo, São Paulo, 2007.

SILVEIRA, I. C. A. 2004. Protótipo de sistema de previsão oceânica e costeira para o leste brasileiro. São Paulo: IOUSP, 30 p.

SILVEIRA, I. C. A.; CALADO, L.; CASTRO, B. M.; CIRANO, M.; LIMA, J. A. M.; MASCARENHAS, A. D. S. 2004. On the baroclinic structure of the Brazil CurrentIntermediate Western Boundary Current system at $22^{\circ}-23^{\circ} \mathrm{S}$. Geophys. Res. Lett., Estados Unidos, v. 31, p. 4308.

SOUSA, S.H.M.; PASSOS, R.F.; FUKUMOTO, M.; SILVEIRA, I.C.A.; FIGUEIRA, R.C.L.; KOUTSOUKOS, E.; MAHIQUES, M.M.; REZENDE, C.E. 2006. Mid-lower bathyal benthic foraminifera of the Campos Basin, Southeastern Brazilian margin: Biotopes and controlling ecological factors. Mar. Micropaleontol.. v.61, p. 40-57. 
SOUSA, S.H.M.; YAMASHITA' C.; NAGAI, R.H.; MARTINS, M.V.; ITO, C.; VICENTE, T.; TANIGUCHI, N.; BURONE' L.; FUKUMOTO, M.; ALUIZIO, R.; KOUTSOUKOS, E.A.M. 2006. Foraminíferos bentônicos no talude continental, Platô de São Paulo e cânions, in press.

STRAMMA, L.; ENGLAND, M. 1999. On the water masses and mean circulation of the South Atlantic Ocean. J. Geophys. Res., v. 104, n. C9, p. 20,863- 20, 883.

SUN. X.; CORLISS, B. H.; BROWN, C. W.; SHOWERS, W. J. 2006. The effect of primary productivity and seasonality on the distribution of deep-sea benthic foraminifera in the North Atlantic. Deep.-Sea Res. I, v. 53, p. 28-47.

SZAREK, R., NOMAKI, H., KITAZATO, H. 2007. Living deep-sea benthic foraminifera from the warm and oxygen-depleted environment of the Sulu Sea. Deep.Sea Res. II. v.54, p.145-176.

U.S. EPA (1996). Method 3052: Microwave assisted acid digestion of siliceous and organically based sediments, In Test Methods for Evaluating Solid Waste, Physical/Chemical Methods - SW-846. USEPA, Washington, DC, USA.

VAN DER ZWANN, G.J.; DUIJNSTEE,I.A.P.; DEN DULK, M.; ERNST, S.R.;JANNINK, N.T.;KOUWENHOVEN, T.J. 1999. Benthic foraminifers: proxies or problems? A review of paleocological concepts. Earth-Sci. Rev., v.4, p.213-236.

VAN MORKOVEN, F. P. C. M.; BERGGREN, W. A.; EDWARDS, A.S., 1986. Cenozoic Cosmopolitan Deep-Water Benthic Foraminifera. Bull. Cent. Rech. Explor. Prod. Elf-Aquitaine, Mem., v.11, p. 421.

VIANA, A.R. 2002. Seismic expression of shallow- to deep-water contourites along the south-eastern Brazilian margin. Mar. Geophys. Res., v. 22, p. 509-521.

VIANA, A. R.; FAUGERES, J. C.; KOWSMANN, R. O.; LIMA, J. A. M.; CADDAH, L. F. G.; RIZZO, J. G. 1998a. Hydrology, morphology and sedimentology of the Campos continental margin, offshore Brazil. Sediment. Geol., v.115, p.133-157.

VICENTE,T.M. Relações entre a biomassa dos foraminíferos bentônicos vivos e modelos de fluxo vertical de partículas orgânicas na região da Bacia de Campos RJ. 2012. 121 f. Dissertação (Mestrado em Oceanografia Geológica) - Instituto Oceanográfico, Universidade de São Paulo, São Paulo, 2012. 
VOLKMAN, J.K. Lipid markers for marine organic matter. 2006. In: Volkman, J.K. (Ed.) Handbook of Environmental Chemistry: Reactions and Processes $2(\mathrm{~N})$. vol. 2.Springer, Berlin, p. 27-70.

WAKEHAM, S.G.; PETERSON, M.L.; HEDGES, J.I.; LEE, C. 2002. Lipid biomarker fluxes in the Arabian Sea, with a comparison to the equatorial Pacific Ocean. Deep.-Sea Res. II, v. 49, p. 2265-2301.

WINTER, W. R.; JAHNERT, R. J.; FRANÇA, A. B. 2007. Bacia de Campos. Bol. Geoc. PETROBRAS. v. 15, n. 2, 511p.

YUNKER, M.B.; MACDONALD, R.W.; VELTKAMP, D. J.; CRETNEY,W.J. 1995. Terrestrial and marine biomarkers in a seasonally ice-covered Arctic estuary integration of multivariate and biomarker approaches. Mar. Chem., v. 49, p. 1-50. 


\section{Anexos}

ANEXO A: Densidade das espécies mais abundantes $(>3 \%)$ em $10 \mathrm{~cm}$ de sedimento, com suas respectivas profundidades médias de habitat $\left(\mathrm{ALD}_{10}\right)$, microhábitat e abundância da estação I06.

\begin{tabular}{|c|c|c|c|c|c|c|c|c|c|c|c|c|c|c|}
\hline \multicolumn{15}{|c|}{ Estação I06 (417m) } \\
\hline \multicolumn{15}{|c|}{ Profundidade $(\mathrm{cm})$} \\
\hline Espécies mais abundantes & $0-1$ & $1-2$ & $2-3$ & 3-4 & $4-5$ & $5-6$ & 6-7 & $7-8$ & 8-9 & $9-10$ & TOTAL (N) & $\mathbf{A L D}_{10}$ & Microhabitat & Abundância (> 3\%) \\
\hline Globocassidulina minuta (Cushman, 1933) & 49 & 0 & 0 & 0 & 0 & 0 & 0 & 0 & 0 & 0 & 49 & 0.5 & EP/IR & 3 \\
\hline Lagenammina difflugiformis (Brady, 1879) & 27 & 3 & 6 & 10 & 11 & 11 & 6 & 7 & 5 & 10 & 96 & 4 & II/IP & 6 \\
\hline Pullenia bulloides (d'Orbigny, 1846) & 50 & 2 & 3 & 2 & 1 & 0 & 0 & 0 & 0 & 0 & 58 & 1 & IR & 3 \\
\hline Pyrgo insularis McCulloch, 1977 & 55 & 2 & 2 & 2 & 0 & 0 & 1 & 0 & 1 & 0 & 63 & 1 & IR & 4 \\
\hline Pyrgo nasuta Cushman, 1935 & 70 & 4 & 4 & 0 & 1 & 1 & 1 & 3 & 0 & 0 & 84 & 1 & IR & 5 \\
\hline Reophax calcareus (Cushman, 1947) & 34 & 2 & 1 & 1 & 1 & 0 & 0 & 2 & 1 & 0 & 42 & 1 & IR & 3 \\
\hline Reophax caribensis (Seiglie and Bermudez, 1969) & 454 & 80 & 22 & 9 & 3 & 7 & 0 & 5 & 2 & 0 & 582 & 1 & IR & 35 \\
\hline Reophax minimus Zheng, 1988 & 18 & 2 & 6 & 30 & 11 & 12 & 9 & 18 & 11 & 14 & 131 & 5 & IP & 8 \\
\hline Uvigerina parvula Cushman, 1923 & 63 & 0 & 2 & 0 & 1 & 0 & 0 & 2 & 1 & 0 & 69 & 1 & IR & 4 \\
\hline Uvigerina peregrina Cushman, 1923 & 49 & 4 & 0 & 1 & 1 & 0 & 0 & 0 & 3 & 1 & 59 & 1 & IR & 4 \\
\hline
\end{tabular}

ANEXO B: Densidade das espécies mais abundantes $(>3 \%)$ em $10 \mathrm{~cm}$ de sedimento, com suas respectivas profundidades médias de habitat ( ALD $_{10}$ ), microhábitat e abundância da estação I08.

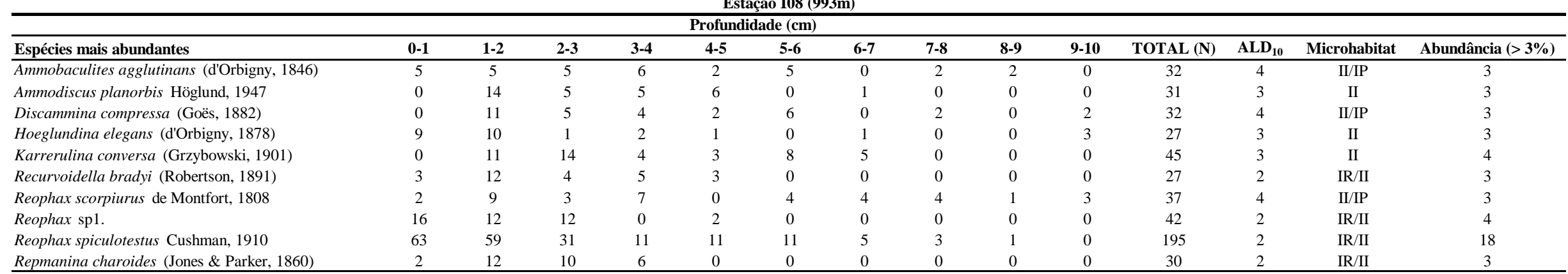


ANEXO C: Comparação dos dados de microhábitat obtidos a partir dos valores de $\mathrm{ALD}_{10}$ com os microhábitat encontrados na literatura das espécies mais abundantes (I06). As siglas dos microhábitats da literatura representam: $\mathrm{EP}=$ epifauna, $\mathrm{I}=$ infauna, $\mathrm{IR}=$ infauna rasa, $\mathrm{II}=$ infauna intermediária, $\mathrm{IP}=$ infauna profunda, $\mathrm{EP} / \mathrm{I}=$ epifaunal e/ou infaunal, $\mathrm{IR} / \mathrm{II}=$ infauna rasa e/ou intermediária, $\mathrm{m}=$ morfotipo, $\mathrm{g}=$ gênero.

\begin{tabular}{lccc}
\hline & & & Estação I06 (417m) \\
\hline Espécies mais abundantes I06 & $(\mathbf{3} \%)$ & ALD $_{\mathbf{1 0}}$ (cm) & Microhabitat (dado) \\
\hline Globocassidulina minuta & 0.5 & EP/IR & Microhabitat (literatura) \\
Lagenammina diffugiformis & 4 & II/IP & I (m) (Corliss e Chen, 1988) \\
Pullenia bulloides & 1 & IR & I (g) (Murray, 1991)(Szarek et al., 2007), IR (Kurbejeweit et al., 2000) \\
Pyrgo insularis & 1 & IR & I (g) (Murray, 1991) \\
Pyrgo nasuta & 1 & IR & EP (g) (Murray, 1991), EP (Miliolídeos) (Corliss, 1991) \\
Reophax calcareus & 1 & IR & EP (g) (Murray, 1991),EP (Miliolídeos) (Corliss, 1991) \\
Reophax caribensis & 1 & IR & I (Murray, 1991; Fontanier et al., 2005; Koho et al., 2008) \\
Reophax minimus & 5 & IP & I (Murray, 1991; Fontanier et al., 2005; Koho et al., 2008) \\
Uvigerina parvula & 1 & IR & I (Murray, 1991; Fontanier et al., 2005; Koho et al., 2008) \\
Uvigerina peregrina & 1 & IR & EP/I (g) (Murray, 1991), II (g) (Fontanier et al., 2002), IR (g) (Fontanier et al., 2002) \\
\end{tabular}

ANEXO D: Comparação dos dados de microhábitat obtidos a partir dos valores de $\mathrm{ALD}_{10}$ com os microhábitat encontrados na literatura das espécies mais abundantes (I08). As siglas dos microhábitats dos dados estão disponíveis em material e método, já as siglas do microhábitat da literatura representam: EP = epifauna, I = infauna, IR = infauna rasa, II = infauna intermediária, IP = infauna profunda, EP/I = epifaunal e/ou infaunal, IR/II = infauna rasa e/ou intermediária, $\mathrm{m}=$ morfotipo, $\mathrm{g}=$ gênero.

\begin{tabular}{lccc}
\hline & & & Estação I08 (993m) \\
\hline Espécies mais abundantes I08 $(>\mathbf{3} \%)$ & ALD $_{\mathbf{1 0}}$ (cm) Microhabitat (dado) & Microhabitat (literatura) \\
\hline Ammobaculites agglutinans & 4 & II/IP & IR (m) (Duros et al., 2011),IR (ALD10=0.98 Fontanier et al., 2005), IP (g) (Buzas et al., 1993) \\
Ammodiscus planorbis & 3 & II & EP (m)(Setoyama, 2013), IP (Szarec et al., 2007; ALD5 =2.75) \\
Discammina compressa & 4 & EP (g) (Kamisky, 1995) \\
Hoeglundina elegans & 3 & II & EP (Rathburn et al., 1996), IR (Fontanier et al., 2005) \\
Karrerulina conversa & 3 & II & IP (m) (Khunt, 1992); (g) (IR/II ALD10=1.10 Fontanier et al., 2005) \\
Recurvoidella bradyi & 2 & IR/II & sem informação \\
Reophax scorpiurus & 4 & II/IP & IR (Kurbejeweit et al., 2000; Duros et al., 2011), II (ALD10=1.87 Fontanier et al., 2005) \\
Reophax spl & 2 & IR/II & I (Murray, 1991; Fontanier et al., 2005; Koho et al., 2008) \\
Reophax spiculotestus & 2 & IR/II & I (Murray, 1991; Fontanier et al., 2005; Koho et al., 2008) \\
Repmanina charoides & 2 & IR/ II & EP (Reolid et al., 2012)
\end{tabular}


ANEXO E: Prancha das fotomicrografias dos foraminíferos bentônicos vivos

Prancha 1: Fotomicrografias dos foraminíferos bentônicos vivos das espécies mais abundantes das estações I06 (417m) e I08 (993m) da Bacia de Campos, retiradas no MEV.

1. Ammodiscus planorbis Höglund, 1947

2. Discammina compressa (Goës, 1882)

3. Recurvoidella bradyi (Robertson, 1891)

4. Ammobaculites agglutinans (d'Orbigny, 1846)

5. Karrerulina conversa (Grzybowski, 1901)

6. Lagenammina difflugiformis (Brady, 1879)

7. Reophax spiculotestus Cushman, 1910

8. Reophax caribensis (Seiglie and Bermudez, 1969)

9. Reophax scorpiurus de Montfort, 1808

10.Reophax sp1.

11. Reophax calcareus (Cushman, 1947)

12. Reophax minimus Zheng, 1988 


\section{Prancha 1}

1

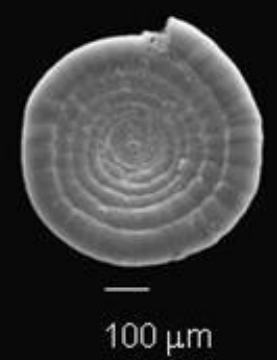

4

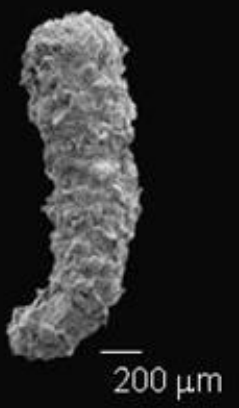

7

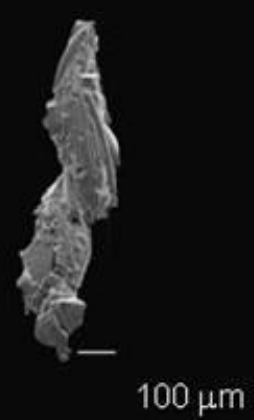

10

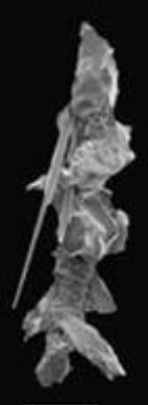

2

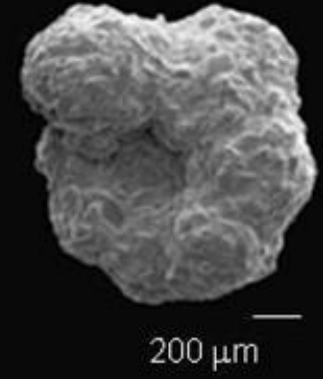

5

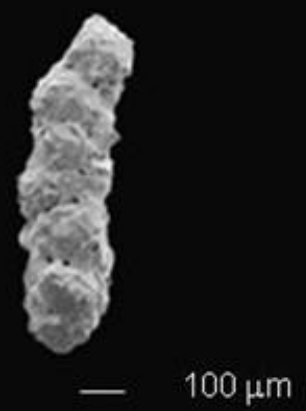

8

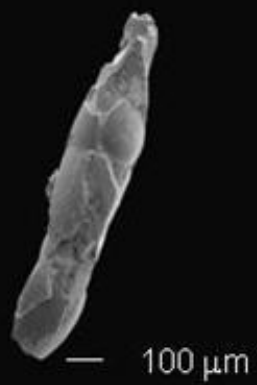

11

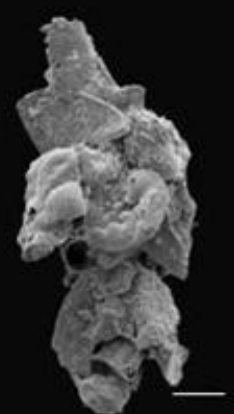

$100 \mu \mathrm{m}$
3

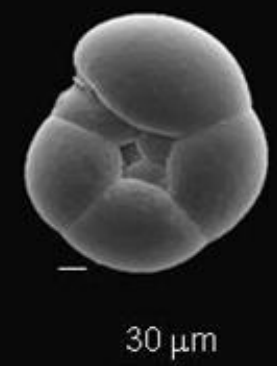

6

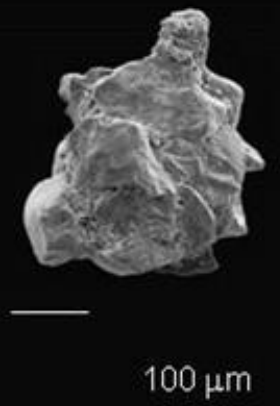

9

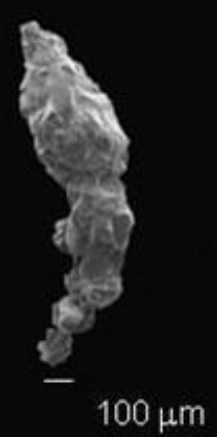

12

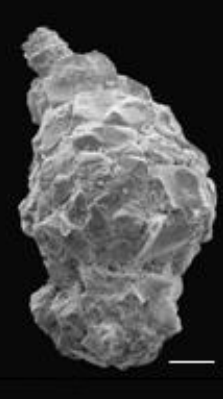

$100 \mu \mathrm{m}$ 
Prancha 2: Fotomicrografias dos foraminíferos bentônicos vivos das espécies mais abundantes das estações I06 (417m) e I08 (993m) da Bacia de Campos, retiradas no MEV.

1. Repmanina charoides (Jones \& Parker, 1860)

2. Repmanina charoides (abertura) (Jones \& Parker, 1860)

3. Globocassidulina minuta (Cushman, 1933)

4. Pyrgo nasuta (abertura) Cushman, 1935

5. Pyrgo nasuta Cushman, 1935

6. Pyrgo insularis McCulloch, 1977

7. Hoeglundina elegans (d'Orbigny, 1878)

8. Hoeglundina elegans (d'Orbigny, 1878)

9. Pullenia bulloides (abertura) (d'Orbigny, 1846)

10. Pullenia bulloides (d'Orbigny, 1846)

11. Uvigerina peregrina Cushman, 1923

12. Uvigerina parvula Cushman, 1923 


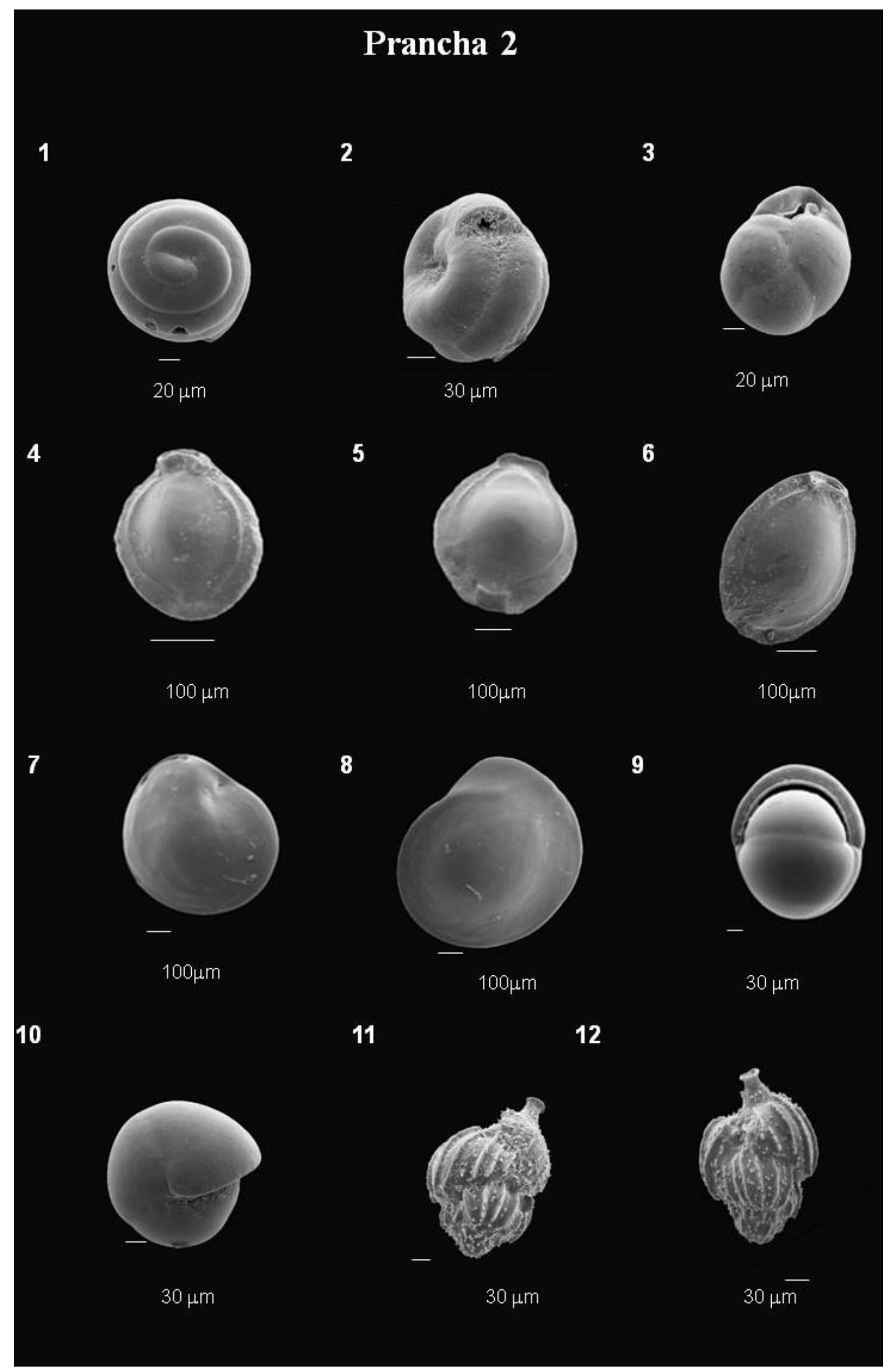

